\title{
Innovative Environmental Management of Winter Salt Runoff Problems at INDOT Yards
}

FHWA/IN/JTRP-2001/27

by

James E. Alleman, Professor [Purdue University]

Barry K. Partridge, $P h D, P E$ [Director, INDOT Research Division]

Lee Yeung, $M S$ [Purdue University]

Project No: C-3636EE

File No: 6-14-31

SPR-2379

\section{Joint Transportation Research Program Purdue University}

Prepared as Part of an Investigation Conducted by the

\section{Indiana Department of Transportation}

and the

\section{Federal Highway Administration}

The contents of this report reflect the views of the authors who are responsible for the facts and accuracy of the data presented herein. The contents do not necessarily reflect the official views of, or policies of any of the sponsors. Furthermore, this report does not constitute a standard, specification, or regulation.

School of Civil Engineering

Purdue University

West Lafayette, Indiana 47907-1284

December 2004 


\section{TECHNICAL Summary}

INDOT Research

Technology Transfer and Project Implementation Information

TRB Subject Code: 23-5 Waste Water and Sewer Disposal

Publication No.: FHWA/IN/JTRP-2001/27

December 2004

Final Report

\section{Innovative Environmental Management of Winter Salt Runoff Problems at INDOT Yards}

\section{Introduction}

This INDOT-JTRP project examined an innovative strategy for mitigating, and possibly obviating, the environmental impact of winter-time salt release within INDOT yard areas specifically associated with the generation and release of salt truck wash waters, whereby these waste streams could be beneficially reused in the manufacture of salt brine solutions suitable for subsequent prewetting and anti-icing applications. The associated environmental problem stems from the fact that these wash waters carry elevated levels (e.g., from 100's of mg/L to percentilelevel) salt concentrations whose uncontrolled release via local surface or ground waters must be discontinued pursuant to tightened environmental regulations. Potential environmental impacts of brine runoffs include damage and loss of vegetation, increased salt concentrations in soils, lakes, rivers and streams, increased salt concentrations in ground water supplies, and increased salt loadings to wastewater treatment plants. While there are presently no numerical standards for stormwater or wash water discharges of this sort in Indiana, the stringent magnitude of the following relevant Indiana Water Quality Standards criteria highlights the commensurate importance of reducing or obviating INDOT's salt truck wash water problem:

- 860 mg/l “criterion maximum concentration” (CMC) for chloride concentration in point-source effluent.

- $230 \mathrm{mg} / \mathrm{l}$ “criterion continuous concentration” (CCC) for chloride concentration outside of the mixing zone for protection of aquatic life.

- Standards for oil and grease in Indiana identify narrative limits on visual "sheen" and "turbidity".

Beneficial collection and reuse of these salt-laden truck wash waters will, therefore, not only resolve, either in part or wholly, this environmental problem but will also save material cost in preparation of valuable salt brine solutions.

\section{Findings}

Based on the findings of this research effort, it is evident that salt truck wash water can be successfully collected and reused in the manufacture of brine solutions that may then be constructively reapplied in conjunction with prewetting and anti-icing operations. Indeed, this wash water reuse strategy appears to provide an environmentally and economically beneficial means of mitigating or obviating INDOT's “winter salt truck wash water” problem.

As described in the report, the process of beneficial salt truck wash water reuse involves six (6) key factors, including: 1) wash water collection, 2) wash water pretreatment, 3) temporary wash water storage, 4) brine manufacturing hardware and operational details, 
5) product brine storage, and 6) brine application procedures and timing. The first five of these aspects have been addressed within this report, and relevant details regarding the sixth item (brine application, etc.) have previously been provided by the Federal Highway Administration's “Manual of Practice for an Effective Anti-Icing Program: A Guide For Highway Winter Maintenance Personnel.”

The equipment required for making brine solution from recycled truck wash water includes an oil/water separator, sedimentation/retention tank for wash water, brine making tank, storage tank(s), and pumps. The plumbing should be setup in a way that recirculation of brine can be completed in both the brine-making tank and the storage tank. Due to the corrosive nature of salt water, all containers, equipment, and plumbing in contact with the wastewater and brine solution should be made of corrosion resistant materials (e.g., using either plastic, such as polyethylene, or stainless steel). Flexible hoses with appropriate couplings should be attached to the storage tank for transfer of brine to the truck saddle tank, and a hydrometer will need to be manually used on a routine basis to qualify the desired $23.3 \%$ salt content of the brine solution given that this concentration provides the lowest possible brine freezing point.

Based on observations at existing brinemanufacturing operation, as well as information gleaned from other Midwest DOT’s (e.g., Iowa DOT), it appears that these brine-making systems may either be situated indoors or outdoors at a location adjacent to the wash bays to facilitate ease of transfer. In either case, consideration should be given to the site-specific necessity for installating secondary containment dikes or walls to contain possible spills. Similarly, sizing and selection of the brine manufacturing tank plus accompanying storage, pump, and brine spray equipment capacities should be determined on a site-specific basis to accommodate the expected level of brine manufacturing operations.
Sand, gravel, and other debris (e.g., bird feathers, etc.) introduced both during the truck washing process as well as from the raw salt (which has its own level of expected impurity) may cause plugging problems with brine spray nozzles, and oil and grease washed off from trucks may also cause plugging problems. Steelcased strainers having 80- to 100-mesh reinforced wire would, therefore, be recommended on truck filling lines close to the tank for removal of material that may clog the spraying nozzles on truck. Wash water should be allowed to stand in the sedimentation/retention tank for a period of time before brine making begins, such that small diameter particles will be allowed to settle.

At present, there are twelve (12) brine manufacturing systems in the State of Indiana, six of which (Gary, LaPorte, Monticello, Princeton, Bainbridge, and Bluffton) are set up to use truck wash water to make brine. Three of the twelve brine-manufacturing sites are using "do-it-yourself" brine manufacturing system with the rest using commercial brine making system.

The specific field-scale testing conducted during this project was completed at the Monticello Sub-District unit, with the 'do-ityourself' brine making unit being located within the wash bays. Wastewater from truck washing flowed through the floor grate into a 1,100 gallon underground concrete tank, and from here this wash water was pumped through an oil/water separator and then gravity discharged into a 56 gallon intermediate tank from which it was then intermittently pumped into an interior 750 gallon brine making tank. A 'bobcat' was used to transfer salt on an as-needed basis. Mixing and transfer of the brine, along with intermittent testing of the salt concentrations in both the brine making tank and the storage tank, was achieved through switching specific valves and pumps. A 2,500 gallon tank was used for brine storage. The maximal rate of production of salt brine obtained with this unit was approximately 1,000 gallons per hour. The cost of this Monticello brine making system was approximately $\$ 3,000$.

\section{Implementation}

Pursuant to this project's findings and the following three (3) specific 'implementation' demonstrated success, albeit on a limited basis, 
recommendations are being provided as a means of extending this research effort.

- First, an effort should be made to maintain an on-going evaluation of INDOT's six (6) existing winter-period wash water brine manufacturing operations, relative to their available storage capacity and conditions as well as characterizing non-salt contaminant impacts,

- Second, further 'proof-of-concept' wash water reuse operations should be initiated within INDOT district regions currently not using this technology, whereby the potential utility of this technical strategy might be further demonstrated (NOTE: this effort was initially begun via a specific set of 'implementation' initiatives conducted at the Bainbridge [INDOT Crawfordsville] and Bluffton [INDOT Fort Wayne] sites), and

- Third, further characterization of the magnitude and potential impact of INDOT salt truck wash water discharges on publicly-owned wastewater treatment facilities should be conducted (NOTE: this effort has been initiated in the Spring of 2002 via JTRP SPR-2625.

\section{Contacts}

\section{For more information:}

\section{Prof. James E. Alleman}

Principal Investigator

School of Civil Engineering

Purdue University

West Lafayette IN 47907

Phone: (765) 494-7705

Fax: (765) 496-3449

alleman@purdue.edu
Indiana Department of Transportation

Division of Research

1205 Montgomery Street

P.O. Box 2279

West Lafayette, IN 47906

Phone: (765) 463-1521

Fax: (765) 497-1665

\section{Purdue University}

Joint Transportation Research Program

School of Civil Engineering

West Lafayette, IN 47907-1284

Phone: (765) 494-9310

Fax: (765) 496-1105 


\begin{tabular}{|c|c|c|}
\hline $\begin{array}{l}\text { 1. Report No. } \\
\text { FHWA/IN/JTRP 2001/27 }\end{array}$ & 2. Government Accession No. & 3. Recipient's Catalog No. \\
\hline \multirow{2}{*}{\multicolumn{2}{|c|}{$\begin{array}{l}\text { 4. Title and Subtitle } \\
\text { Innovative Environmental Management of Winter Salt Runoff } \\
\text { Problems at INDOT Yards }\end{array}$}} & 5. Report Date December 2004 \\
\hline & & 6. Performing Organization Code \\
\hline \multicolumn{2}{|c|}{$\begin{array}{l}\text { 7. Author(s) } \\
\text { J.E. Alleman, B.K. Partridge, and L. Yeung }\end{array}$} & $\begin{array}{l}\text { 8. Performing Organization Report No. } \\
\text { FHWA/IN/JTRP-2001/27 }\end{array}$ \\
\hline \multirow{2}{*}{\multicolumn{2}{|c|}{$\begin{array}{l}\text { 9. Performing Organization Name and Address } \\
\text { Joint Transportation Research Project } \\
\text { Civil Engineering Building } \\
\text { Purdue University } \\
\text { West Lafayette, Indiana } 47907-1284\end{array}$}} & 10. Work Unit No. \\
\hline & & $\begin{array}{l}\text { 11. Contract or Grant No. } \\
\text { SPR-2379 }\end{array}$ \\
\hline \multirow{3}{*}{\multicolumn{2}{|c|}{$\begin{array}{l}\text { 12. Sponsoring Agency Name and Address } \\
\text { Indiana Department of Transportation } \\
\text { State Office Building } \\
100 \text { North Senate Avenue } \\
\text { Indianapolis, IN } 46204\end{array}$}} & 13. Type of Report and Period Covered \\
\hline & & Final Report \\
\hline & & 14. Sponsoring Agency Code \\
\hline
\end{tabular}

15. Supplementary Notes

Prepared in cooperation with the Indiana Department of Highways and Federal Highway Administration.

16. Abstract

This INDOT-JTRP project examined an innovative strategy for mitigating, and possibly obviating, the environmental impact of wintertime salt release within INDOT yard areas specifically associated with the generation and release of salt truck wash waters, whereby these waste streams may be beneficially reused in the manufacture of salt brine solutions suitable for subsequent pre-wetting and anti-icing applications. The associated environmental problem stems from the fact that these wash waters carry high-level (e.g., from 100's of mg/L to percentile-level) salt concentrations whose uncontrolled release via local surface or ground waters will have to be discontinued pursuant to the onset of tightened environmental regulations. Specifically, current Indiana Water Quality Standards restrict total dissolved solids in natural waters to $750 \mathrm{mg} / \mathrm{L}$. Reusing these salt-laden truck wash waters will, therefore, not only resolve, either in part or wholly, this environmental problem but will also save material cost in preparation of valuable salt brine solutions. Six (6) key aspects were identified for this proposed activity, including: 1) wash water collection, 2) wash water pretreatment, 3) temporary wash water storage, 4) brine manufacturing hardware and operational details, 5) product brine storage, and 6) brine application procedures and timing. The first five of these aspects are addressed within this report; relevant details regarding the sixth item (brine application, etc.) are given in the "Manual of Practice for an Effective Anti-Icing Program: A Guide For Highway Winter Maintenance Personnel," published by the Federal Highway Administration (i.e., as referenced in this report). Lastly, a condensed, Web-based synopsis of this project is available at the following URL: http://rebar.ecn.purdue.edu/Salt-Wash-Reuse/

\section{Key Words \\ 18. Distribution Statement}

Environmental, salt brine, waste, wastewater, disposal

No restrictions. This document is available to the public through the National Technical Information Service, Virginia, 22161

\begin{tabular}{|c|c|c|c|c|}
\hline $\begin{array}{c}\text { 19. Security Classif. (of this } \\
\text { report) } \\
\text { Unclassified }\end{array}$ & $\begin{array}{l}\text { 20. Security Classif. (of this } \\
\text { page) }\end{array}$ & $\begin{array}{l}\text { 21. No. of } \\
\text { Pages: } 139\end{array}$ & 22. Price \\
\hline
\end{tabular}




\section{ACKNOWLEDGMENTS}

During the course of this project, many individuals and organizations provided considerable, and enthusiastic, support to the development and completion of the research effort detailed within this report. Among the others, they include:

- $\quad$ Tom Konieczny, INDOT

- $\quad$ Wayne Dittelberger, INDOT

- $\quad$ Tom Duncan, INDOT

- $\quad$ Don Johnson, Purdue

- $\quad$ Lynn Corson, Purdue

Please refer to Appendix A of the report for a list of personal contacts and companies consulted during the preparation of this report. 


\section{TABLE OF CONTENTS}

ACKNOWLEDGMENTS …................................................................ ii

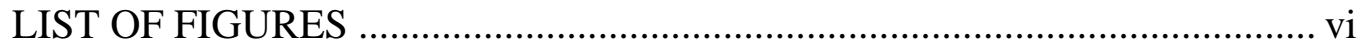

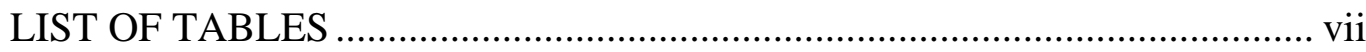

IMPLEMENTATION REPORT.................................................................. ix

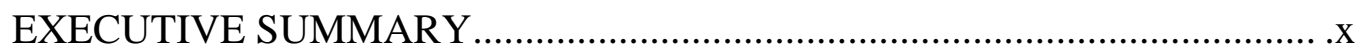

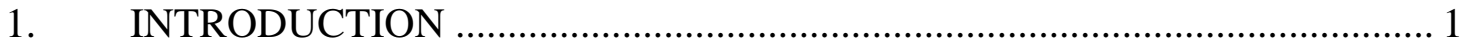

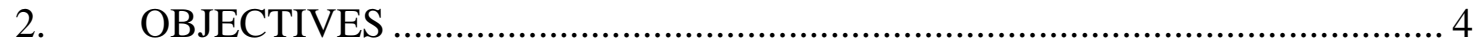

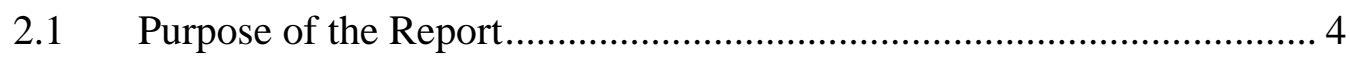

2.2 Organization of the Report................................................................... 4

3. GENERAL DEICING OPTIONS AND PRACTICES.................................... 5

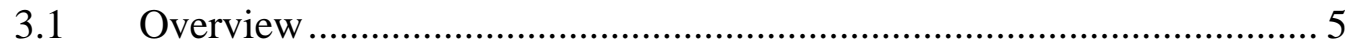

3.2 Chemical Options............................................................................... 5

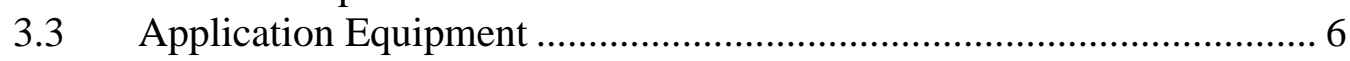

3.4 Application Conditions and Rates............................................................ 8

3.5 Relative Usage of Deicing and Anti-icing Material................................. 9

4 GENERAL ANTI-ICING OPTIONS AND PRACTICES …………………..... 15

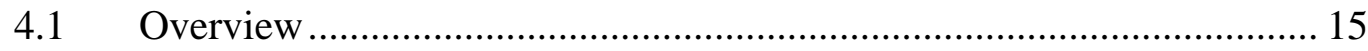

4.2 Chemical Options........................................................................... 15

$4.3 \quad$ Equipment ....................................................................................... 15

4.3.1 Liquid Application Equipment............................................... 15

4.3.2 Pavement Temperature Sensors ........................................... 16

4.3.3 Road Weather Information Systems (RWIS)......................... 18

4.4 Application Rates ................................................................................. 18

5 SALT BRINE MANUFACTURE, STORAGE AND TRANSFER ......................21

$5.1 \quad$ Production Related Aspects........................................................................21

5.1.1 Basic System Components.......................................................21

5.1.2 Eutectic Control of Salt Brine ................................................ 21

5.1.3 Recirculation of Brine............................................................ 21

5.1.4 Preparation of Eutectic Salt Brine........................................ 22

5.1.4.1 Changing the Concentration of a Brine Solution 22

5.1.5 Using Truck Wash Water to Make Brine Solution ................ 23

5.1.5.1 Collection of Wash Water..................................... 24

5.1.5.2 Quantity of Wash Water........................................ 24

5.1.5.3 Quality of Wash Water......................................... 25 
Total Suspended Solids ................................... 26

Chloride Concentration .................................. 26

Corrosive Nature of Brine............................. 26

Oil and Grease and Other Contaminants....... 26

5.2 Hardware Related Aspects ................................................... 26

5.2.1 Basic Options .................................................................... 26

5.2.2 Basic Facility Requirement ................................................... 27

5.2.2.1 Brine Manufacturing Tank................................ 27

5.2.2.2 Brine Storage Tank ......................................... 27

5.2.2.3 Pumps ................................................................. 27

5.2.2.4 Plumbing and Electrical Equipment .................... 27

5.2.2.5 Comparison of Commercial Brine Manufacturing

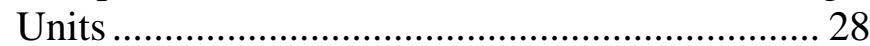

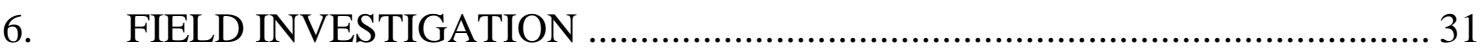

6.1 Monticello Experimental System........................................................... 31

6.1.1 Siting Details..................................................................... 31

6.1.2 Brine Manufacturing Hardware ............................................ 31

6.1.3 Storage Hardware.................................................................. 31

6.1.4 Pumping Hardware .............................................................. 31

6.1.5 Bill of Materials ................................................................. 32

6.1.6 Operational Aspects .............................................................. 33

6.1.6.1 Brine Making Procedure ........................................ 33

6.1.6.2 Evaluation of Operation ......................................... 35

2000-2001 Brine Use .................................... 35

Equipment and Facilities............................... 35

Brine Production Rate................................... 36

Wash Water and Brine Quality ...................... 36

6.2 Other Experimental Brine Production and Usage System ........................ 37

6.2.1 INDOT LaPorte Sub-District Unit ......................................... 40

6.2.2 INDOT Plymouth Sub-District Unit ..................................... 43

6.2.3 INDOT Winamac Sub-District Unit ..................................... 44

6.2.4 INDOT Greenfield Sub-District Unit.................................... 46

6.2.5 INDOT Princeton Sub-District Unit ..................................... 48

6.2.6 Missouri DOT Hannibal Sub-District Unit............................ 50

7. ENVIRONMENTAL AND REGULATORY CONCERNS ……………….......52

7.1 Environmental Impacts of Salt and Brine Runoff...................................... 52

7.1.1 Salt Storage and Handling..................................................... 52

7.1.2 Road Salt ....................................................................... 52

7.1.3 Anti-caking Agent in Road Salt ............................................. 53

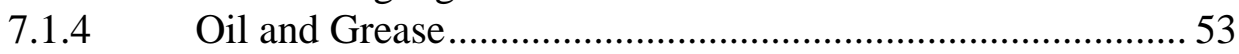

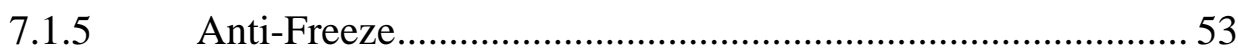

7.2 Pertinent Regulations .......................................................................... 54

7.2.1 Intermodal Surface Transportation Efficiency Act of 1991.. 54

7.2.2 NPDES Stormwater Phase II Regulations ............................. 54 
7.2.3 Current Status in Indiana Regarding Stormwater Discharges from MS4 ................................................................. 54

7.2.4 Current Statues in Other State Regarding Brine Runoffs from DOT Maintenance Facilities .................................................... 55

7.2.5 Secondary Containment and Spill Contingency Plan ............ 56

7.2.6 Drinking Water Standards........................................................ 57

7.2.7 Ground Water Standards ...................................................... 57

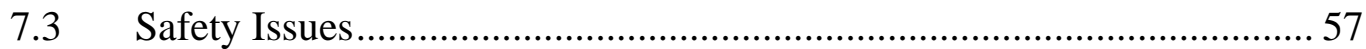

7.3.1 OSHA Hazard Communication Standard ............................... 57

7.3.2 Safety and Handling of Deicing Chemicals ............................ 58

$7.4 \quad$ INDOT Yards Survey ……………………………………………….... 58

7.5 Future Direction of Stormwater Control: The TMDL Program............... 59

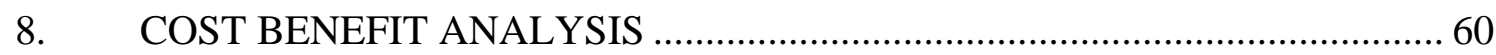

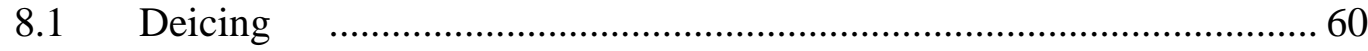

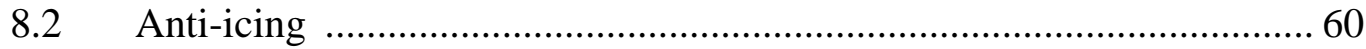

8.3 Cost Benefit Analysis of Deicing/Anti-icing Chemicals ............................ 61

8.3.1 Corrosiveness and Environmental Concerns .......................... 61

8.4 Cost Benefit of Pre-wetting: Using Salt Brine Manufactured with the

"Do-it-yourself" Brine Maker ................................................................ 62

8.4.1 Effect of Salt Brine when Added to Solid Sodium Chloride 62

8.4.2 Effect of Salt Brine when Added to Sand ............................... 63

8.4.3 Cost Analysis of Using "Do-it-yourself” Brine Manufacturing

System for Pre-wetting............................................................. 63

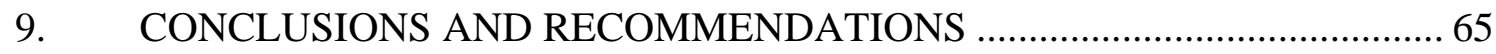

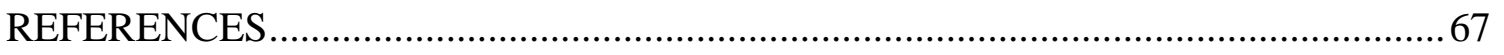

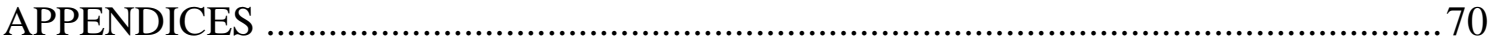

Appendix A - Contact List

Appendix B - Salt Brine Properties

B.1 Eutectic diagram of sodium chloride

B.2 Hydrometer readings and the corresponding salt concentration for a solution with temperature of 15 ${ }^{\circ} \mathrm{C}\left(59^{\circ} \mathrm{F}\right)$.

B. $323 \%$ Salt brine concentration conversion chart

Appendix C - Water quality data for the truck washing facility located in Greenfield, IN

Appendix D - Flow meter data for the INDOT Bluffton truck washing facility

Appendix E- Brine making procedure with "do-it-yourself" brine manufacturing system at Monticello, IN 
Appendix F - Laboratory results for water samples taken from Monticello and LaPorte, IN

Appendix G - INDOT Field Operations Manual, Operating Procedure No. 22

Appendix H - Salt and Brine Storage Manual, Michigan Department of Environmental Quality

Appendix I - INDOT Yards Survey

Appendix J: INDOT Yard Proximity to Local POTW

(i.e., Sites within 2 miles of POTW) 


\section{LIST OF FIGURES}

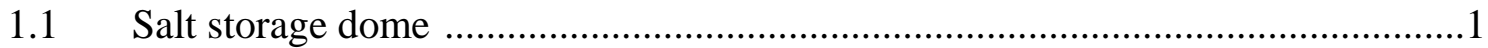

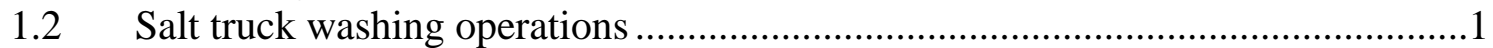

1.3 Spraying and scraping off debris after truck washing ......................................2

3.1 Time required to break ice bond by penetration of chemical to surface of road...5

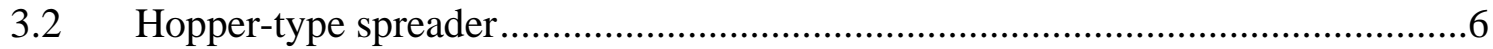

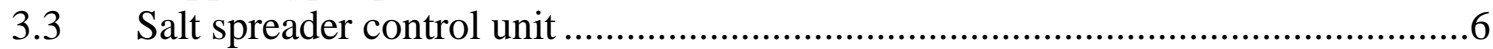

3.4 Pre-wetting truck load using overhead spray bars ............................................6

3.5 Liquid chemical can be sprayer onto the spinner when spreading salt onto the

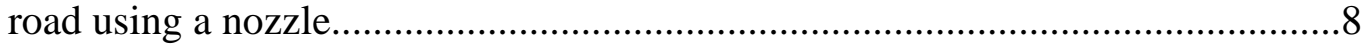

3.6 Saddle tank mounted on truck for on-board pre-wetting system ..........................8

3.7 INDOT Non-Brine Deicer and Anti-Icer Use

Chronology @ FY2002 to FY2004......................................14

3.8 INDOT NaCl Brine Use @ FY2002-FY2004....................................14

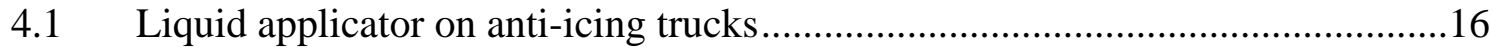

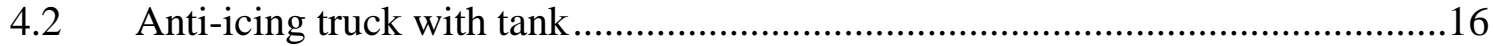

4.3 Vehicle mounted pavement temperature sensor and LCD display (Sprague Controls) ...........................................................................................17

4.4 Vehicle mounted pavement temperature sensor and LCD display (Control Products)

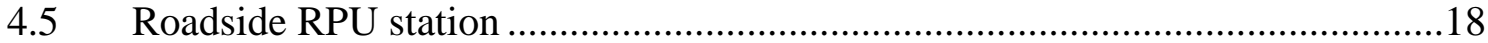

4.6 INDOT RWIS Sensor Locations ................................................................18

4.7 Sample INDOT RWIS Weather Data Information .........................................19

5.1 Plot of weight per unit volume of brine vs. \% brine .......................................23

5.2 Oil-Water separator overflow modifications ................................................24

6.1 Operator recirculating brine in the brine manufacturing tank ...........................33

6.2 Brine production equipment layout in Monticello, IN......................................34

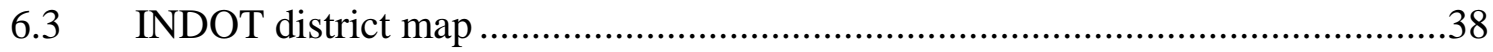

6.4 Current 2004 INDOT locations with 'wash water collection and brine manufacturing' verus 'brine manufacturing only' .............................39

6.5 LaPorte Sub-District brine production equipment layout ...................................42

7.1 Representative salt storage yard area .........................................................52

8.1 Accident rate before and after salt spreading.............................................60 


\section{LIST OF TABLES}

1 Current 2004 Distribution of INDOT Brine Manufacturing Locations .................3

3.1 Summary of deicers/anti-icers' effectiveness and costs ...................................

3.2 Application rates of liquid chemicals for pre-wetting ....................................9

3.3 INDOT District Use of 'Liquid Calcium Chloride' During FY02-FY04............10

3.4 INDOT District Use of 'Liquid Magnesium Chloride’ During FY02-FY04 ......11

3.5 INDOT District Use of 'Liquid Agricultural Deicer’ During FY02-FY04 .........12

3.6 INDOT District Use of 'Liquid NaCl Brine’ During FY02-FY04 .....................13

4.1 Application rates of liquid chemicals for anti-icing .......................................20

5.1 Proportions for preparing sodium chloride solutions from

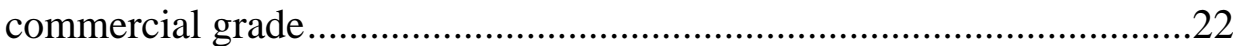

5.2 Wash water flow from truck washing facility at Bluffton, IN (1998-1999) ........24

5.3 Truck wash water quality from Greenfield, IN (1999) ....................................25

5.4 Comparison of commercial brine manufacturing units ....................................28

6.1 Bill of materials for Monticello Sub-District brine production setup..................32

6.2 INDOT Monticello Sub-District brine manufacturing setup ...............................35

6.3 Water characteristics from Monticello, IN and LaPorte, IN (Year 2001) ...........36

8.1 Estimated cost for pre-wetting ..............................................................64

8.2 Cost comparison with and without pre-wetting ...........................................64 


\section{IMPLEMENTATION REPORT}

Based on the findings documented within the following research report, it is evident that salt truck wash water can be successfully collected and used in the manufacture of brine solutions that may then be constructively used for pre-wetting and anti-icing operations. Indeed, full-scale implementation efforts have now transferred this experimental wash water reuse strategy into six (6) INDOT-operated locations as a beneficial and environmentally-acceptable means of proactively negating the 'salt truck wash water' problem. Pursuant to these findings, therefore, the following three (3) specific suggestions are being provided as a means of implementing and extending this research effort:

1) Maintain On-Going Evaluation of INDOT's Six Existing Wash Water Brine Manufacturing Operations Relative to Necessary Storage Capacity and Conditions plus Non-Salt Contaminant Impacts

Routine observation of the current INDOT using the 'wash water reuse' strategy should be maintained with the intent of further qualifying and establishing necessary storage levels (both for the raw waste and product brine), exterior storage requirements (for brine, relative to the necessity for heating), operational requirements, non-salt contaminant impacts, and ongoing troubleshooting solutions.

\section{2) Continued Expansion of Wash Water Reuse Operations Within All INDOT District Regions}

Continued efforts should be made to further expand INDOT's use of this wash water reuse concept, and in particular at INDOT districts having no such current locations (e.g., Seymour). These additional sites will continue to provide a highly synergistic opportunity for INDOT operations personnel in all districts to further establish their first-hand validation of the involved technical aspects and the consequent benefits of brine use as a whole.

3) Characterize the Magnitude and Potential Impact of INDOT Salt Truck Wash Water Discharges on Publicly Owned Wastewater Treatment Facilities

Given the likelihood that some INDOT sites may be suitably positioned to discharge their salt truck wash waters into a sanitary sewer for downstream passage through a municipal wastewater treatment facility, a study is warranted to qualify and confirm whatever consequent impacts may be realized with these measures. Specifically, this investigation will both establish the relative magnitude of this salt-bearing discharge relative the on-going influx of salt into these same systems via home-owner water softeners, as well as identifying and resolving whatever negative impacts may be realized on the plant performance levels.

4) Examine the Possible Discharge of INDOT Salt Truck Wash Water Discharges at Publicly Owned Wastewater Treatment Facilities Relative to Administrative Approval and Project CostEffectiveness

This effort would have two elements of effort, including that of identifying which INDOT yards might be potentially able to tie into local POTWs within piping distances which are considerable cost-effective (e.g., less than 2 miles), and also that of beginning pro-active discussions with POTW operations considered potentially suited for such connections in order to constructively promote this option. 


\section{EXECUTIVE SUMMARY}

\section{Technical Project Overview}

The Indiana Department of Transportation (INDOT) has extensively used deicing chemicals, predominantly in the form of dry salt (sodium chloride), to improve highway safety during winter periods since the 1930's. In recent years, though, concerns regarding the environmental impacts associated with these activities have escalated, relative to the release of contaminants during the process of handling and storage of these deicing chemicals. In addition, it is evident that runoffs which may be created following truck washing during post-deicing cleanup activities may also release considerable amounts of salt into the local environment.

For example, according to flow data obtained from a typical INDOT Sub-District yard (e.g., at the INDOT Bluffton Sub-District) wash water flows during a peak winter month were found to reach 45,536 gallons per month, which corresponds to an average daily volume of more than 1,500 gallons. These potentially large volumes of wash water discharge will not only carry high salt levels, but they may also carry additional wash water contaminants such as oil and grease, anti-freeze, and suspended solids into the environment. Potential environmental impacts of brine runoffs include damage and loss of vegetation, increased salt concentrations in soils, lakes, rivers and streams, increased salt concentrations in ground water supplies, and increased salt loadings to wastewater treatment plants.

Over the past few years, though, there has also been growing interest amongst coldweather states in regard to the use of liquid salt brine (e.g., including sodium, calcium, and magnesium chloride forms), as an alternative to dry salt, for anti-icing and pre-wetting salt. Prewetting of dry salt with liquid brines has also been shown to have many advantages, such as better adhesion to the road surface and faster snow and ice melting action. Anti-icing completed with these same brine forms, or relatively newer organic, agriculture-based solutions (e.g., 'IceBan,' etc.) offers yet another additional advantage in regard to preventing the formation of bonded snow or ice to the pavement.

In fact, brine usage for both deicing and anti-icing measures has significantly increased within the State of Indiana over the course of this project's 5-year lifetime (1999-2004), with roughly one-quarter of its operational yards now equipped for on-site salt ( $\mathrm{NaCl}$ ) brine manufacture and use. This INDOT-JTRP project, therefore, was developed to examine an environmentally-pro-active solution for this wintertime salt release whereby INDOT locations could innovatively recover and reuse truck wash water while at the same time facilitating an enhanced means of production for salt brine used for deicing and anti-icing activities.

Wash water testing conducted at various INDOT yards has indeed shown that the salt levels present in salt truck wash waters often reach a concentration ranging from $2 \%$ to $9 \%$, at which point the notion of reusing this wash water for brine production appears both environmentally sound and economically reasonable. Reusing the salt-laden truck wash water will not only save material cost in making brine solution but will also conserve water use. Furthermore, the amount of salt released as runoffs into the local environment, or sewer system, will be commensurately decreased.

\section{Salt Brine Manufacture - Hardware and Operational Requirements}

The equipment required for making brine solution from recycled truck wash water will include an oil-water separator, sedimentation/retention tank for wash water, brine making tank, storage tank(s), and pumps. The plumbing should be setup in a way that brine recirculation and fine-adjustment of its salt density can be completed in both the brine making and storage tanks. 
Due to the corrosive nature of salt water, all containers, equipment and plumbing in contact with the wastewater and brine solution should be made of corrosion resistant materials such as polyethylene. Flexible hoses with appropriate couplings should be attached to the storage tank for transfer of brine to the truck saddle tank. A hydrometer will be used to control the salt content of the brine solution, which should be as close to the eutectic concentration of $23.3 \%$ as possible.

These brine making operations may either be conducted indoors or outdoors at a location adjacent to the wash bays to facilitate ease of transfer, and consideration should be given to the installation of secondary containment dikes to contain possible spills. A “do-it-yourself” brinemanufacturing tank should have a wide brim for easy loading of salt using a bobcat or a frontend loader.

Site-specific brine manufacturing and storage capacities will need to be sized on an asneeded local basis. As for temporary storage of the brine product prior to its final use, a minimum tank size of 2,500 gallon is recommended. A one-half horsepower pump should be able to provide 20-40 gallons per minute of flow at $15 \mathrm{ft}$ head, which allows for top filling of most on-site storage tanks and brine tanks on trucks. Selection of plumbing line sizes will be controlled by production flow rate, system design and pump specifications. Sizes should be established in conjunction with the pump supplier.

Fine sand and other particulates present in the wash water may cause plugging problems with sprayer outlet ports. Oil and grease washed off from trucks may also cause plugging problems. Stainless-steel strainers, with 80 - to 100-mesh reinforced wire sizes, should consequently be used on truck filling lines close to the tank for removal of these contaminant solids. Wash water should also be allowed to stand in the sedimentation/retention tank for a period of time before brine making begins, such that particles and other crud might be allowed to settle.

\section{Brine Production and Usage Systems in Indiana}

As of 2004 there were thirty-three (33) brine manufacturing systems in the State of Indiana, six of which (Gary, LaPorte, Monticello, Princeton, Bainbridge, and Bluffton) were set up to use truck wash water to make brine. Three of these sites were built with "do-it-yourself" brine manufacturing system with the rest using commercial brine making system.

The Monticello Sub-District unit was the site of a field implementation of a proof-ofconcept brine production system using recycled truck wash water. The experimental brine making unit was located within the wash bays. Wastewater from truck washing flows through the floor grate into the 1,100 gallon underground concrete tank. From the underground tank, water is pumped through the oil-water separator and then gravity flow to a 56 gallon tank. A 'bobcat'-style loader is used to transfer salt into a 750 gallon brine manufacturing tank. The water is pumped over to the brine manufacturing tank, while the overflow may be discharged to the city sewer line with restriction.

Mixing of brine, and testing salt concentration in both the brine making tank and the storage tank is achieved through switching specific valves and pumps. A 2,200 gallon tank is available for brine storage. The rate of production of salt brine is up to approximately 1,000 gallons per hour. About 3,600 gallons of salt brine was used for pre-wetting purposes during the winter of 2000-2001. The cost of the brine making system is about $\$ 3,055$. In addition, additional expenditures would be likely required for on-site plumbing and electrical installation (estimated at $\sim 2,000$ ) as well as the cost for procuring a brine sprayer (i.e., commercial units are $\sim \$ 8,000)$. 
Another well-designed brine making facility is located at the LaPorte Sub-District. Part of the facility is located within the truck washing area. Truck wash water flows through the floor grate and passes through the oil-water separator. The wash water then flows into the underground concrete sedimentation tank and pumped over to a 1,025 gallon tank, which then gravity flows to a brine manufacturing tank. Two outdoor 1,250 gallon tanks are available for storage of brine.

\section{Environmental and Safety Issues}

Although salt-laden truck wash water has the potential to make brine solution for prewetting and anti-icing purposes, there are contaminants of concern in the wash water that must be monitored. The presence of organic contaminants, such as oil, grease, and anti-freeze may pose environmental problems when contaminated salt brine is sprayed onto roads. High concentrations of oxidizable organic matter in a wastewater can result in depletion of oxygen and jeopardizing aquatic life if this wastewater was to be discharged to a stream or lake. Ferrocyanide, an anti-caking agent present in some forms of salt, may also accumulate in ground and surface water. In turn, ferrocyanide residuals on the surface may possibly convert to a problematic cyanide form when exposed to sunlight, but the photoconversion reaction rate is considered to be quite slow.

As established by current Indiana Administrative Code (327 IAC 2-1-6) relevant to 'minimum surface water quality standards,' a specific maximal dissolved solids concentration of $750 \mathrm{mg} / \mathrm{L}$ is stipulated for all natural waters of the State. While the standards for oil and grease in these same natural Indiana waters is rather more vague (i.e., the absence of visual "sheen" and "turbidity") than that for dissolved solids, these requirements collectively highlight the commensurate importance of reducing or obviating INDOT's salt truck wash water problem

Under the Stormwater Phase II regulations of the National Pollution Discharge Elimination System (NPDES), states transportation facilities fall under operators of "municipal separate storm sewer systems" (MS4). MS4's that discharge to a state drainage system will need to implement stormwater control measures. With the advent of the national total maximum daily loads (TMDL) program, states, EPA, and citizen groups now increasingly seek to impose numerical concentration and mass limits on stormwater discharges. The Indiana Department of Environmental Management (IDEM) is currently in the process of establishing TMDL for chloride. INDOT environmental and stormwater managers may need to scrutinize state lists of "impaired" waters to ensure a sound technical basis for listings that may impact their discharges. Simply put, therefore, INDOT officials will need to carefully review their current practice of discharging salt-laden runoffs from salt storage and salt truck washing facilities to ensure compliance. The "327 IAC 2-10 Rule" also addresses secondary containment for salt brine storage tanks. Double walled storage tanks or concrete containment dikes may be required since INDOT may ultimately be held responsible for any spills or problems associated with storage tanks containing brine and other deicing chemical. Deicing chemicals stored in INDOT yards are also subjected to the rules in the OSHA Hazard Communication Standards to ensure hazards in the workplace are identified and communicated to all employees.

A survey of INDOT maintenance facilities conducted in 1997-1998, with updates in 2001 was examined. It was found that about half of the facilities do not have connections to a publicity owned treatment plant, and many have off-site discharges to the environment. These sites will have to obtain NPDES permits unless outside washing of trucks are stopped and all wash water connected to a treatment plant. Good housing keeping procedures in handling salts are also needed to ensure compliance. 


\section{INTRODUCTION}

Deicing chemicals, such as sodium chloride $(\mathrm{NaCl})$, calcium chloride $\left(\mathrm{CaCl}_{2}\right)$, magnesium chloride $\left(\mathrm{MgCl}_{2}\right)$, and a number of other organic-based deicing agents (e.g., Ice Ban, Caliber M-1000, etc.) have been used by the Indiana Department of Transportation (INDOT) on Indiana roads during cold-weather periods to promote highway safety. In turn, given the characteristics of these materials and the quantities that are used, it is inevitable that environmental problems will arise relative to contaminant release and runoff within the INDOT yards at which these salts are stored and handled.

At the same time, an increased degree of environmental concern has lead to public awareness of the problems which salt runoffs have created. INDOT has already established snow and ice chemical pollution control guidelines in their Field Operations Manual, and ideally brine runoff from salt storage facilities will be directed straight into a local sanitary sewer line (with permission of the local municipalities) or collected within a lined, impervious detention pond. However, there are cases where neither of these options are available and environmental problems or discharge violations may be incurred. Besides runoffs from salt storage pads and salt handling operations, runoffs from truck washing may also contain considerable amount of salt and be discharged to the environment if appropriate measures are not implemented.

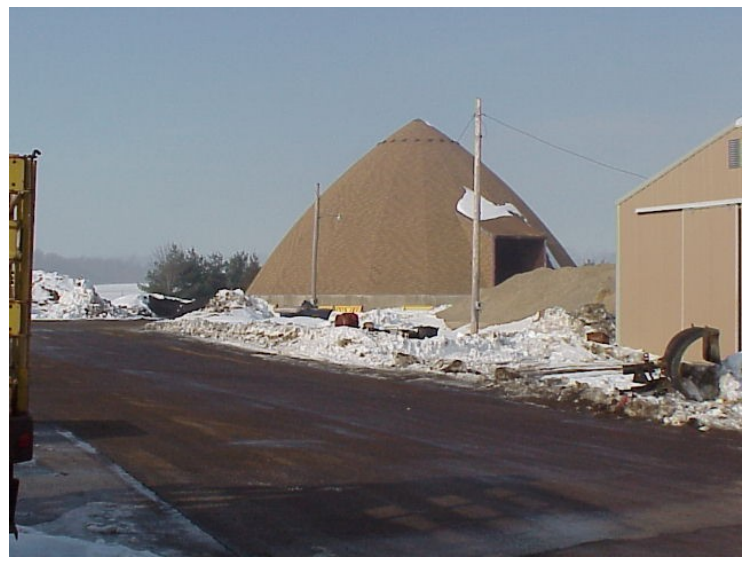

Figure 1.1: Salt storage dome

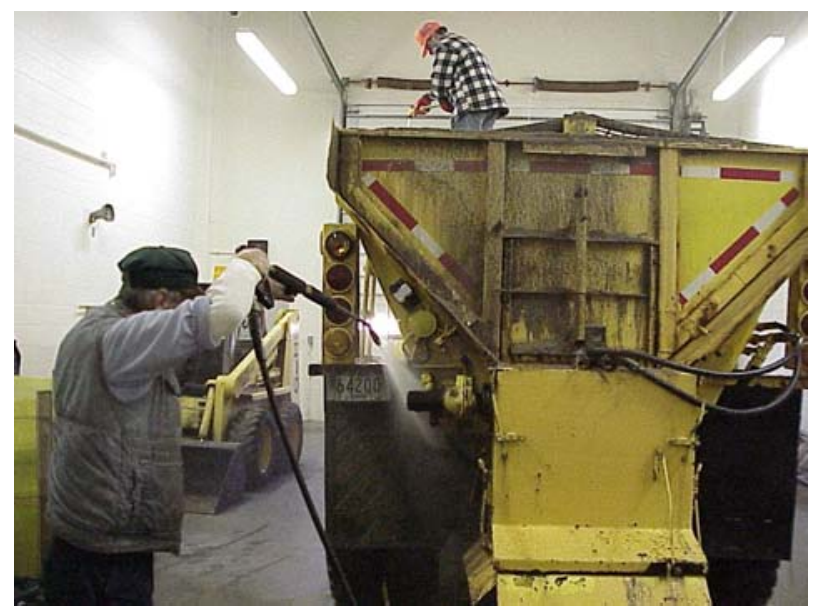

Figure 1.2: Salt truck washing operation 


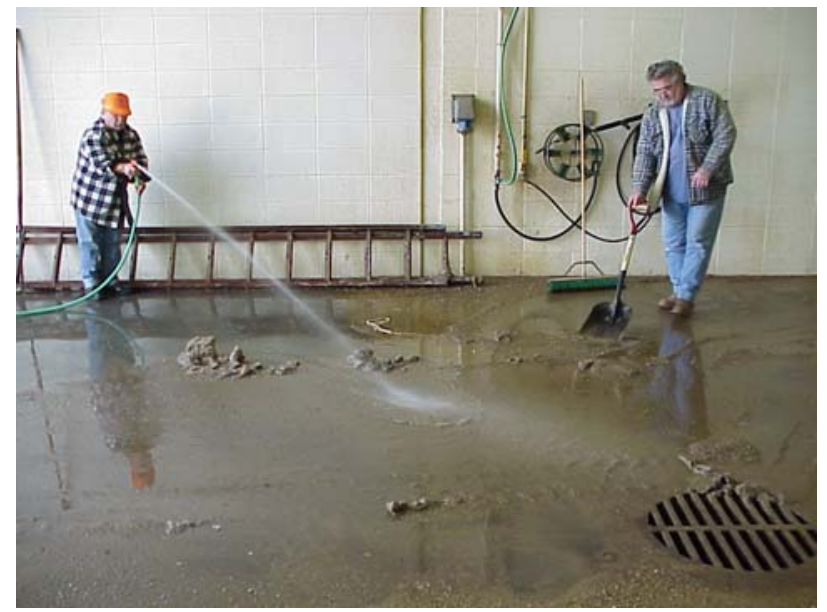

Figure 1.3: Spraying and scraping off debris after truck washing

In recent years there has been growing interest among the mid-western cold-weather states to utilize salt brine for anti-icing and pre-wetting salt. On-the-road research has shown that prewetting dry salt or salt-and-sand mixtures has many advantages, which include (Iowa DOT, 1997):

- Better adhesion to the road surface (with an estimated level of 25 to 65\% better retention)

- Acts faster

- Works at lower temperature to prevent snow accumulation

- Reduces salt usage by $20-30 \%$

- Requires less time and labor to put salt on the roads

Salt brine can also be used in anti-icing, which is the practice of preventing the formation of bonded snow or ice to the pavement by timely applications of a chemical freezing point depressant.

Several brine manufacturing systems are commercially available and currently utilized by many DOT agencies, including INDOT. Table 1 given on the following page lists INDOT's group of 33 locations currently equipped on-site manufacture of rock salt $(\mathrm{NaCl})$ brine.

All of these systems were designed to use fresh water to make brine, but it appears that the salt-laden truck wash water has a potential to be reused to make brine solution. Reusing truck wash water to make salt brine will not only save water, but also decrease the amount of salt released as runoffs or into the local sewer system. 
Table 1. Current 2004 Distribution of INDOT Brine Manufacturing Locations (Note: Figure 6.4 also provides a visual overview of these locations)

[Reference: Partridge, 2004]

\begin{tabular}{|c|c|c|}
\hline Number & District & Specific Locations per District \\
\hline 7 each & Crawfordsville & $\begin{array}{l}\text { Terre Haute Sub-district } \\
\text { Veedersburg Unit } \\
\text { Lafayette Unit } \\
\text { Frankfort Sub-district } \\
\text { Cloverdale Sub-district } \\
\text { Bainbridge Unit } \\
\text { Plainfield Unit (Under Construction) }\end{array}$ \\
\hline 4 each & Fort Wayne & $\begin{array}{l}\text { Bluffton Sub-district } \\
\text { Elkhart Sub-district } \\
\text { Fort Wayne Sub--district } \\
\quad \text { North Manchester Unit }\end{array}$ \\
\hline 9 each & Greenfield & $\begin{array}{l}\text { Indianapolis Sub-district } \\
\text { Five Points (Sub Location) } \\
\text { Madison/Morris Unit } \\
71^{\text {st }} \text { St. Unit } \\
\text { Greenfield Sub-district } \\
\text { Greenfield Unit } 1 \\
\text { Anderson Unit } \\
\text { Centerville Sub-district } \\
\text { Richmond Unit } \\
\text { Tipton Sub-district } \\
\text { Westfield Unit } \\
\text { Tipton Unit } \\
\text { Albany Sub-district } \\
\text { Muncie Unit (Planned for Calendar Year 2005) }\end{array}$ \\
\hline 7 each & LaPorte & $\begin{array}{l}\text { Winamac Sub-district } \\
\text { LaPorte Sub-district } \\
\text { Monticello Sub-district } \\
\text { Rensselaer Sub-district } \\
\quad \text { Wanatah Unit } \\
\text { Gary Sub-district } \\
\text { Plymouth Sub-district }\end{array}$ \\
\hline 3 each & Seymour & $\begin{array}{l}\text { Columbus Sub-district } \\
\text { Madison Sub-district } \\
\text { Falls City Sub-district (On order) }\end{array}$ \\
\hline 3 each & Vincennes & $\begin{array}{l}\text { Evansville Sub-district } \\
\text { Boyle Lane Unit } \\
\text { Tell City Sub-district } \\
\text { Birdseye Unit } \\
\text { Vincennes Sub-district } \\
\text { Princeton Unit }\end{array}$ \\
\hline
\end{tabular}




\section{OBJECTIVES}

\subsection{Purpose of the Report}

The purpose of the report is to address the environmental issue of winter salt runoffs problems at INDOT salt storage and truck washing facilities. An emphasis of this report is developing a systematic way to reuse salt runoffs to make brine solution, which can be used either as a pre-wetting agent or an anti-icing solution. Application rates and equipment required to make use of brine solution in snow and ice operations will also be examined. Environmental laws and regulations pertaining to salt brine runoffs will also be presented.

A comparative study was conducted to examine existing INDOT yards practices and that of the other states. In preparation of the report, extensive research was conducted from technical journals, the Internet, and literature provided by institutions such as the Salt Institute and the Federal Highway Administration (FHWA). A trip was made on April 4-6, 2000 to attend the Annual Mid-west Snow and Ice Conference at Hannibal, Missouri. The Purdue graduate student attended the Annual Purdue Road School held on March 20 and 21, 2001, and the project investigator and graduate student also attended the APWA Snow and Ice Conference held at Indianapolis on April 10, 2001. These meetings provided valuable opportunities for obtaining snow and ice experiences from the various states, and allowed for many avenues for networking and exchange of ideas.

\subsection{Organization of the Report}

The report is divided into nine chapters. The third and forth chapters gives an overview of general deicing and anti-icing options and practices. They include chemical options, application equipment and rates, and annual usage by various states. The fifth chapter deals with the production, storage and transfer of salt brine. Brine making facility requirement, production procedures and concerns are discussed. Chapter six describes in detail a field investigation of the Monticello Sub-District experimental brine making system and gives an overview of other experimental systems. This chapter is followed by the seventh chapter, which highlights the environmental and regulatory concerns of brine runoffs, with emphasis in stormwater runoffs. The eighth chapter gives the cost benefit analysis of deicing, anti-icing and pre-wetting. The last chapter lists final conclusions and recommendations obtained from this research. 


\section{GENERAL DEICING OPTIONS AND PRACTICES}

\subsection{Overview}

Deicing is the practice of applying a melting agent after some accumulation of snow and ice. Salt or other deicing chemicals are applied directly on top of the snow and ice pack. The deicing chemical will penetrate through to reach the pavement and break the bond between the snow and ice and the pavement, such that the snow and ice can be plowed or shoveled away.

\subsection{Chemical Options}

Various deicing chemical options are available and decision has to be made based on factors such as cost, materials availability and road conditions. Other than the application of plain salt, other options which have been historically used include the following:

- Applying salt and sand mixtures

- Applying salt pre-wetted with inorganic liquid brines, including rock salt (i.e., $\mathrm{NaCl}$ ), calcium chloride and magnesium chloride brine options

- Applying a mixture of dry salt and solid calcium chloride

- Applying other liquid agricultural deicing chemicals

Sand and salt mixtures were used some years ago when a rapid increase in friction coefficient is required, particularly at temperatures so low that chemical action is slow. However the obtained increase was general short-lived since traffic rapidly dispersed these abrasives (FHWA, 1996). Furthermore, sand use can also lead to drain clogging and/or other physical problems, and as a result is no longer practiced by INDOT.

The use of pre-wetted salt as deicing agent is based on the fact that dry salt is incapable of melting snow and ice until it comes into contact with moisture. During snow storms with cold air temperatures and low humidity, where available moisture is scare, the melting process may be slowed considerably. Adding brine or other liquid deicers to dry salt at the spinner, or directly on top of the truckload may provide extra moisture to quicken the melting process. Many DOTs also use

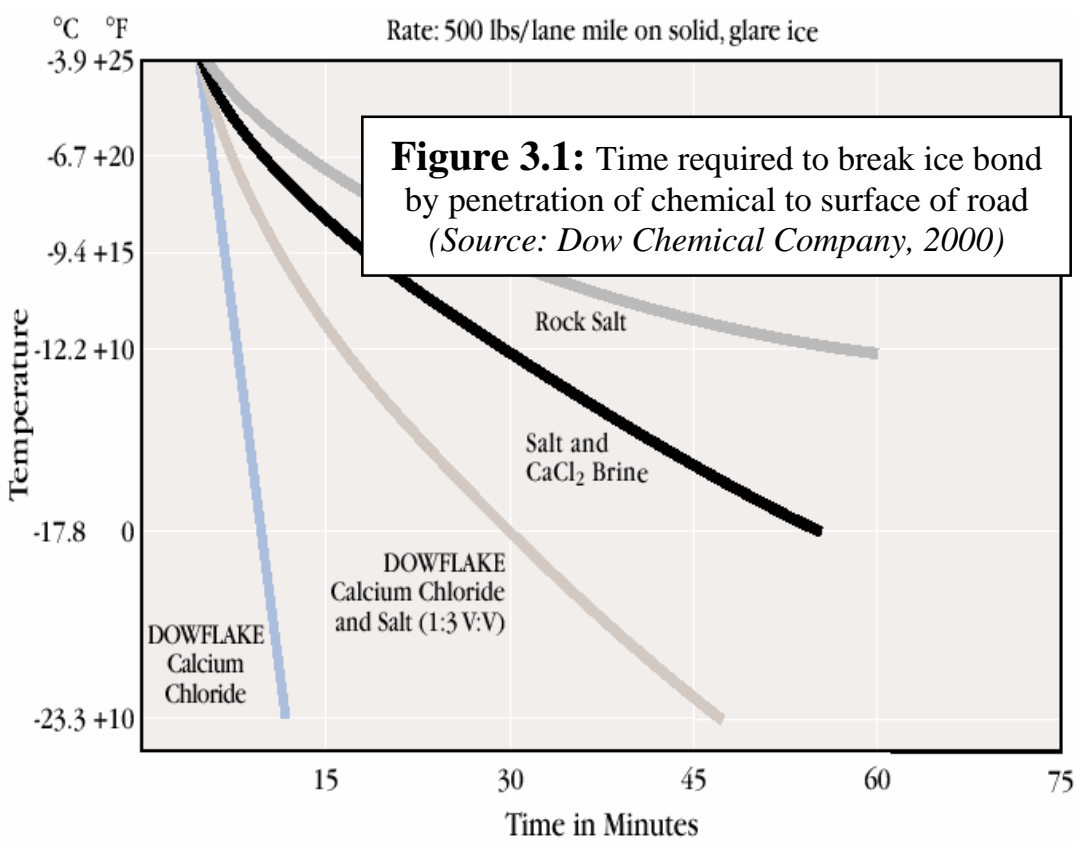
flake or pallet calcium chloride blended with rock salt to create a mixture that provides faster action and lower temperature effectiveness than rock salt alone. Figure 3.1, which first appeared in an August 1978 issue of Better Roads, shows the time required to break ice bond by penetration of various mixture of salt and calcium chloride to surface of road. 
In terms of agricultural chemicals derived from agricultural by-products (e.g., such as Ice Ban and Caliber M-1000), these materials have also been used for highway ice control in the State of Indiana. INDOT's LaPorte and Seymour districts represent the dominant users, but overall their use over the past several years has been fairly nominal in volume in comparison to any of the inorganic brine solutions.

Table 3.1 provides a summary of some of the most common deicers' effectiveness and costs.

\subsection{Application Equipment}

Solid deicers are usually applied onto the road with a hopper type spreader mounted on trucks (Figure 3.2), which can be taken out at the end of the winter season. These spreader units

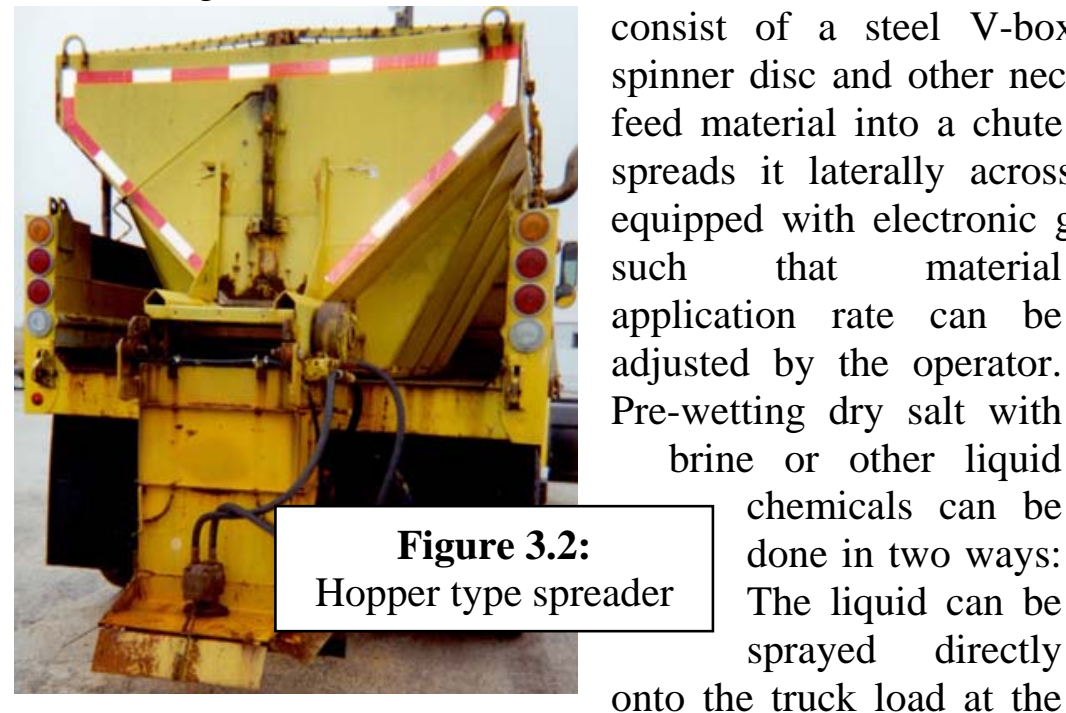
yard, or during spreading operations using saddle tank and sprayer at the spinner to apply the liquid to the salt at time of application. Applying liquid chemicals directly onto the load is accomplished by an overhead sprayer with nozzles that dispense the liquid (Figure 3.4). One notable disadvantage of

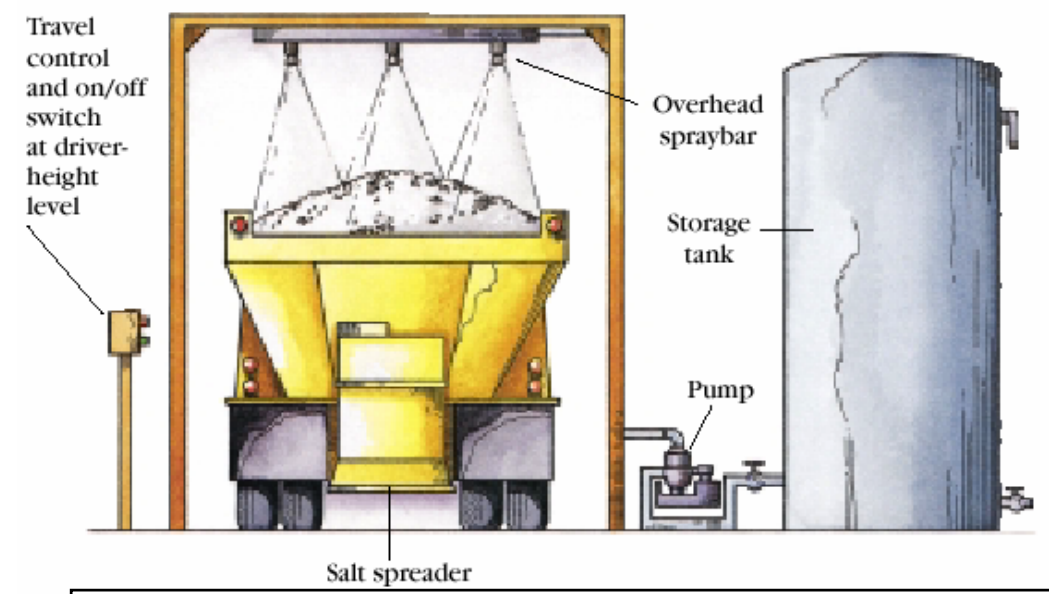

Figure 3.4: Pre-wetting truck load using overhead spray bars (Source: Dow Chemical Companv. 2000) this method is that it has a very high corrosive effect on the truck equipment. It is also very difficult to get uniform particle coating with this method.

The on-board pre-wetting system will allow direct application of liquid while the material is being spread (Figure 3.5). Both electric and hydraulic spray systems are used, with equipment like pumps, in-cab controls, nozzles, saddle tanks (Figure 3.6) and other fittings. All spreaders should be calibrated periodically. 
Table 3.1: Summary of deicers/anti-icers' effectiveness and costs

\begin{tabular}{|c|c|c|c|c|c|c|}
\hline & $\begin{array}{c}\text { Sodium chloride (rock } \\
\text { salt) } \mathrm{NaCl}\end{array}$ & $\begin{array}{l}\text { Calcium chloride } \\
\mathrm{CaCl}_{2} \text { or DowFlakes } \\
\text { (77-80\% } \mathrm{CaCl}_{2} \text { with } \\
\text { corrosion inhibitor) }\end{array}$ & $\begin{array}{c}\text { Magnesium } \\
\text { chloride } \mathrm{MgCl}_{2}\end{array}$ & $\begin{array}{c}\text { Calcium magnesium } \\
\text { acetate (CMA) }\end{array}$ & $\begin{array}{c}\text { Ice Ban M50 (50\% Ice } \\
\text { Ban and } 50 \% \mathrm{MgCl}_{2} \\
\text { brine) }\end{array}$ & Caliber M-1000 \\
\hline Eutectic Temp. $\left({ }^{\circ} \mathrm{F}\right)$ & -5.8 & -60 & -28 & -17.5 & \multirow{3}{*}{$\begin{array}{c}\text { (performance of Ice Ban } \\
\text { M50 varies from batch } \\
\text { to batch and over time) }\end{array}$} & -85 \\
\hline Concentration (\%) & $23.30 \%$ & $29.80 \%$ & $21.60 \%$ & $32.50 \%$ & & $30 \%$ solids $+30 \% \mathrm{MgCl}_{2}$ \\
\hline Working Temp. ( $\left.{ }^{\circ} \mathrm{F}\right)$ & +15 to 20 & -20 & +5 & +20 to 25 & & \\
\hline Purchase Price & $\begin{array}{c}\text { \$20-40/ton } \\
\$ 0.04-0.05 / \text { gal (liquid) }\end{array}$ & $\begin{array}{c}\$ 260 / \text { ton (pellets) } \\
\$ 200 / \text { ton (flakes) } \\
\$ 445 / \text { ton (DowFlakes) } \\
\$ 0.15-0.63 / \text { gal (liquid) }\end{array}$ & $\begin{array}{l}\text { \$69-95/ton (liquid) } \\
\$ 0.4-0.7 / \text { gal (liquid) }\end{array}$ & $\begin{array}{l}\$ 700 / \text { ton (solid) } \\
\$ 1.25 / \text { gal (liquid) }\end{array}$ & \$1.25/gal (liquid) & $\$ 0.75-0.85 / g a l$ (liquid) \\
\hline Corrosivity & High & Moderate & Low & \begin{tabular}{|c|} 
Low \\
\end{tabular} & Low & $70 \%$ less than salt \\
\hline Effectiveness & Very effective & $\begin{array}{l}\text { Liberates heat when } \\
\text { goes into solution: } \\
\text { aiding in melting }\end{array}$ & $\begin{array}{c}\text { Similar to } \mathrm{CaCl}_{2} \text {, } \\
\text { slightly less melting } \\
\text { capability } \\
\end{array}$ & Has a residual effect & Varies & Effective in anti-icing \\
\hline Surface effects & $\begin{array}{c}\text { Dries completely, leaving } \\
\text { a white residue }\end{array}$ & $\begin{array}{l}\text { Leaves moist film on } \\
\text { road which reduces } \\
\text { friction slightly }\end{array}$ & $\begin{array}{l}\text { Residual effect on } \\
\text { pavement without } \\
\text { slippery film }\end{array}$ & $\begin{array}{l}\text { Not perform well. } \\
\text { Requires } 40 \% \text { more } \\
\text { to equal salt's } \\
\text { effectiveness }\end{array}$ & $\begin{array}{c}\text { No impact on effect of } \\
\mathrm{NaCl} \text { on concrete scaling } \\
\text { or metal corrosion }\end{array}$ & No impact \\
\hline $\begin{array}{l}\text { Environmental } \\
\text { effects }\end{array}$ & $\begin{array}{l}\text { High concentration cause } \\
\text { plant stresses and } \\
\text { aquatic environment }\end{array}$ & $\begin{array}{c}\text { Adds hardness to } \\
\text { water }\end{array}$ & $\begin{array}{l}\text { Large quantities } \\
\text { contribute to } \\
\text { eutrophication in } \\
\text { water bodies }\end{array}$ & $\begin{array}{l}\text { Acetate ion may } \\
\text { contribute to loss of } \\
\text { oxygen in water } \\
\text { bodies }\end{array}$ & N.A. & N.A. \\
\hline Use & $\begin{array}{l}\text { - wetted with } \mathrm{CaCl} \\
\text { - plain } \\
\text { - wetted with } \mathrm{NaCl} \text { brine }\end{array}$ & $\begin{array}{l}\text { - mixed with salt } \\
\text { - pre-wet salt } \\
\text { - straight/alone or } \\
\text { in solution }\end{array}$ & $\begin{array}{l}\text { - sprayed directly on } \\
\text { sand } \\
\text { - pre-wet salt }\end{array}$ & $\begin{array}{l}\text { - liquid mixed with } \\
\text { salt or sand } \\
\text { - liquid alone }\end{array}$ & $\begin{array}{l}\text { - liquid mixed with } \\
\text { salt or sand } \\
\text { - liquid alone }\end{array}$ & $\begin{array}{l}\text { - liquid for anti-icing } \\
\text { - liquid for deicing } \\
\text { - liquid for pre-wetting }\end{array}$ \\
\hline
\end{tabular}



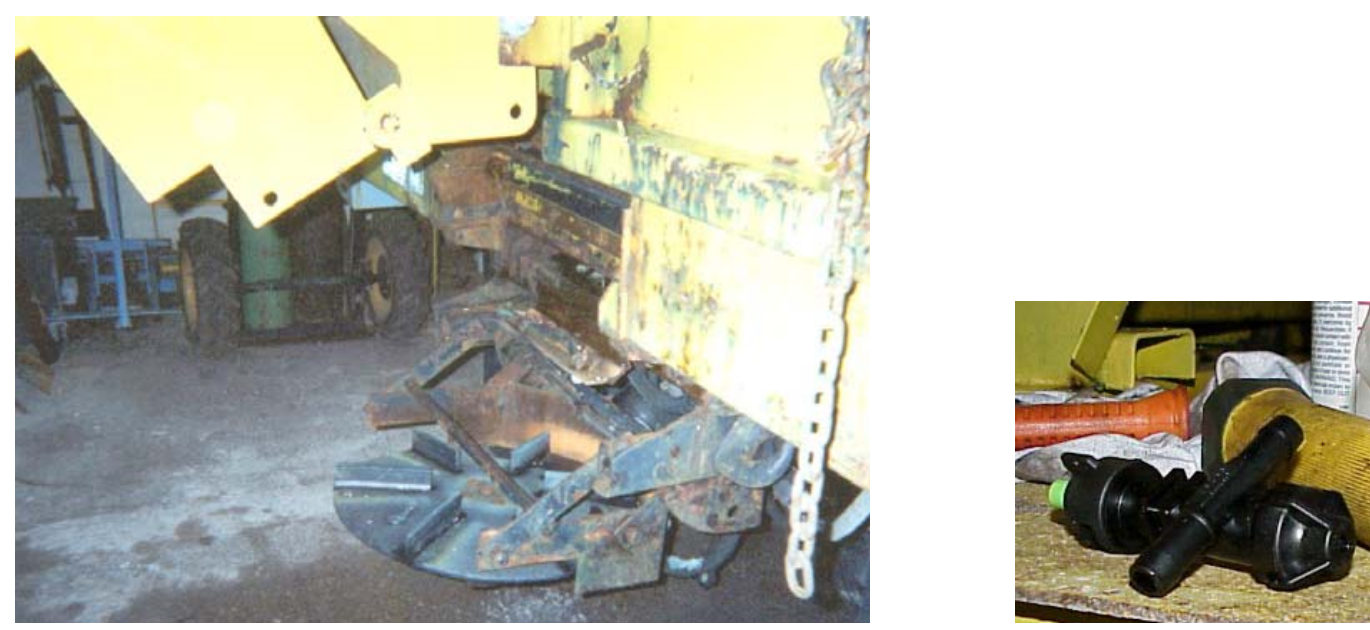

Figure 3.5: Liquid chemical can be sprayed onto the spinner (left) when spreading salt onto the road using a nozzle (right)

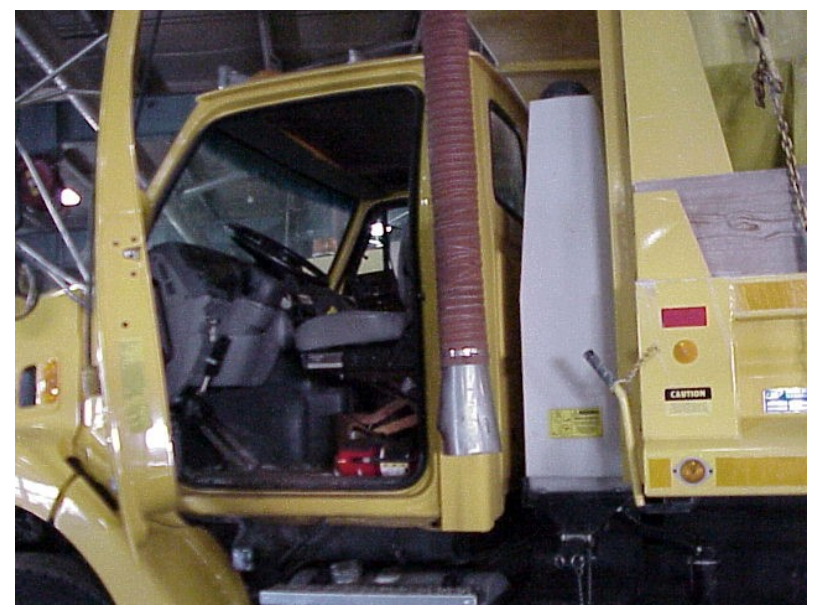

Figure 3.6: Saddle tank mounted on truck for on-board pre-wetting system

\subsection{Application Conditions and Rates}

Application rates with deicing chemicals are dependent upon weather and road condition. In general, an application rate of 100 to $400 \mathrm{lb} / \mathrm{lane}$-mile of dry chemical is used for deicing purposes. At the INDOT Monticello Sub-District, $250 \mathrm{lb} / \mathrm{lane}$-mile of salt is typically used.

Deicing with straight salt is to be used at pavement temperature above $+10{ }^{\circ} \mathrm{F}$. When salt is mixed with other solid chemicals with a lower freezing temperature, such as calcium chloride, deicing can be accomplished at a lower temperature. For example, it was reported that at the INDOT Logansport District, a 3:1 salt and solid calcium chloride mixture applied at $250 \mathrm{lb} / \mathrm{lane}-$ mile will be effective with pavement temperatures down to $0{ }^{\circ} \mathrm{F}$. 
Pre-wetting salt with brine or other liquid chemicals has proved to reduce application rates by $20-30 \%$. This benefit will only be realized if operators and managers follow through and modify their spread rates when using pre-wetted chemicals. It was reported that the INDOT Winamac district had been able to apply $120 \mathrm{lb} /$ lane mile of salt when pre-wetted with liquid calcium chloride.

Application rates of liquid chemicals range from 10 gal-salt brine/ton-dry salt to 25 galsalt brine/ton-dry salt. Table 3.2 shows representative application rates of liquid chemicals per ton of salt for pre-wetting, collected from various states agencies:

Table 3.2: Representative application rates of liquid chemicals for pre-wetting

\begin{tabular}{|c|c|c|c|c|}
\hline & Sodium chloride & Magnesium chloride & Ice-Ban & Caliber M-1000 \\
\hline From Supplier & N.A. & N.A. & 8-12 gal/ton & 5-15 gal/ton \\
\hline \begin{tabular}{|c|}
$\mathrm{MN}$ \\
\end{tabular} & 12 to $14 \mathrm{gal} / \mathrm{ton}$ & $10 \mathrm{gal} / \mathrm{ton}$ & N.A. & \multirow{7}{*}{ N.A. } \\
\hline 10 & 12 to $25 \mathrm{gal} / \mathrm{ton}$ & \multirow{6}{*}{ N.A. } & & \\
\hline $\mathrm{IL}$ & 12 to $30 \mathrm{gal} / \mathrm{ton}\left(18^{\circ} \mathrm{F}\right.$ pavement) & & $8 \mathrm{gal} / \mathrm{ton}$ & \\
\hline IN -Monticello & $10 \mathrm{gal} / \mathrm{ton}$ & & \multirow{4}{*}{ N.A. } & \\
\hline \begin{tabular}{|l|} 
Plymouth \\
\end{tabular} & $8 \mathrm{gal} / \mathrm{ton}$ & & & \\
\hline Winamac & $30 \mathrm{gal} / \mathrm{ton}$ & & & \\
\hline LaPorte & $12 \mathrm{gal} / \mathrm{ton}$ & & & \\
\hline
\end{tabular}

\subsection{Relative Usage of Deicing and Anti-icing Material}

INDOT's use of various liquid deicing and anti-icing agents has dramatically increased over the past few years. Tables 3.3 through 3.6 given on the following four pages provides specific per-district details for the four major chemical options with deicing and anti-icing, including: calcium chloride (Table 3.3), magnesium chloride (Table 3.4), agricultural-based agents (e.g., Ice-Ban, etc.; Table 3.5), and standard $\mathrm{NaCl}$ brine (Table 3.6).

Making a quick assessment of this tabulated data, there are a number of quick 'observations' to be made, including: 1) that there appear to be district-related preferences in terms of their choice of applied chemicals (e.g., Seymour and Vincennes INDOT districts have higher useage rates for $\mathrm{MgCl} 2$ ), 2) that the use of $\mathrm{NaCl}$ brine has escalated significantly at most districts, and 3) that the volume of $\mathrm{NaCl}$ brine use is sizably larger that all other chemical forms. 
Table 3.3 INDOT District Use of 'Liquid Calcium Chloride’ During FY02-FY04

\begin{tabular}{|c|c|c|c|c|c|}
\hline $\begin{array}{l}\text { IND } \\
\text { Note: Green shaded cells show m }\end{array}$ & JID CALCIUM & I USAGE HIST & TORY FY200 & & \\
\hline Note: Pink shaded cells show highs & & & & & \\
\hline Crawfordsville Subdistrict & FY02 & FY03 & FY04 & 3-Yr. Avg & Subdistrict \\
\hline Terre Haute & 290.00 & $14,093.00$ & $3,773.00$ & $6,052.00$ & 1100 \\
\hline Crawfordsville & 0.00 & $19,138.00$ & $4,868.00$ & $8,002.00$ & 1200 \\
\hline Fowler & 690.00 & $13,829.00$ & $2,300.00$ & $5,606.33$ & 1300 \\
\hline Frankfort & $1,250.00$ & $12,651.00$ & $1,745.00$ & $5,215.33$ & 1400 \\
\hline Cloverdale & 0.00 & $17,449.00$ & 0.00 & $5,816.33$ & 1500 \\
\hline Veedersburg & 0.00 & 0.00 & 0.00 & 0.00 & 1600 \\
\hline TOTAL & $\overline{20,230.00}$ & $7 \overline{77,160.00}$ & $=12,686.00$ & 30 & I TOTAL \\
\hline Fort Wayne Subdistrict & FY02 & FY03 & FY04 & 3-Yr Avg & Subdistrict \\
\hline Warsaw & $8,273.00$ & $18,720.00$ & $17,826.00$ & $14,939.67$ & 2100 \\
\hline Goshen & $2,570.00$ & $16,740.00$ & $9,734.00$ & $9,681.33$ & 2200 \\
\hline Fort Wayne & $4,800.00$ & $26,050.00$ & $21,400.00$ & $17,416.67$ & 2300 \\
\hline Angola & $5,833.00$ & $14,993.00$ & $10,250.00$ & $10,358.67$ & 2400 \\
\hline Wabash & $6,700.00$ & $17,084.00$ & $15,780.00$ & $13,188.00$ & 2500 \\
\hline Bluffton & $6,023.00$ & $102,802.00$ & $10,085.00$ & $39,636.67$ & 2600 \\
\hline TOTAL & $34,199.00$ & $196,389.00$ & $85,075.00$ & $105,221.00$ & IOTTAL \\
\hline Greenfield Subdistrict & FY02 & FY03 & FY04 & 3-Yr Avg & Subdistrict \\
\hline Indianapolis & $3,333.00$ & $20,724.00$ & $7,096.00$ & $10,384.33$ & $3 \quad 3100$ \\
\hline Greenfield & $18,329.00$ & $37,552.00$ & $26,690.00$ & $27,523.67$ & 3200 \\
\hline Centerville & 800.00 & $28,673.00$ & $9,300.00$ & $12,924.33$ & 3300 \\
\hline Anderson & 0.00 & 0.00 & 0.00 & 0.00 & 3400 \\
\hline Tipton & $2,690.00$ & $34,495.00$ & $14,970.00$ & $17,385.00$ & 3500 \\
\hline Albany & $13,115.00$ & $54,002.00$ & $34,820.00$ & $33,979.00$ & 3600 \\
\hline TOTAL & $38,267.00$ & $1775,446.00$ & $=92,876.00$ & $102,196.33$ & 3 TOTAL \\
\hline LaPorte Subdistrict & FY02 & FY03 & FY04 & 3-Yr Avg & Subdistrict \\
\hline LaPorte & 0.00 & 0.00 & 0.00 & 0.00 & 4100 \\
\hline Monticello & $2,077.00$ & $16,099.00$ & $9,543.00$ & $9,239.67$ & 4200 \\
\hline Plymouth & 0.00 & 0.00 & 230.00 & 76.67 & 4300 \\
\hline Rensselaer & $5,050.00$ & $21,146.00$ & $14,288.00$ & $13,494.67$ & 4400 \\
\hline Valparasio & 0.00 & 0.00 & 0.00 & 0.00 & 4500 \\
\hline Winamac & $4,250.00$ & $10,026.00$ & $2,695.00$ & $5,657.00$ & 4600 \\
\hline Gary & $19,539.00$ & $51,501.00$ & $3,525.00$ & $24,855.00$ & 4700 \\
\hline TOTAL & $30,916.00$ & $98,772.00$ & $\overline{30,281.00}$ & $53,323.00$ & T TOTAL \\
\hline Seymour Subdistrict & FY02 & FY03 & FY04 & 3-Yr Avg & Subdistrict \\
\hline Aurora & 0.00 & 0.00 & 0.00 & 0.00 & 5100 \\
\hline Bloomington & 0.00 & 0.00 & 0.00 & 0.00 & 5200 \\
\hline Columbus & 0.00 & 0.00 & 0.00 & 0.00 & 5300 \\
\hline Falls City & 0.00 & 0.00 & 0.00 & 0.00 & 5400 \\
\hline Madison & 0.00 & 0.00 & 0.00 & 0.00 & 5500 \\
\hline Scottsburg & 0.00 & 0.00 & 0.00 & 0.00 & 5600 \\
\hline TOTAL & 0.00 & 0.00 & 0.00 & 0.00 & TOTAL \\
\hline Vincennes Subdistrict & FY02 & FY03 & FY04 & 3-Yr Avg & Subdistrict \\
\hline Linton & 0.00 & $2,688.00$ & $2,627.00$ & $1,771.67$ & 6100 \\
\hline Dale & 0.00 & 0.00 & 0.00 & 0.00 & 6200 \\
\hline Evansville & $8,426.00$ & $7,970.00$ & $4,366.00$ & $6,920.67$ & 6300 \\
\hline Paoli & $1,050.00$ & $9,741.00$ & $9,007.00$ & $6,599.33$ & 6400 \\
\hline Tell City & $3,131.00$ & $10,524.45$ & $15,595.00$ & $9,750.15$ & 6500 \\
\hline Vincennes/Petersburg & $12,607.00$ & $30,923.45$ & $6,070.00$ & $16,533.48$ & 6600 \\
\hline TOTAL & $25,214.00$ & $61,846.90$ & $373,665.00$ & $40,575.30$ & I TOTAL \\
\hline State Avg. & $21,804.33$ & $101,602.32$ & $43,097.17$ & $55,501.27$ & State Avg. \\
\hline TOTAL & $130,826.00$ & $609,613.90$ & $258,583.00$ & $333,007.63$ & 3 TOTAL \\
\hline
\end{tabular}


Table 3.4 INDOT District Use of ‘Liquid Magnesium Chloride’ During FY02-FY04

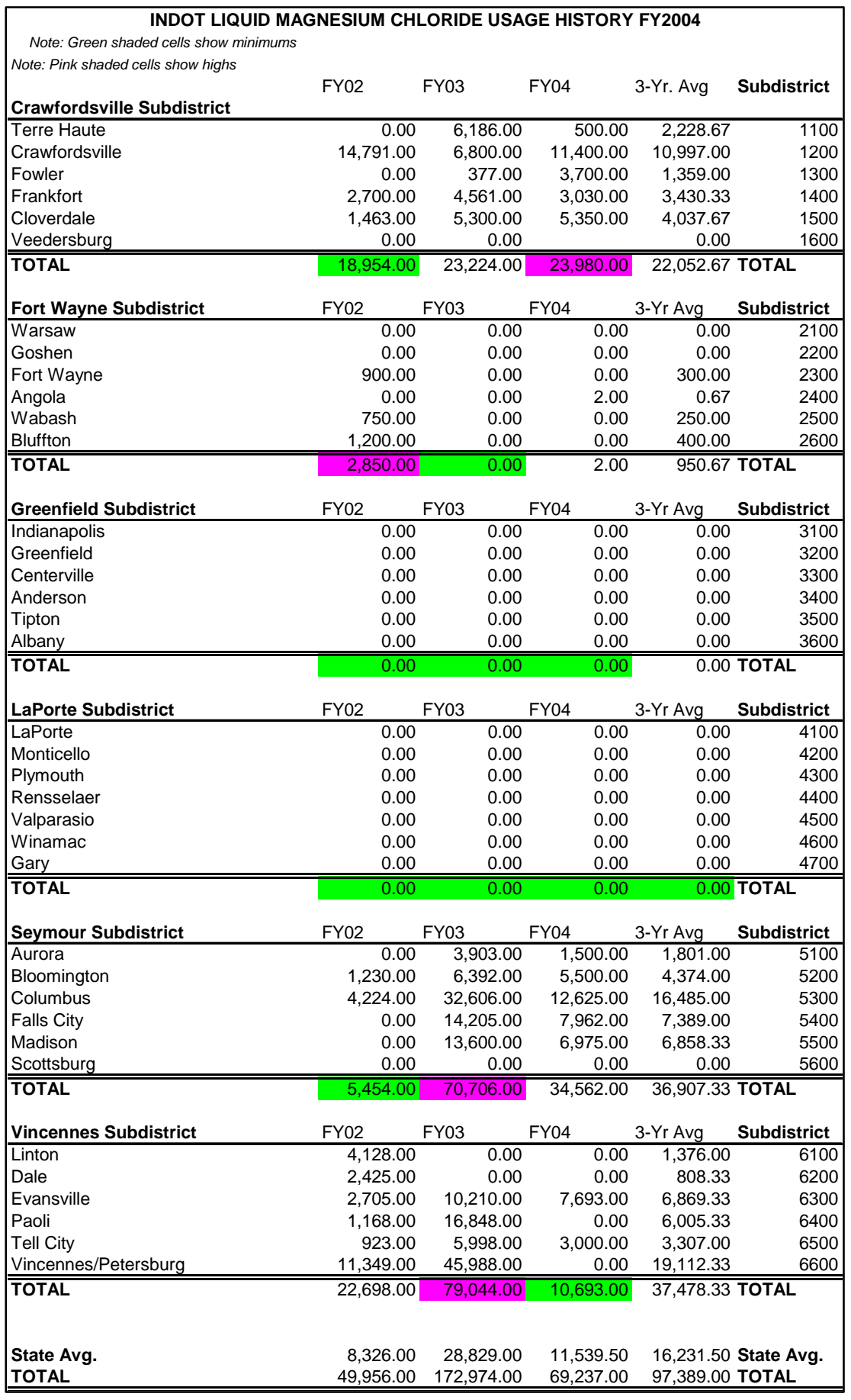


Table 3.5 INDOT District Use of 'Liquid Agricultural Deicer’ During FY02-FY04

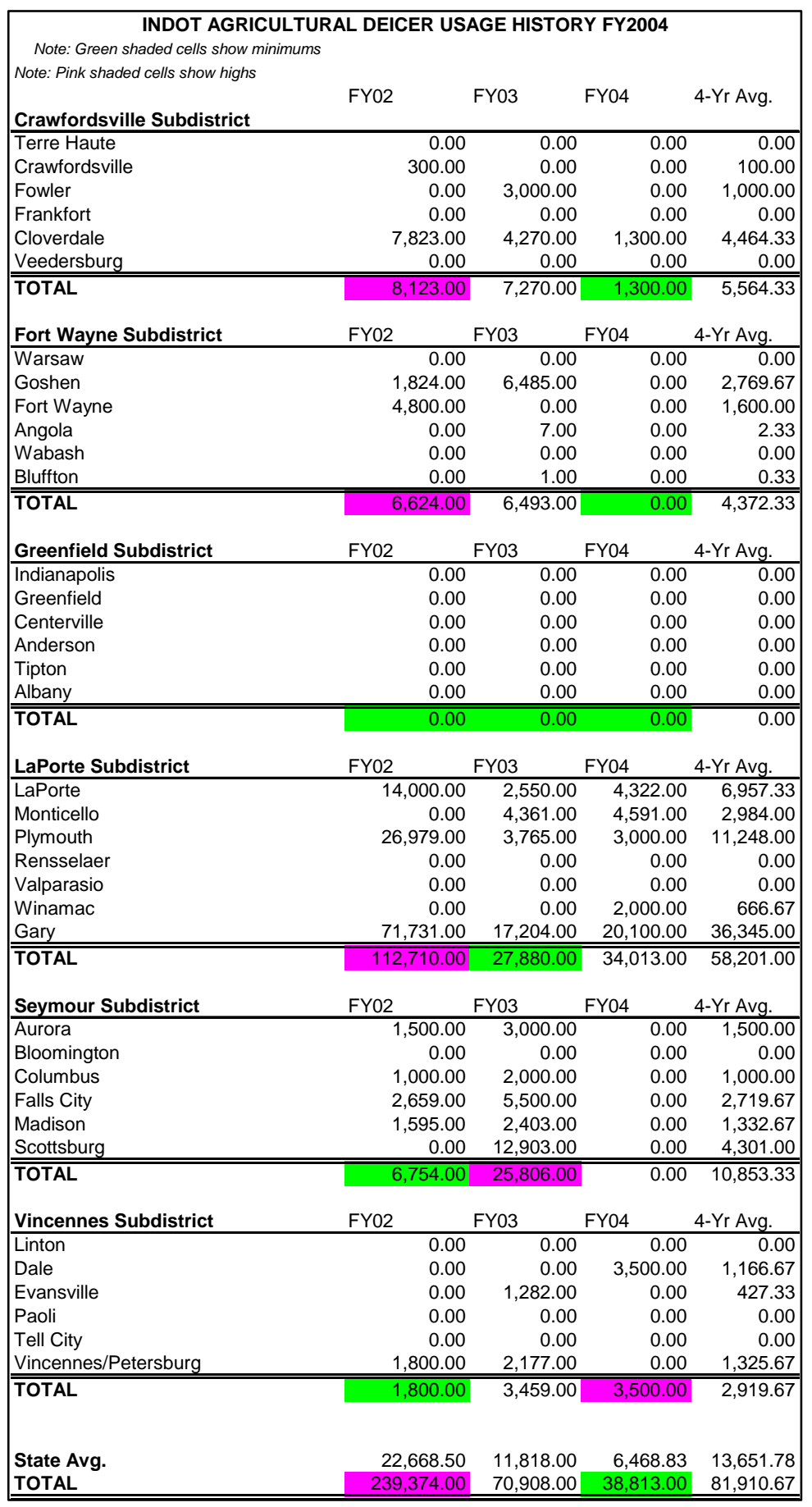


Table 3.6 INDOT District Use of 'Liquid NaCl Brine’ During FY02-FY04

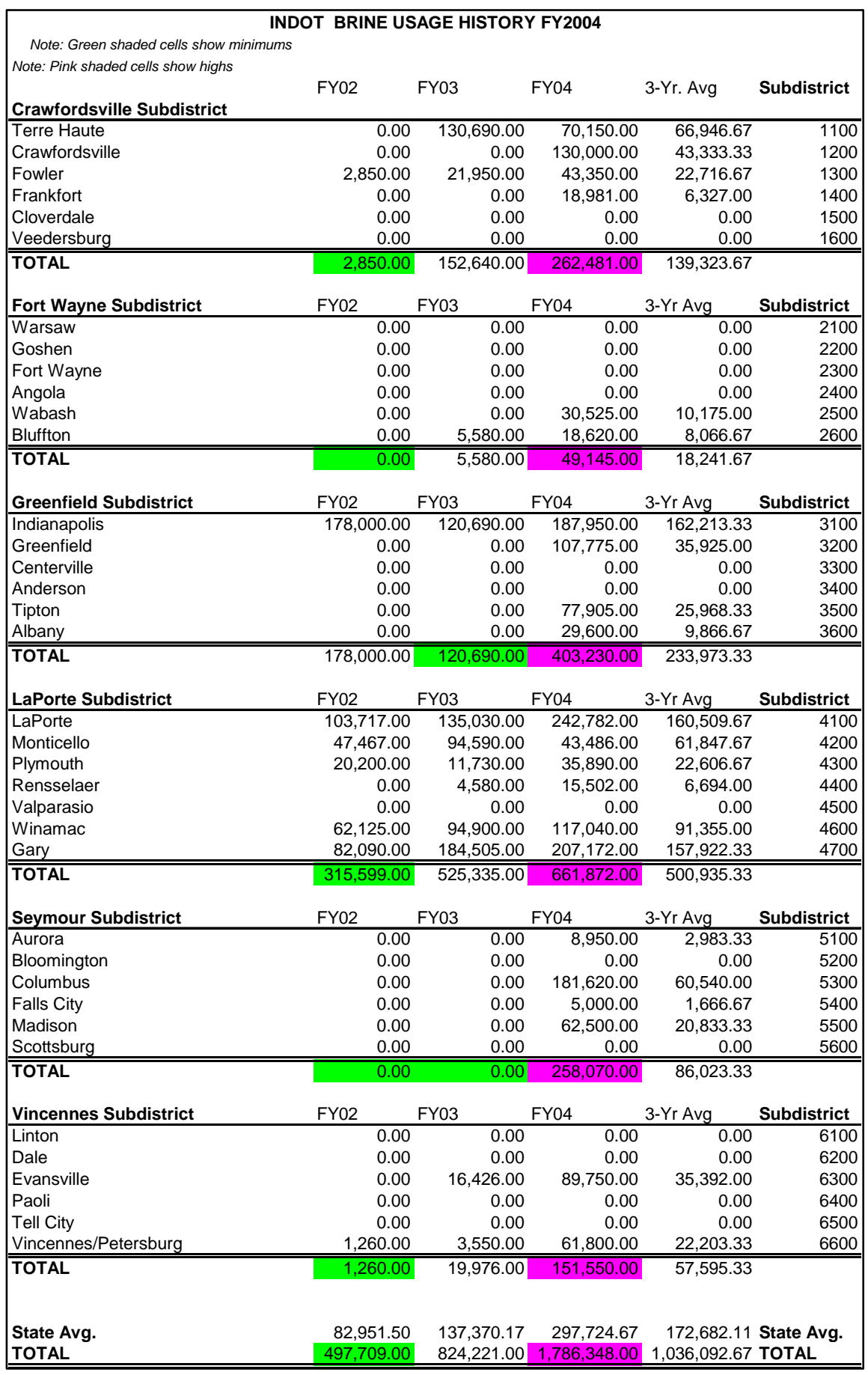


Given the complexity of the data offered in the preceding chemical- and district-specific chronologies of chemical deicer and anti-icer use, the following four visual schematics (Figures $3.7 \& 3.8$ ) have been developed to visually clarify their involved usage patterns.
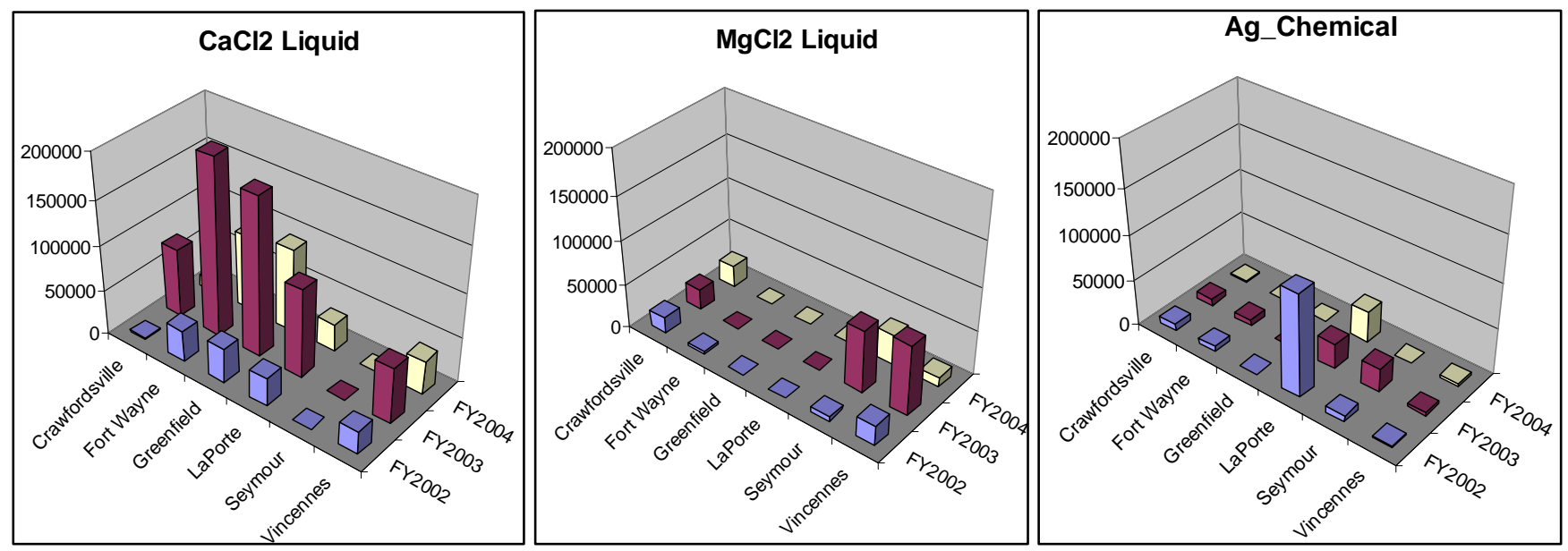

Figure 3.7 INDOT Non-Brine Deicer and Anti-Icer Use Chronology @ FY2002 to FY2004

The vertical axes with all three figures given in Figure 3.7 have been maintained at a range of 0 to 200,000 gallons, such that a quick view of these annual usage plots reveals the following details: 1) that calcium chloride has been, by far, the dominant option amongst these three liquids, 2) that some districts have a clear preference for calcium chloride use while other districts tend to rely on magnesium chloride, and 3) that the use of agricultural chemicals over the past three years has been far less in volume than that of the inorganic salt options, and that the agriculturechemical usage rates at most districts are rather nominal in volume.

By comparison, though, Figure 3.8 solely focuses on $\mathrm{NaCl}$ brine use, and is presented here at a somewhat larger size, and with a vertical axis scale 3.5-times larger, in order to facilitate a more accurate appreciation of the involved usage rates. What is immediately noticeable is the fact that $\mathrm{NaCl}$ brine use over the past three years has been far higher in volume than any other chemical option. In two instances (i.e., Seymour and Vincennes) $\mathrm{NaCl}$ brine use has dramatically increased in the space of only the past year. INDOT's largest $\mathrm{NaCl}$ brine user is the LaPorte district, and their level of consumption has

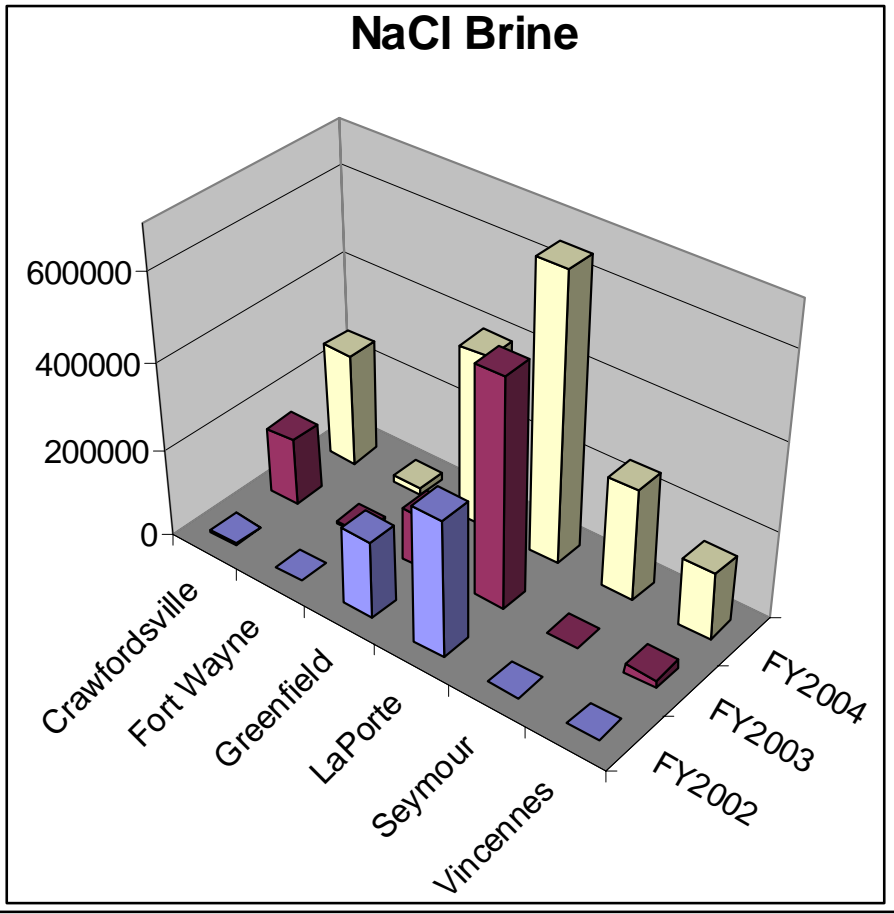

Figure 3.8 INDOT NaCl Brine Use @ FY2002-FY2004 increased steadily over the past three years to a recent peak of nearly 700,000 gallons. 


\section{GENERAL ANTI-ICING OPTIONS AND PRACTICES}

\subsection{Overview}

Anti-icing refers to the practice of preventing the formation of bonded snow or ice to the pavement by timely application of a chemical freezing point depressant (FHWA, 1996). This is different from deicing, which applies a melting agent only after some accumulation of snow or ice on the pavement. Anti-icing requires accurate, local weather data as well as equipment to measure pavement temperature and friction. Accurate storm prediction is the key element to successful application of anti-icing agent. Applying the material on the roadway too early or too late may be wasteful and ineffective.

\subsection{Chemical Options}

The chemical options of anti-icing are similar to that of deicing when solid or pre-wetted solids are used as anti-icing treatments. Although solids or pre-wetted solid chemicals can be used as anti-icing treatments, there are advantages to use of liquids. These include the ability to place chemical onto dry pavement as a pre-storm treatment to avert delays that may lead to bonded snow or ice (FHWA, 1996). Chemical anti-icers include salt brine, liquid calcium chloride, magnesium chloride, and alternative deicers/anti-icers such as Ice Ban or Caliber M1000. Please refer to Table 3.1 for properties and costs of common anti-icers.

\subsection{Equipment}

\subsubsection{Liquid Application Equipment}

Liquid anti-icing chemicals are usually applied onto the pavement with a distributor bar with nozzles (Figure 4.1). These spreaders spray the liquid from nozzles at a low height above the road to reduce the influence of air turbulence behind the vehicle that can cause the liquid to disperse before hitting the pavement. The unit is designed to be towed by a truck equipped with a liquid tank. Experience has shown that liquid chemicals can be successfully applied at speeds up to 40 to $50 \mathrm{mph}$ for spray bar type speeds.

If large, truck-mounted tanks (Figure 4.2) are used, it should be equipped with internal baffles to prevent the liquid from suddenly shifting in the tank and creates a hazardous control situation for the operator (Salt Institute, 1999b). It is also important that nozzles and filters be checked frequently to ensure uniformity and efficiency of liquid spreading. 


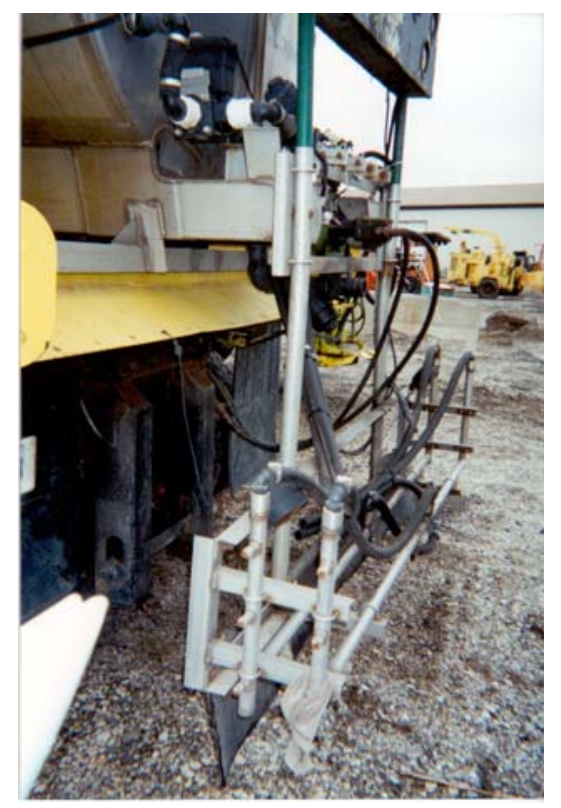

Figure 4.1: Liquid applicator on anti-icing trucks

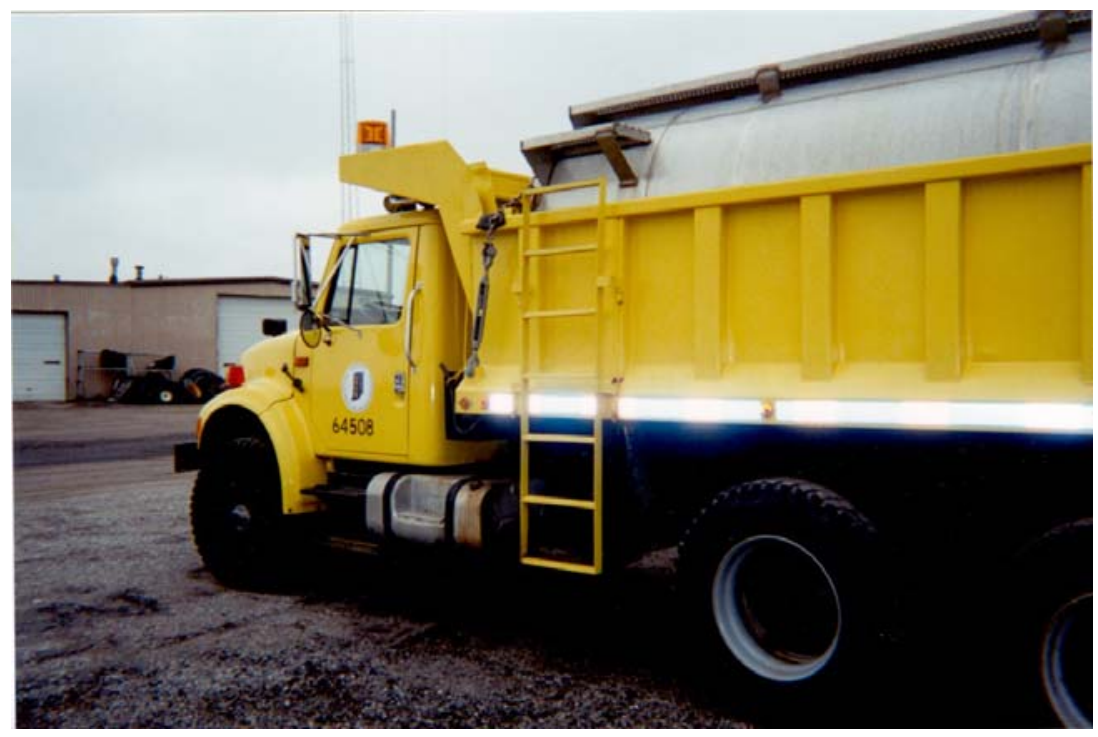

Figure 4.2: Anti-icing truck with tank

\subsubsection{Pavement Temperature Sensors}

Pavement temperature is the controlling item in the effective treatment of highways during winter storms (Boselly et al., 1993). An ice-control chemical must form a solution in order to depress the freezing point. Pavement temperature will determine if chemicals applied will form an ice-melting interface. Pavement temperature data can be used to customize the rates of material application and the types of material utilized to match road conditions. In addition to their real-time monitoring function, pavement temperature sensors can be used to generate a forecast of pavement temperature trend and warn when it will drop below freezing temperature (FHWA, 1996). It should be noted that pavement temperature sensors only measure what is in 
their field of vision. Thus if the roadway is covered with snow or ice, an operator will need to clear a portion of the pavement so that accurate pavement temperature can be obtained

Control Products, Inc (Figure 4.3) and Sprague Controls, Inc (Figure 4.4) are two of the most common manufacturers for vehicle-mounted pavement temperature sensors. These sensors work by using infrared technology to convert heat energy from the road surface to an electrical signal and display it onto an LCD panel. The display is mounted in the driver's view and shows both the air temperature as well as the road surface temperature. The temperature sensors from Sprague Control cost about $\$ 400$, and that from Control Products cost about $\$ 1,000$. While each manufacturer's units have their own strengths and weaknesses, the Sprague sensor is easier to install, while that from Control Products allows for calibration in the yards and has a protective sleeve where the sensor resides.

Utilizing pavement temperature sensors in deicing/anti-icing operations has proven to be cost effective. Missouri DOT estimated that by utilizing pavement temperature sensors, about $\$ 186,469$ savings state wide was achieved due to the reduction or elimination of chemical applications that are not appropriate (Missouri DOT, 1999)
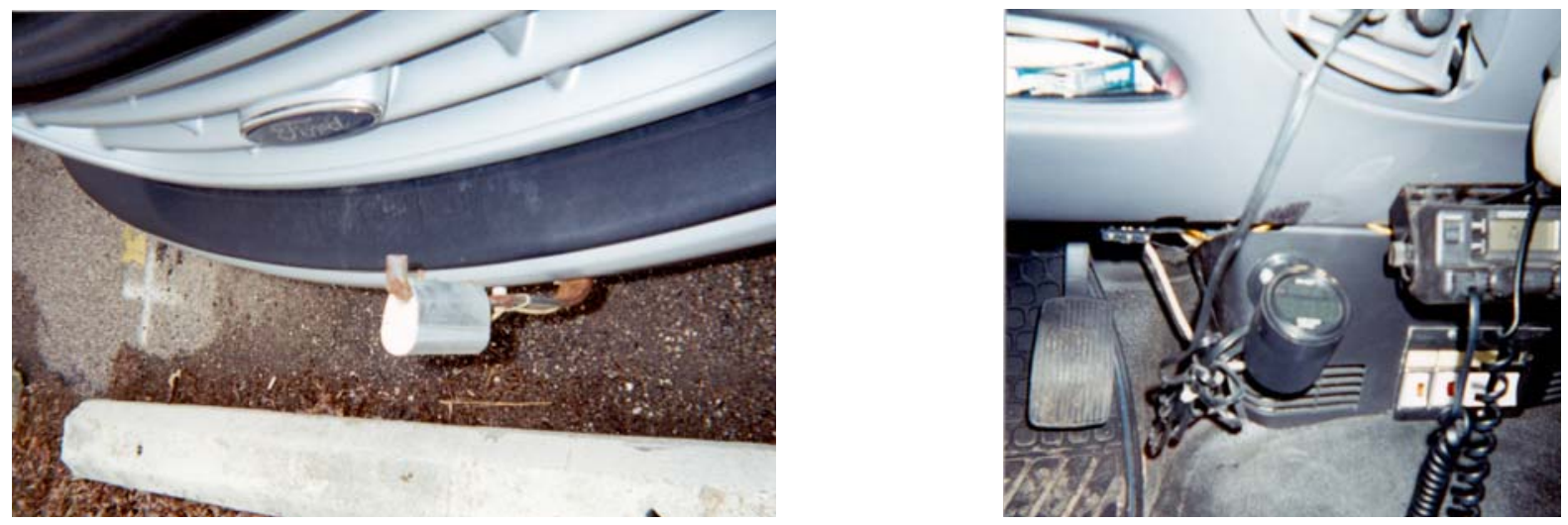

Figure 4.3: Vehicle mounted pavement temperature sensor and LCD display (Sprague Controls)

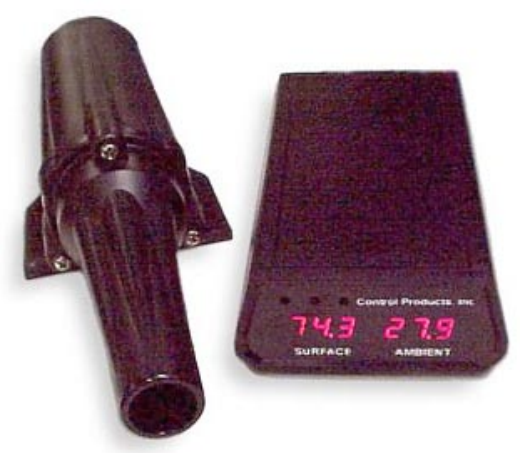

Figure 4.4: Vehicle mounted pavement temperature sensor and LCD display (Controls Products) 


\subsubsection{Road Weather Information Systems (RWIS)}

INDOT currently operates an extensive road weather information systems (RWIS) network encompassing weather datagathering and road condition monitoring systems and their associated communications, processing, and display facilities to aid in roadway decision making. Roadside sensory systems which are distributed across the State of Indiana typically consist of atmospheric sensors mounted on some form of tower (as shown in Figure 4.5) or embedded in or below the pavement surface, from which locations their data is transmitted to a central data acquisition system for subsequent real-time display. Figure 4.6 identifies the array of weather-related data collection stations currently maintained in the State of Indiana, and Figure 4.7 depicts a data 'snapshot' of the weather-related information recently available data. Using this information allows INDOT district offices to develop cold-weather "snowcasts" or forecasts.

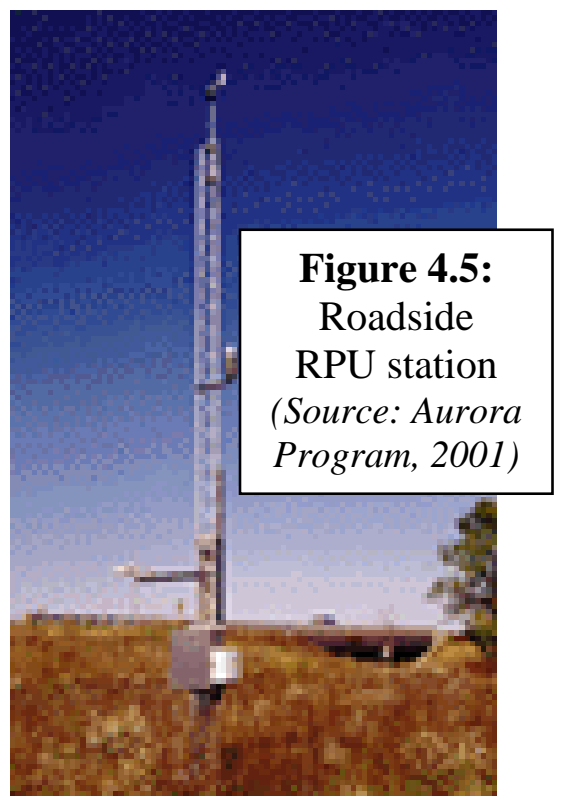
These forecasts can then be used to predict site-specific weather and pavement conditions, and to develop appropriate action plans for highway deicing and anticing measures.

\subsection{Application Rates}

Anti-icing should be done in anticipation of or in prompt response to a worsening pavement conditions (FHWA, 1996). According to recommendations by FHWA, anti-icing should not be conducted when the pavement temperature is at or below about $20^{\circ} \mathrm{F}$. At the INDOT yard at Plymouth, no anti-icing is conducted using salt brine when the temperature is below $28{ }^{\circ} \mathrm{F}$. Field test results from Iowa DOT also indicate that winds should be less than 15 miles an hour with little or no potential for drifting snow such that chemicals will not trap blowing snow.

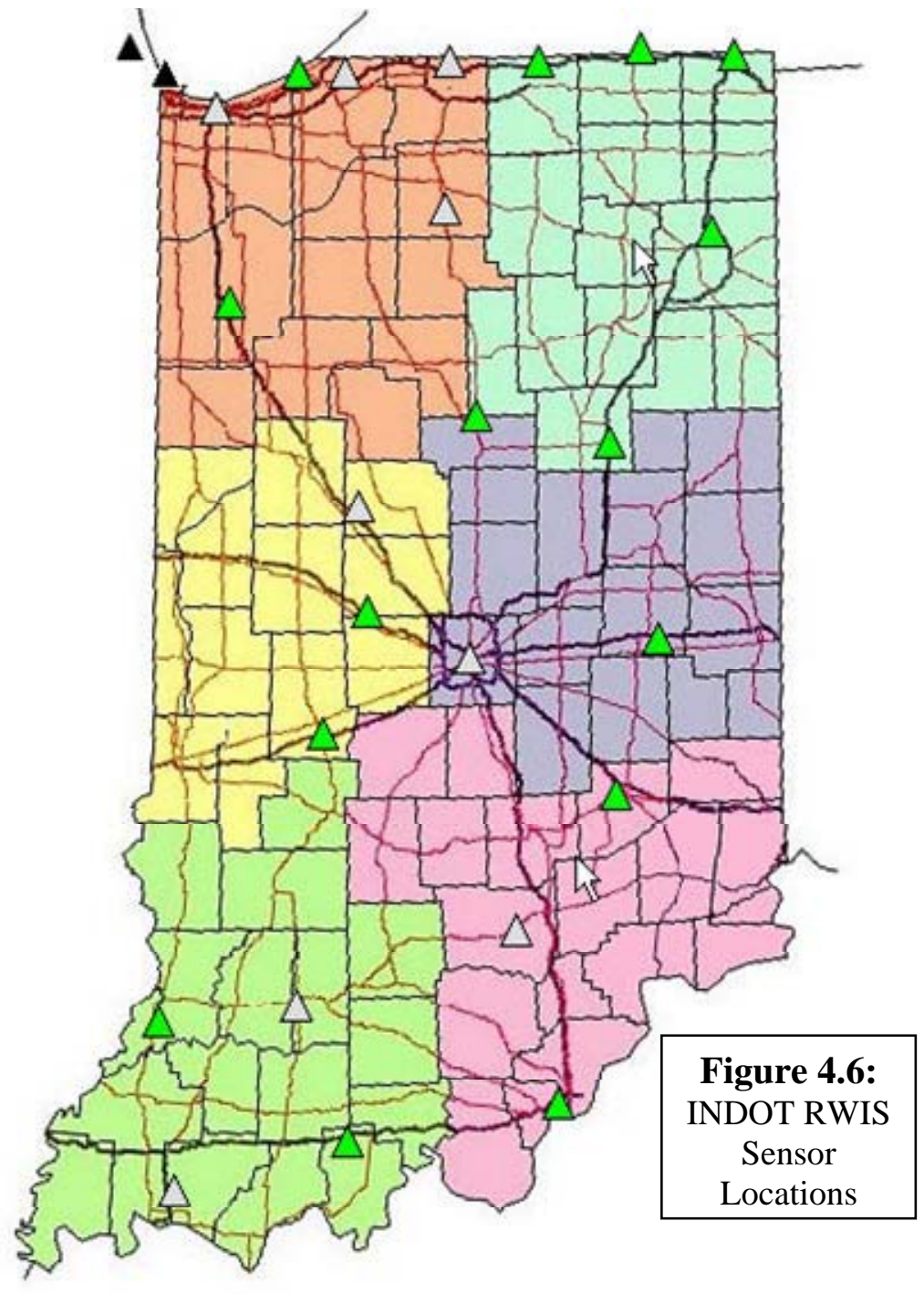

(Deck Sensors Only) 


\begin{tabular}{|c|c|c|c|c|c|c|c|c|c|c|c|c|c|}
\hline & & & & & & $\mathbf{S S I}^{\circledR}$ & \multicolumn{7}{|c|}{$\begin{array}{r}\text { IN -State } \\
\text { Site SuI } \\
\text { [Selected surface sensor }\end{array}$} \\
\hline \multicolumn{14}{|c|}{ Current Time: 09/04/2004 11:44 EST } \\
\hline$\underline{\text { Status }}$ & $\underline{\text { Sto }}$ & $\underline{\text { Sub }}$ & Air & $\underline{\mathrm{RH}}$ & Dewn & BaroPs & Precip & Intens & Rate & $\underline{\text { Vis }}$ & SpdAwg & DirAvg & \\
\hline \multirow{2}{*}{ Dny } & \multicolumn{7}{|c|}{ Fort Wayne - 1.469 NB Deck $(356000.1)$} & \multicolumn{5}{|c|}{$09 / 04 / 200411: 00$ (EST) } & \multirow[t]{2}{*}{ Histon } \\
\hline & $87.1 \mathrm{~F}$ & - & $74 \mathrm{~F}$ & $85 \%$ & $69 \mathrm{~F}$ & - & None & None & - & - & Calm & $\mathrm{N}$ & \\
\hline \multirow{2}{*}{ Dny } & \multicolumn{7}{|c|}{ ArgoS - US-31 SB (356001.0) } & \multicolumn{5}{|c|}{$09 / 04 / 200411: 01$ (EST) } & \multirow[t]{2}{*}{ Histon } \\
\hline & $97.5 \mathrm{~F}$ & $77 \mathrm{~F}$ & $80 \mathrm{~F}$ & $71 \%$ & $70 \mathrm{~F}$ & - & None & None & - & - & Calm & $\mathrm{E}$ & \\
\hline \multirow{2}{*}{ Dny } & \multicolumn{7}{|c|}{ Rensselaer - SR-114 w日 Brdg Deck (356002.0) } & \multicolumn{5}{|c|}{$09 / 04 / 200411: 02$ (EST) } & \multirow[t]{2}{*}{ Histon } \\
\hline & $96.4 \mathrm{~F}$ & $82 \mathrm{~F}$ & $81 \mathrm{~F}$ & $61 \%$ & $66 \mathrm{~F}$ & $\cdot$ & None & None & - & - & Calm & SE & \\
\hline \multirow{2}{*}{$\begin{array}{l}\text { Trace } \\
\text { Moisture }\end{array}$} & \multicolumn{7}{|c|}{ Frankfort - SR.28 EB Approach (356003.0) } & \multicolumn{5}{|c|}{ 08/18/2004 02:03 (EST) } & \multirow[t]{2}{*}{ Histon } \\
\hline & $72.1 \mathrm{~F}$ & $83 \mathrm{~F}$ & $68 \mathrm{~F}$ & $90 \%$ & $65 \mathrm{~F}$ & $\cdot$ & Unknown & Unknown & - & - & $7 \mathrm{mph}$ & SE & \\
\hline \multirow{2}{*}{ Dny } & \multicolumn{7}{|c|}{ Kokomo - US-31 NB Brdg Deck (356004.1) } & \multicolumn{5}{|c|}{$09 / 04 / 200410: 04$ (EST) } & \multirow[t]{2}{*}{ Histon } \\
\hline & $91.6 \mathrm{~F}$ & - & $81 \mathrm{~F}$ & $68 \%$ & $69 \mathrm{~F}$ & - & None & None & - & - & Calm & SE & \\
\hline \multirow{2}{*}{ Dny } & \multicolumn{7}{|c|}{ Gas City - 1-69 NB Brdg Approach (356005.0) } & & $04 / 200$ & $411: 0$ & (EST) & & Histony \\
\hline & $97.5 \mathrm{~F}$ & $76 \mathrm{~F}$ & $81 \mathrm{~F}$ & $67 \%$ & $69 \mathrm{~F}$ & $\cdot$ & None & None & - & - & $4 \mathrm{mph}$ & $\mathrm{N}$ & \\
\hline$D \sim$ & Crawford & sville - & - SR.75 & $5 \mathrm{SB} \mathrm{Dec}$ & dk $(356$ & $006.1)$ & & & $04 / 200$ & $411: 0$ & (EST) & & Histony \\
\hline DNy & $99.3 \mathrm{~F}$ & 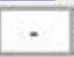 & $80 \mathrm{~F}$ & $73 \%$ & $70 \mathrm{~F}$ & - & None & None & - & - & Calm & SE & \\
\hline Dry & New Cas & te - 1 & 1.70 Wอ & Brdg De & ck (35e) & $8007.0)$ & & & $04 / 200$ & $411: 0$ & (EST) & & History \\
\hline Dory & $92.5 \mathrm{~F}$ & $76 \mathrm{~F}$ & $81 F$ & $65 \%$ & $68 \mathrm{~F}$ & $\cdot$ & Unknown & Unknown & $\cdot$ & $\cdot$ & Calm & $\mathrm{NE}$ & \\
\hline Dry & Cloverda & $e-1.7$ & 70 WB B & Brdg Dec & $k(3560$ & $008.1)$ & & & $04 / 200$ & $411: 1$ & (EST) & & Histony \\
\hline Doy & 95.9F & - & $81 F$ & $62 \%$ & $66 \mathrm{~F}$ & - & None & None & - & - & Calm & SE & \\
\hline Dry & Greensb & $\mathrm{rg}-\mathrm{u}$ & US. 421 & NB Brdg & Deck & (356009.1 & & & $04 / 200$ & $411: 0$ & (EST) & & Histony \\
\hline Diy & $106.7 \mathrm{~F}$ & - & $83 \mathrm{~F}$ & $59 \%$ & $67 \mathrm{~F}$ & - & None & None & - & - & Calm & SE & \\
\hline$\underline{\text { Status }}$ & $\underline{\text { Sto }}$ & $\underline{\text { Sub }}$ & Ait & $\underline{\mathrm{RH}}$ & $\underline{\text { Deini }}$ & Barops & Precip & Intens & Rate & $\underline{\text { Vis }}$ & Spdarg & DitAug & \\
\hline Drs & Seymout & - US.6 & $50 \mathrm{~EB}$ & Brdg App & proach & (356010) & & & $04 / 200$ & $411:$ & (EST) & & Histony \\
\hline & $98.4 \mathrm{~F}$ & $82 \mathrm{~F}$ & $81 \mathrm{~F}$ & $70 \%$ & $70 F$ & - & Unknown & Unknown & - & - & Calm & $E$ & \\
\hline DNy & Loogoote & e - us & S.231 N & AB Passin & و (356) & $011.0)$ & & & $04 / 200$ & 411: & (EST) & & Histon \\
\hline & 106.9F & $83 \mathrm{~F}$ & $84 \mathrm{~F}$ & $55 \%$ & $67 \mathrm{~F}$ & - & None & None & $\cdot$ & $\cdot$ & Calm & $\mathrm{N}$ & \\
\hline Dns & Vincenne & $s-u s$ & S. $41 \mathrm{SE}$ & B Brdg D & eck ( 35 & 66012.1) & & & $04 / 200$ & 4 11: & (EST) & & Histony \\
\hline & $104.4 \mathrm{~F}$ & $\cdot$ & $87 \mathrm{~F}$ & $54 \%$ & $68 \mathrm{~F}$ & - & Unknown & Unknown & $\cdot$ & - & Calm & NW & \\
\hline Dry & Evansvill & -1.16 & $64 \mathrm{SB} E$ & Brdg App & roach & $(356013.0$ & & & $04 / 200$ & $411: 2$ & (EST) & & Histong \\
\hline & 105.1F & $83 \mathrm{~F}$ & $85 \mathrm{~F}$ & $50 \%$ & $64 \mathrm{~F}$ & - & None & None & - & - & Calm & W & \\
\hline Dry & Birdseye & -1.64 & Brdg D & eck 1356 & 014.1) & & & & $04 / 200$ & 411: & (EST) & & Histon \\
\hline & $96.1 \mathrm{~F}$ & $\cdot$ & $83 \mathrm{~F}$ & $63 \%$ & $69 \mathrm{~F}$ & $\cdot$ & None & None & - & - & Calm & $\mathrm{N}$ & \\
\hline Dry & Jefferson & ville - & $1.265 \mathrm{E}$ & E Brdg & Deck (3 & $56015.0)$ & & & $04 / 200$ & $411: 2$ & (EST) & & Histon \\
\hline Din & 101.1F & $79 \mathrm{~F}$ & $82 \mathrm{~F}$ & $63 \%$ & $69 \mathrm{~F}$ & $\cdot$ & Unknown & Unknown & $\cdot$ & - & Calm & NE & \\
\hline
\end{tabular}

Figure 4.7:

Sample INDOT RWIS Weather Data Information 
Table 4.1 shows representative application rates of liquid chemicals per lane mile for anti-icing collected from various states agencies:

Table 4.1: Representative application rates of liquid chemicals for anti-icing

\begin{tabular}{|c|c|c|c|c|}
\hline & Sodium chloride & Ice-Ban & Magnesium chloride & Caliber M-1000 \\
\hline From Supplier & N.A. & \multirow[t]{3}{*}{ N.A. } & \multirow[t]{3}{*}{ N.A. } & $\begin{array}{c}\text { 30-40 gal/lane mile } \\
\text { 15-20 gal/lane mile (frost } \\
\text { prevention on bridge } \\
\text { decks) }\end{array}$ \\
\hline $\mathrm{IL}$ & $50 \mathrm{gal} / \mathrm{lane}$ mile & & & \multirow{4}{*}{ N.A. } \\
\hline 10 & $50 \mathrm{gal} / \mathrm{lane}$ mile & & & \\
\hline $\mathrm{KS}$ & $50 \mathrm{gal} / \mathrm{lane}$ mile & & & \\
\hline IN - Plymouth & $35 \mathrm{gal} / \mathrm{lane}$ mile & $35-40 \mathrm{gal} / \mathrm{lane}$ mile & $35-40 \mathrm{gal} /$ lane mile & \\
\hline IN - Toll Road & N.A. & N.A. & N.A. & $\begin{array}{l}20 \mathrm{gal} / \mathrm{lane} \text { mile (two } \\
\text { hours before storm) }\end{array}$ \\
\hline
\end{tabular}

Specific and concise recommendations for anti-icing operations for different weather events, stipulated by the Federal Highway Administration (FHWA) can be found in the Manual of Practice for an Effective Anti-icing Program. 


\section{SALT BRINE MANUFACTURE, STORAGE AND TRANSFER}

\subsection{Production-Related Aspects}

Salt brine production system that is relatively trouble-free and easy to operate becomes a necessity with the use of salt brine for pre-wetting of salt or anti-icing treatment of roads. The major aspects of the salt brine production system will be examined as follow:

\subsubsection{Basic System Components}

The equipment required for making brine solution from recycled truck wash water will include an oil-water separator with an accompanying overflow diversion box and pump, retention tank for wash water collection, brine making tank, storage tank(s), and pumps. Plumbing should be setup in a way that recirculation of brine can be done in both the brine making tank and the storage tank. Flexible hose with appropriate couplings should be attached to the storage tank for transfer of brine to the truck saddle tank. A hydrometer will be used to control the salt content.

\subsubsection{Eutectic Control of Salt Brine}

Salt brine is produced by mixing water with rock salt. Production involves passing water through a bed of salt and collecting the brine in a holding tank. The brine supplying tank should be kept half full or fuller of rock salt to ensure a $26 \%$ salt solution, which is at $100 \%$ saturation with water at room temperature.

The final brine solution to be used as a pre-wetting or anti-icing agent should have a eutectic concentration of $23.3 \%$. If the concentration of salt is too high or too low, the solution will freeze at a higher temperature than the $23.3 \%$ solution. Appendix B.1 shows a eutectic diagram of salt. When storing salt brine, it will be necessary to store the solution at no less than the eutectic percentage between $23 \%$ to $24 \%$.

To achieve a eutectic concentration of 23.3\%, pumping and recycling the brine from the supply tank to a storage tank can be done, with adjustment of the brine concentration by adding water as needed. The final concentration should be checked using a hydrometer, which is a device used to measure the specific gravity of a solution in water. Appendix B.2 lists the hydrometer readings and the corresponding salt concentrations for a solution with temperature of $15{ }^{\circ} \mathrm{C}\left(59^{\circ} \mathrm{F}\right)$. A salimeter can also be used to measure the percentage concentration of salt solution directly.

\subsubsection{Recirculation of Brine}

Brine has a higher density than fresh water, which can lead to a stable stratification if no mixing is done. It is the same situation if two portions of brine with different concentrations are brought together. Thus, recirculation of the brine manufacturing tank should continue until the surface has a salt concentration of about $23 \%$. 


\subsubsection{Preparation of Eutectic Salt Brine}

Salt brine is made by passing water through a bed of rock salt. Production involves loading a tank with salt, running water slowly through it and collecting the brine in a holding tank. The weight of sodium chloride per volume of water is determined by multiply the total volume of water by the number from the "per volume water" column of Table 5.1.

Table 5.1. Proportions for preparing sodium chloride solutions from commercial grade salt (i.e., up to $5 \%$ impurities)

\begin{tabular}{|c|c|c|c|c|}
\hline \multirow{2}{*}{ \% NaCl actual } & \multicolumn{2}{|c|}{ Weight NaCl } & Crystallization \\
\cline { 2 - 3 } & $\begin{array}{c}\text { per volume } \\
\text { solution (Ib/gal) }\end{array}$ & $\begin{array}{c}\text { per volume } \\
\text { water (Ib/gal) }\end{array}$ & $\begin{array}{c}\text { Weight per unit } \\
\text { Volume of solution (Ib/gal) }\end{array}$ & \\
\hline 10 & 0.9 & 0.8 & 20 & 8.95 \\
\hline 15 & 1.4 & 1.3 & 12 & 9.28 \\
\hline 20 & 1.9 & 1.7 & 0 & 9.6 \\
\hline 23.3 & 2.3 & 1.9 & -6 & 9.76 \\
\hline 25 & 2.5 & 2.1 & 16 & 10.3 \\
\hline 26 & - & - & - & 10.6 \\
\hline
\end{tabular}

(Source: FHWA, 1996)

For example, to make a $23.3 \%$ salt brine solution with 200 gal of water, $1.9 \mathrm{lb} / \mathrm{gal}$ x $200 \mathrm{gal}=380 \mathrm{lb}$ of salt will be required.

\subsubsection{Changing the Concentration of a Brine Solution}

If the concentration of a solution is lower than the eutectic concentration of $23.3 \%$, more salt can be added to bring it to the desired concentration. Equation 5.1 is used to calculate the weight of salt to add.

23.3\% - \% concentration weak solution

$$
100 \%-23.3 \%
$$

(Equation 5.1)

$\times$ weight of weak solution (per unit volume of brine) (From Figure 5.1)

$\times$ volume of weak solution $=$ lbs dry salt to add

Example. To increase the concentration of 500 gals of $20 \%$ solution to $23.3 \%$,

$$
\frac{(23.3-20)}{100-23.3} \times 9.6 \times 500=206.5 \text { lb of dry salt }
$$

If the concentration of a solution is higher than the eutectic concentration of $23.3 \%$, dilute the strong solution by adding more water. Equation 5.2 is used to determine the amount of water to add. 
\% concentration of strong solution - $23.3 \%$

$23.3 \%$

(Equation 5.2)

$\times \frac{\text { weight of strong solution (lb / gal) }}{8.34} \times$ volume of strong solution

= gals of water to add

Example. To dilute 500 gals of $25 \%$ solution to $23.3 \%$

$\frac{(25-23.3)}{23.3} \times \frac{10.3}{8.34} \times 500=45$ gals of water to add

A “23\% Salt brine concentration conversion chart" obtained from Steve Geise at the INDOT Plymouth unit given in Appendix B can also be used to determine the amount of fresh water needed to dilute an amount of brine to a concentration of $23 \%$.

*Note: Weight of brine solution can be obtained either from Table 5.1 or from interpolating Figure 5.1.

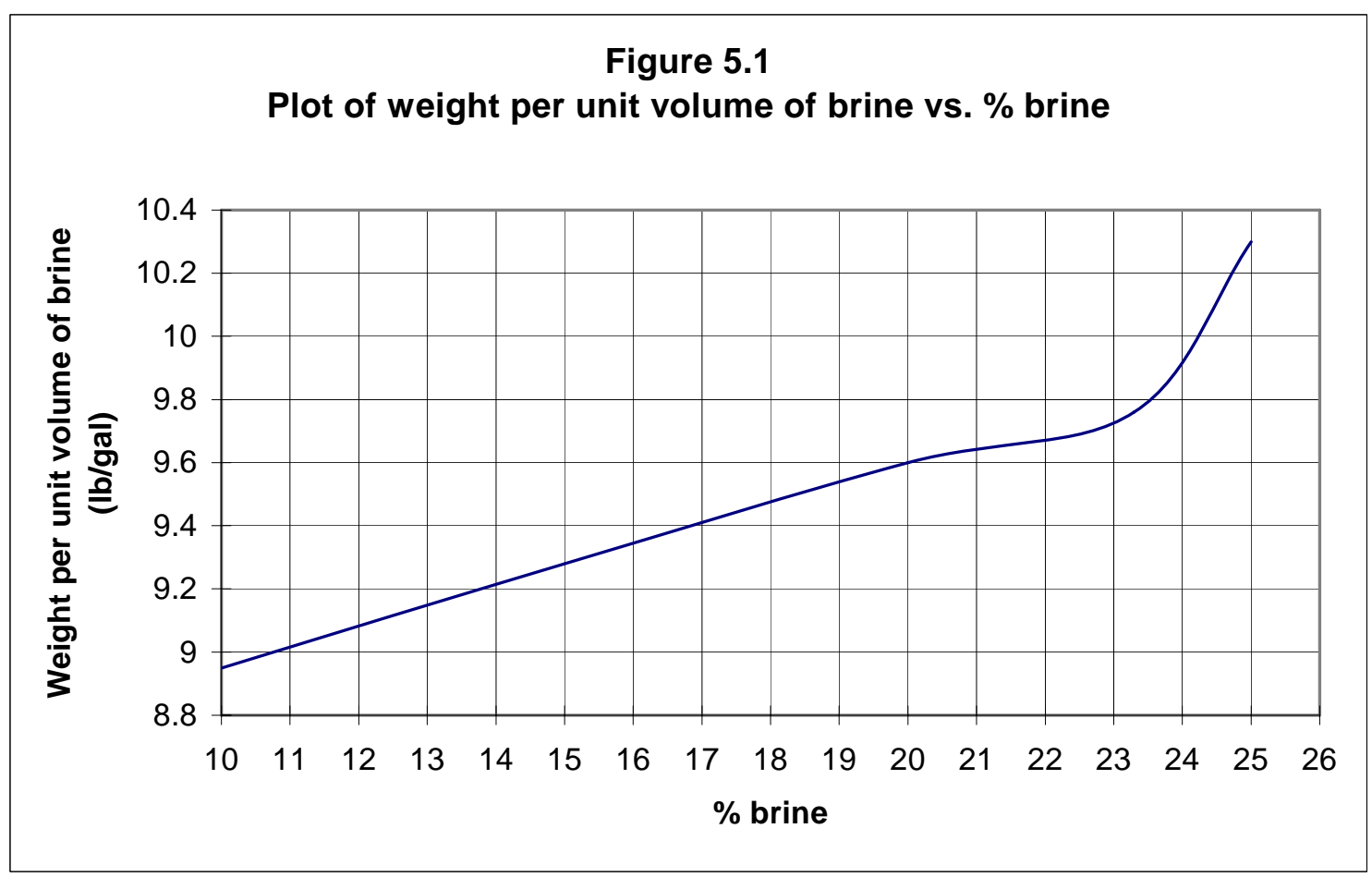

\subsubsection{Using Truck Wash Water to Make Brine Solution}

Salt truck wash water may be used to make salt brine instead of fresh water. Reusing the salt laden truck wash water will save material cost in making brine solution and conserve water 
use. The amount of salt released as runoffs into the local sewer system or the environment may also be decreased.

\subsubsection{Collection of Wash water}

It is expected that if salt truck washing water is to be reused to make salt brine, washing activities will be conducted in facilities where wash bays and oil-water separators are available. Wastewater from truck washing will flow through the floor grate into an underground sedimentation basin, where settable materials such as grit will be removed. The wash water should then be passed through an oil-water separator to remove oil and grease before being used to make brine solution.

The accompanying Figure 5.2 depicts 'before' and 'after' configurations of an oilwater separator. The top-most 'before' images shows an original, unmodified system which simply discharges the overflow to an immediate drain. As seen in the lower image, the dischargeend of the oil-water separator can be modified such that the discharged, oil-separated wash water is collected for diversion to a downstream brine making system. Note also that this modified overflow box is fitted with an gravity discharge back to the original drain...should the diversion pump fail for some reason and the

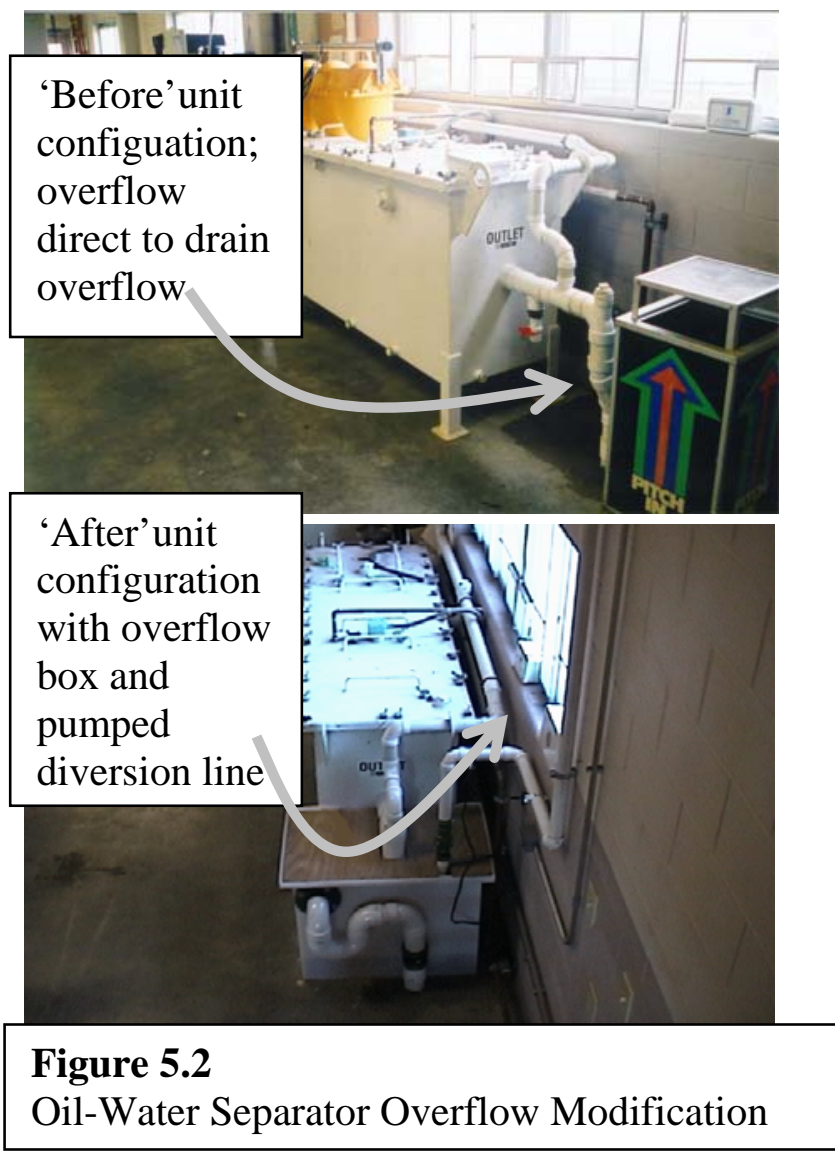
water level in the box were to reach the top of the tank.

\subsubsection{Quantity of Wash Water}

Flow meter data is available for the INDOT Bluffton truck washing facility for the year 1998-1999 (Appendix D). Table 5.2 gives a summary of the wash water flows at the facility:

Table 5.2 Wash water flow from truck washing facility at Bluffton, IN (1998-1999)

\begin{tabular}{|l|l|}
\hline Flows & \\
\hline Peak flow (gals/day) & 3,500 \\
\hline Total annual flow (gals/yr) & 117,646 \\
\hline Peak month total flow (gals/mo.) & 45,536 \\
\hline Winter (Nov.-Mar.), average monthly flow (gals/mo.) & 18,442 \\
\hline Summer (Apr.-Oct.), average monthly flow (gals/mo.) & 3,107 \\
\hline
\end{tabular}

Twenty trucks were being washed at the INDOT Bluffton facility when the flow data was taken. In the absence of flow meter data, estimations for the quantities of wash water for other 
INDOT truck washing facilities may be made by proportioning the truck wash water quantity data from Bluffton with the number of trucks that will be serviced at the facility.

Another method of estimating the quantity of wash water during a winter season at a particular site will be based on:

1) The number of snow storm events, which can either be documented at the site of obtained from the National Weather Service Forecast Office and the National Climate Center.

2) The wash water flow rate at a particular site.

3) The time required to wash a truck.

4) The number of trucks to be serviced at the wash bay.

This method will be used to determine the quantity of wash water, and hence the brine production rate in Section 6.1.7.2 "Evaluations of Operations" of the Monticello Sub-District brine manufacturing setup.

\subsubsection{Quality of Wash Water}

Appendix C provides samples of the water quality data for the truck washing facility located in Greenfield, IN. Table 5.3 provides a summary of truck wash water quality for the facility. It can be seen that contaminant concentrations vary greatly even when only one facility is being considered.

Table 5.3 Truck wash water quality data from Greenfield, IN (winter 1999)

\begin{tabular}{|l|l|l|l|}
\hline & Average & Maximum & Minimum \\
\hline TSS (mg/l) & 2,000 & 5,000 & 100 \\
\hline Chloride (mg/l) & 25,000 & 79,000 & 300 \\
\hline BOD $_{\mathbf{5}}$ (mg/l) & 30 & 100 & 5 \\
\hline Oil and Grease (mg/l) & 60 & 200 & 4 \\
\hline
\end{tabular}

\section{Total Suspended Solids}

Although rather unlikely (since INDOT does not approve sand use) sand residuals may be present in the truck wash water from the remaining deicing materials on truck. Solids concentration and diameter in wash water from winter salt truck washing operations is of importance in recycling of truck wash water to make brine because of the concern in plugging of the spraying system for brine on trucks. Solids concentration and diameter in the wash water will depend on:

1) Salt supplier

2) Whether salt and sand mixtures, or plain salt, was used in deicing operations prior to truck washing

3) Salt loading practices (sand and gravel may already be present in salt loading bucket, or they may be scraped off from the ground while loading the salt)

These factors vary from one facility to another. The ASTM designation for salt used for highway snow and ice control is stipulated in D 632 Standard Specification for Sodium Chloride, 
which allows up to 5\% impurities from salt supplies. However, the actual impurities may be higher than 5\% due to reasons stated above. The largest solid diameter present in the INDOT Sub-District in Monticello was observed to be one-half to one-quarter inches.

Solids concentration and diameter in the wash water will determine the need for a filtering system, or sedimentation basin prior to using the water for brine making.

\section{Chloride Concentration}

Chloride concentration already present in the salt truck wash water will reduce the amount of salt that needs to be added to make salt brine at the required percentage of $23.3 \%$. For example, the salt concentration of wash water from the Monticello, IN Sub-District varies from 4-6\%, while that from the LaPorte Sub-District is found to be approximately 9\%.

\section{Corrosive Nature of Brine}

Due to the corrosive nature of the salt water, all containers, equipment and plumbing in contact with the wastewater and brine solution should be made of corrosion resistant materials, such as plastic, polyethylene or stainless steel. Rubber flexible couplings and piping may also be used as long as they can be replaced easily when necessary.

To extend the life of the pumps and plumbing, the entire brine making setup must be cleaned and flushed with fresh water at the end of the winter season. One of the vendors suggested that the pumps be taken out and put into anti-freeze to keep it lubricated and deactivate the corrosive action of any salt in the pump.

\section{Oil and Grease and Other Contaminants}

The presence of oil and grease, and other contaminants such as anti-freeze from washing salt truck may pose a problem in plugging salt brine spraying system on trucks, and environmental problems when contaminated salt brine is sprayed onto roads. Two useful parameters in determining the amount of oxidizable contaminants, usually organics, are COD (chemical oxygen demand), BOD (biochemical oxygen demand). High concentrations of oxidizable organic matter in wastewater can result in depletion of oxygen and jeopardizing of aquatic life if this wastewater were discharged to a stream or lake.

Further details pertaining to the Indiana Department of Environmental Management (IDEM) and the U.S. Environmental Protection Agency (EPA) regulations with regard to contaminated runoffs from transportation maintenance facilities and from deicing and anti-icing operations will be discussed in Chapter 7.

\subsection{Hardware Related Aspects}

\subsubsection{Basic Options}

The types of brine manufacturing system include:

1) Commercial brine making machine such as the Varitech or Sprayer Specialities units, using fresh water

2) Commercial brine making machine with modifications for use with recycled truck wash water

3) “Do-it-yourself” system using fresh water 
4) “Do-it-yourself” system using recycled truck wash water

\subsubsection{Basic Facility Requirement}

The brine making operation should be housed indoor at or near the wash bays to facilitate operations and prevent freezing of salt brine. Ideally, the brine storage tanks should also be placed indoor, but a survey of INDOT Sub-Districts with outdoor salt brine storage tanks has indicated no freezing problem of the brine solutions. The decision whether to use inside or outside storage facilities depends on the freezing temperature of the solution and the lowest air temperature expected in the area. If the lowest air temperature is at or below the freezing point of the solution, inside storage should be used.

The brine making system and storage tank should be laid on concrete pads or other nonpermeable pads. A secondary containment dike may be required by local regulations to contain spills.

\subsubsection{Brine Manufacturing Tank}

A brine manufacturing tank with a capacity of 1,000 to 2,000 gallon will be enough to handle most brine manufacturing operations. A "do-it-yourself" brine manufacturing tank should have a wide brim, such that loading of salt using a bobcat or a front end loader can be achieved easily and salt spilling minimized. Water should be allowed to percolate through a pile of salt. This method was employed with experiences from other DOTs such as Minnesota DOT and Missouri DOT, where it was found that with similar systems built from animal feed tank, in-feed water will percolates through the salt to form an approximately $23 \%$ concentrated brine.

\subsubsection{Brine Storage Tank}

According to Wayne Dittelberger from the INDOT Vincennes district, the average storm will require about eight trucks making three rounds during a storm for pre-wetting purposes. Assuming the on-board saddle tank on the truck has a capacity of 150 gallon, the total brine required during a storm will be about 3,600 gallons, which will be the preferable capacity of brine storage.

It is recommended that tank walls for brine storage be rated 12 pounds per square inch or greater because of the specific gravity (heavier than water) of brine (Illinois DOT, 1998). The tank should be vented. To save pump effort, it is better to "top-fill" the tank from a ground level pump. Storage should be labeled and secondary containment is recommended.

\subsubsection{Pumps}

The required capacity of the storage tanks and pumps will be determined by the salt truck wash water production rate and the demand for salt brine. A half horsepower pump will be able to provide 20-40 gallons per minute of flow at $15 \mathrm{ft}$ head, which allows for top-filling of most on-site storage tanks and brine tanks on trucks.

\subsubsection{Plumbing and Electrical Equipment}

PVC pipe and fittings or other suitable non-metals should be used for all plumbing in contact with salt water. Selection of line sizes will be controlled by production flow rate, system 
design and pump specifications. Sizes should be established in conjunction with the pump supplier.

Flexible hose should be used as connection to the saddle tank on truck to allow greater flexibility in filling up tanks. Valves and couplings should be made of plastic or stainless steel. Valve life will be lengthened by keeping the valve yokes and stems clean and properly lubricated.

It is suggested that steel-cased strainers having 100-mesh reinforced wire be used on truck filling lines close to the tank for removal of material that may clog the spraying nozzles on truck.

Salt brine can be corrosive to electrical equipment and may cause malfunctioning. Electrical equipment and switches should be housed in a NEMA type enclosure.

\subsubsection{Comparison of Commercial Brine Manufacturing Units}

Several commercial brine making systems are available. These systems have been developed with inputs from various DOTs to meet the particular concerns in snow and ice operations. Table 5.4 gives a comparison of the most common units available in the market, manufactured by Varitech Industries and Sprayer Specialities. Both systems are currently being used by INDOT maintenance facilities.

Table 5.4 Comparison of commercial brine manufacturing units

\begin{tabular}{|l|l|l|}
\hline Vendor & Varitech & Sprayer Specialities \\
\hline Model Number & SB600 Salt Brine System & SB-1400 Salt Brine System \\
\hline Gallons/hr & 2000 & 3400 \\
\hline Gallons/min & 33.3 & 56.7 \\
\hline Pump Type & Cast iron with epoxy coating & Stainless steel \\
\hline Connectors & 1.5 inch water line & 2 inch water line \\
\hline Capacity & 600 gallon & 1250 gallon \\
\hline Dimensions & 5' W x 10' L x 12' H & $11^{\prime}$ W x 7' L x 6' H \\
\hline Clean out & 4 in. clean out on bottom for flushing & $\begin{array}{l}\text { 5 in. clean out on bottom for flushing, residue } \\
\text { must be removed manually }\end{array}$ \\
\hline Material & Welded Plastic & Plastic tank with steel frame \\
\hline Cost & $\$ 6,250$ & $\$ 7,500-\$ 8,000$ \\
\hline
\end{tabular}

The following vendor information is provided to reflect the full range of commercial equipment, including not only the previously mentioned options (Varitech and Sprayer Specialties) but also Dultmeier and Entrye. These manufacturers should be contacted on a sitespecific basis in order to obtain pertinent details regarding model options and design or operational characteristics. 


\section{Dultmeier Inc.}

Address:

- Dultmeier Sales Inc.

- 601 West 76th Street

- Davenport, Iowa

- Phone: 563-386-0930

- FAX: 563-386-5448

- Email: dultmeier@dultmeier.com

- Web: www.dultmeier.com

Brine Maker Details:

- Brine hopper volume $=6.25$ cubic yard

- Stainless steel centrifugal pump@ 3 HP

- 230VAC @30 amp

- Unit weight 3,600 lbs

- $\quad$ 50 gpm brine production rate

- Swing out sump bottom for easy cleanout

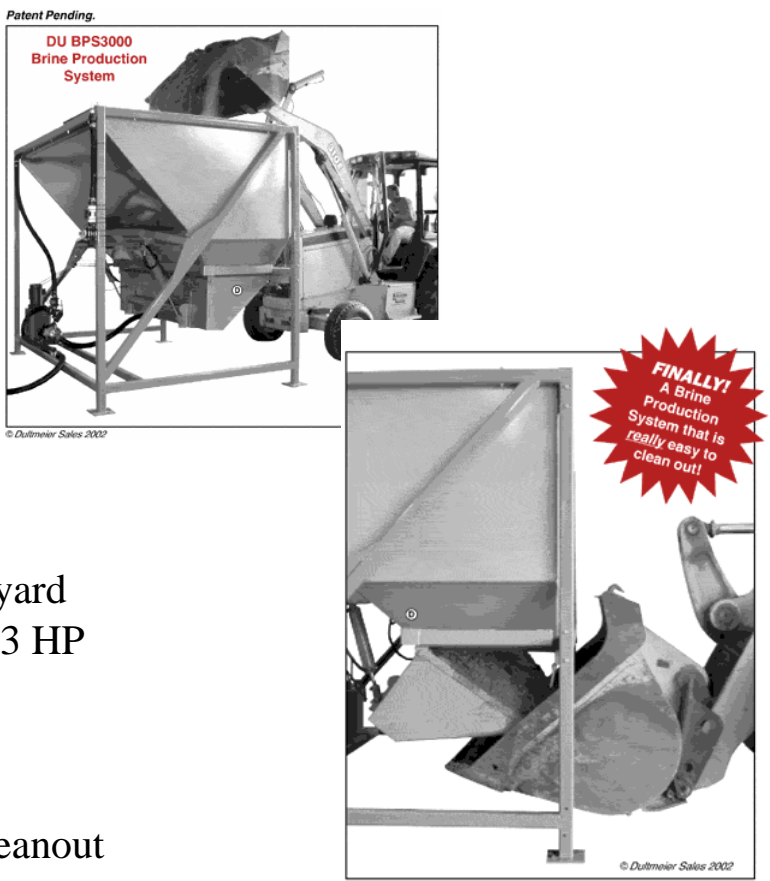

Note: These Dultmeier Inc. equipment images were copied from their Web site

\section{Sprayer Specialities Inc.}

Address:

- Sprayer Specialties Inc.

- 5149 N.W. 111th Drive

- Capital City Industrial Park

- Grimes, Iowa 50111

- Phone: 800-351-1857

- Fax: ss

- Web: www.sprayers.com

Brine Maker Details:

- Plastic brine hopper construction

- Optional stainless-steel, ‘quick-dump’ body

- 115 or 230 VAC

- 60 gpm brine production rate

Notes:

1) These Sprayer Specialties Inc. equipment images include both INDOT location photographs and images copied from the Sprayer Specialities Inc.

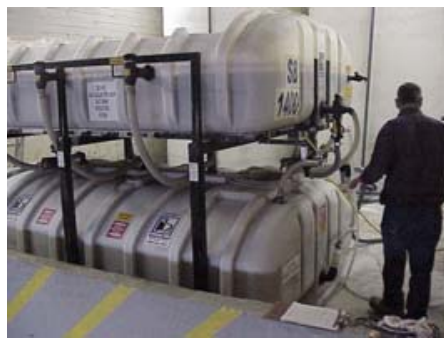
Web site

2) A 'quick-dump' stainless steel Sprayer Specialties Inc. unit was installed at Vincennes' Evansville Subdistrict 


\section{Varitech / Force America Inc.}

Address:

- Force America Inc.

- P.O. Box 111

- Garfield, Minnesota 56332

- Phone: 888-208-0686 / 320-834-2595

- Fax: 320-834-2856

- Web: www.varitech-industries.com

- Email: varitech@rea-alp.com

Brine Maker Details:

- Fiberglass brine tank construction

- Internal holding tank for brine storage

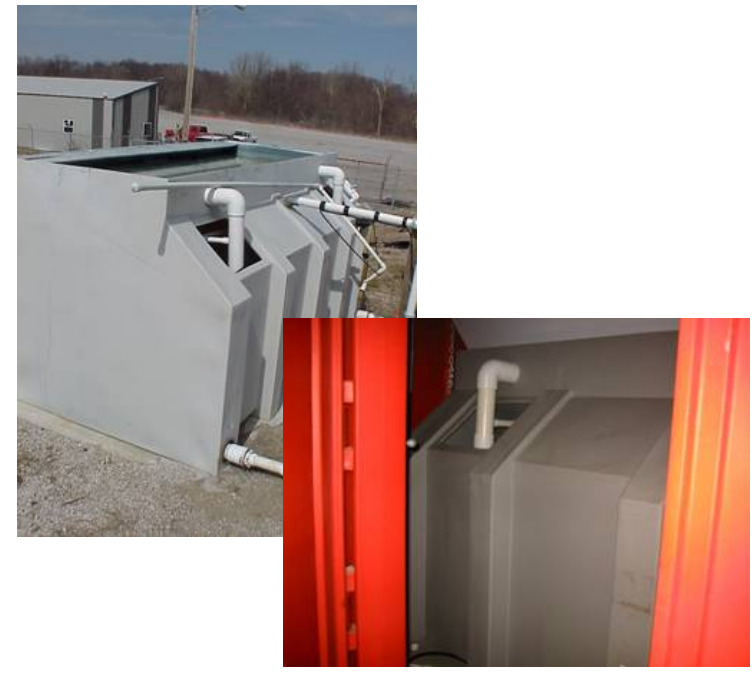

- Centrifugal mixing and recycle pump

- This vendor also offers a stand-alone unit enclosure package

Note: These Varitech equipment photographs were taken at INDOT locations

\section{E.D. Etnyre and Company}

\section{Address:}

- E.D. Etnyre and Company

- 1333 South Daysville Road

- Oregon, Illinois 61061

- Phone: 800-995-2116

- Phone: 815-732-2116

- Fax: 815-732-7400

Brine Maker Detail:

- Epoxy-coated carbon steel construction and support frame

- $\quad$ Brine hopper volume $=6$ cubic yards

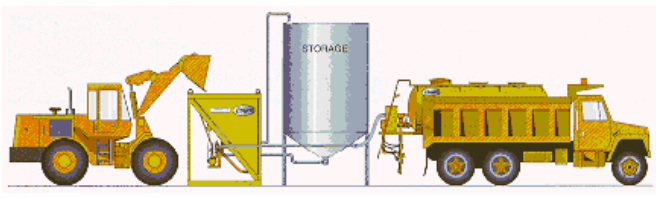

- Centrifugal mixing and transfer pump; pump capacity = 75 gpm

- Brine production rate $=60 \mathrm{gpm}$

- Hinged sump cleanout at tank bottom for easy cleanout

- 115 VAC @30 amp or230 VAC @15 amp

Note: These Etnyre equipment images were copied from their Web site 


\section{FIELD INVESTIGATION}

\subsection{Monticello Experimental System}

\subsubsection{Siting Details}

The INDOT Gary Sub-District Unit was originally selected as the site for a field implementation for a proof-of-concept brine production system using recycled truck wash water. However, due to the move of the existing Gary Sub-District Unit to a new SubDistrict unit and salt building adjacent to the Borman Expressway Traffic Management Center, a decision was made to relocate the brine setup to the INDOT Monticello Sub-District Unit.

The INDOT Monticello Sub-District Unit's building's interior drainage connections and plumbing were thoroughly

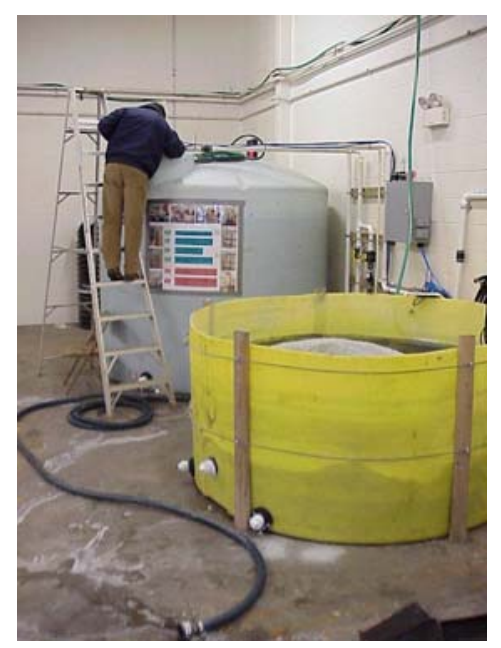
studied. An agreement was reached to locate the experimental brine-making unit within one of the wash bays Any possible brine spill will be contained and may be directed to the city sewer with permission of the local municipalities.

\subsubsection{Brine Manufacturing Hardware}

The tank where water from the oil-water separator flows into is a 56 gallon rectangular polyethylene tank from ChemTainer Industries.

The brine manufacturing tank is a Raven 1,100 gallon storage tank with the top removed such that a wide delivery cross section for salt can be achieved by the on-site front-end loader, and the spillage of salt is reduced. A plywood platform with many holes drilled was installed in the brine manufacturing tank to enable water to percolate through the bed of salt to form an approximately $23 \%$ concentrated brine. A nylon screen was put on the top of the platform to act as a filter to keep the large particles on the top. This open-top tank is reinforced by wooden bars and steel cables. The brine making tank should be kept one-half to two-third full of salt.

\subsubsection{Storage Hardware}

All storage tanks and containers used in the Monticello brine manufacturing system are made of high-density polyethylene, which are compatible with salt brine. Bulkhead fittings installed with the storage tank have poly couplings with stainless steel cam-levers. The brine storage tank is a Norwesco 2,200 gallon polyethylene tank with a self-vented lid.

\subsubsection{Pumping Hardware}

Due to the corrosive nature of salt water, the pumps chosen are either marine bilge pumps made entirely of plastic, or heavy-duty sump pumps with epoxy-coated or stainless steel impeller.

The pump used to transfer the brine to the storage tanks is a Rule Industries submersible sump/utility pumps at 47 gallons per minute. Its maximum head is $10 \mathrm{ft}$ at 18 gallons per minute, which is sufficient to transfer the brine to the storage tank opening at the top. The pump has a 
discharge hose of 1-1/2 inches diameter, with stainless steel shaft and thermoplastic housing to protect against rust and corrosion.

The same type of pump was initially used as a transfer and brine recirculation pump in the storage tank. However a decision was made to install a larger pump to expedite brine transfer to the truck saddle tank. A Pacer close-coupled pump will be used, which has a flow rate of 30 gallons per minute at $20 \mathrm{ft}$ head. It is a glass-reinforced polypropylene pump with stainless steel fasteners and built-in check valve, and has a 1-1/2 inch diameter port.

The pump used to transfer the outflow from the oil-water separator to the brine-making tank is a Little Giant submersible sump pump. It has an epoxy-coated impeller and housing with float switch, and the flow rate is 80 gallons per minute at $15 \mathrm{ft}$.

\subsubsection{Bill of Materials}

Table 6.1 illustrates the bill of materials for the brine making setup in the Monticello Sub-District Unit:

Table 6.1 Bill of materials for Monticello Sub-District brine production setup

\section{QUANTITY UNIT ITEM DESCRIPTION}

$\underline{\operatorname{cosT}}$

TANKS

EA 2200 Gallon NORWESCO Polyethylene Tank

$\$ 750$

$1 \quad$ EA 1100 Gallon RAVEN Polyethylene Tank

$\$ 293$

1

EA 56 Gallon Rectangular Polyethylene Tank

$\$ 280$

PUMPS $\quad 2$

EA RULE INDUSTRIES Sump/Utility Pump

$\$ 216$

EA LITTLE GIANT Sewage Sump Pump

$\$ 266$

EA PACER Polyester Pump

$\$ 642$

HYDROMETERS 2

2

2

PLUMBING

2

ELECTRICAL TOTAL
EA Glass Salimeters

EA Plastic Hydrometers

EA Hydrometer Jars

EA Bulkhead Fittings

EA 2" Diameter Flexible Couplings

EA PVC Cement

EA All Purpose Cleaner

FT Brine Transfer Hose

EA 100-mesh Strainer on Brine Delivery Line

EA 1-1/2" BANJO PVC Ball Valves

EA 1-1/2" Ball Valve

EA Rubber Sleeves

Misc. (couplers, clamps, PVC pipes and fittings)

Wire, ON/OFF SWITCHES

EA NEMA Type I Enclosures
$\$ 44$

$\$ 96$

$\$ 29$

$\$ 37$

$\$ 14$

$\$ 6$

$\$ 3$

$\$ 25$

$\$ 20$

$\$ 37$

$\$ 9$

$\$ 10$

$\$ 100$

$\$ 40$

$\$ 141$

$\$ 3,055$ 


\subsubsection{Operational Aspects}

\subsubsection{Brine Making Procedure}

Figure 6.1 shows a schematic representation of the brine making procedure at the INDOT Monticello Sub-District. Wastewater from truck washing flows through the floor grate into the 1100 gallon underground concrete tank, where materials such as grit will be allowed to settle. From the underground tank, water is pumped through the oil-water separator and than gravity flow to the 56 gallon tank. At the same time a 'bobcat'-style loader will be used to transfer salt into the brine manufacturing tank. The water is pumped over to the brine manufacturing tank while the overflow may be directed to the city sewer line with permission. Mixing of brine and testing salt concentration in both the brine making tank and the storage tank is achieved through switching specific valves and pumps, as illustrated in Appendix E. Appendix E also acts as an on-site instruction chart for operators working on the Monticello Sub-District brine manufacturing system.

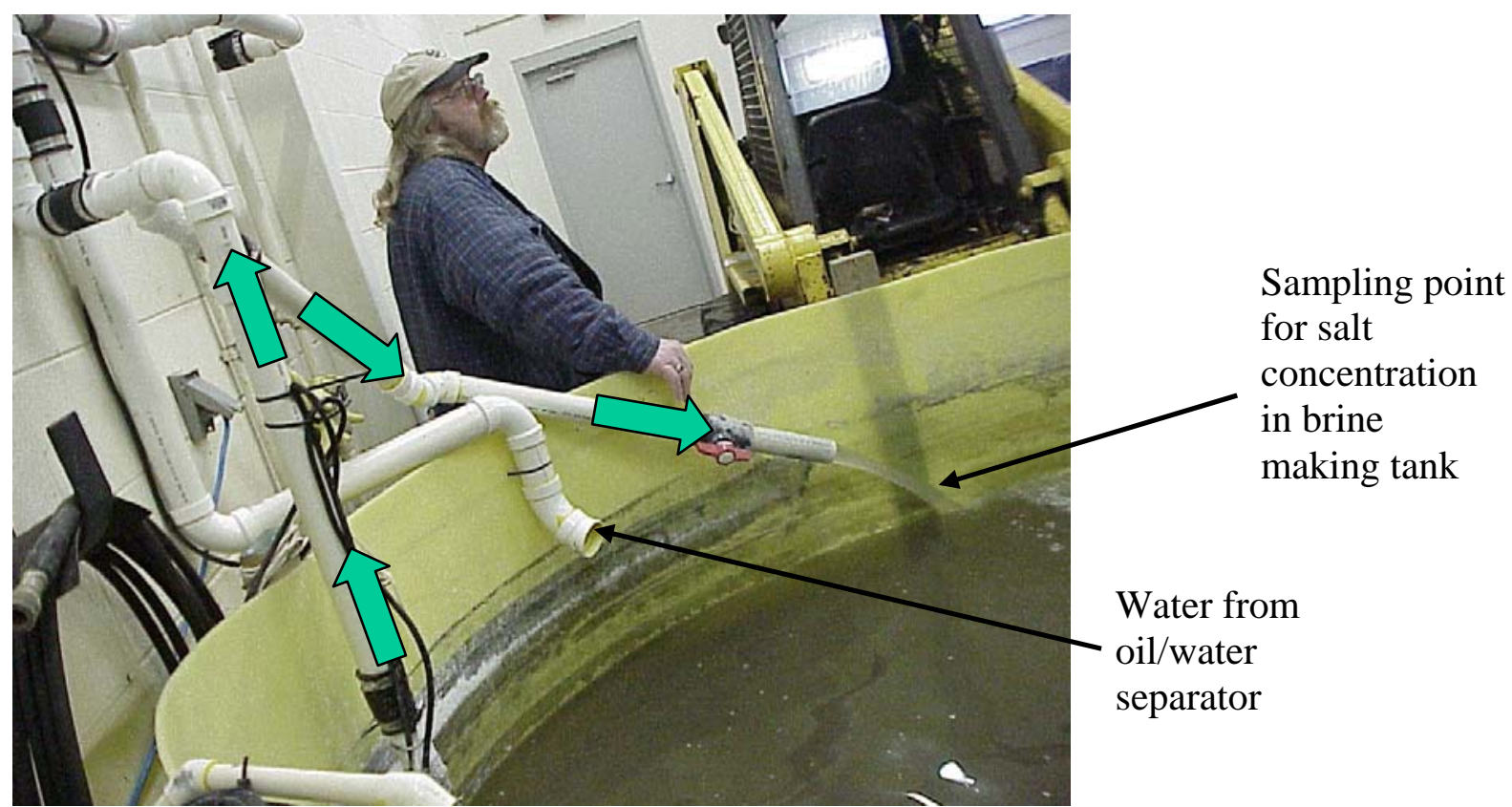

Figure 6.1 Operator recirculating brine in the brine manufacturing tank.

In the case where the brine concentration is above the eutectic concentration of $23.3 \%$, more water will need to be added and conversely more salt will need to be added if the brine concentration is below the eutectic concentration. Please refer to Section 5.1.4.1 for the calculations involved in increasing or decreasing the concentration of a brine solution. 


\subsubsection{Evaluations of Operation}

Table 6.2 gives a summary of the INDOT Monticello Sub-District brine manufacturing setup.

Table 6.2: INDOT Monticello Sub-District brine manufacturing setup

\begin{tabular}{|l|l|}
\hline & \\
\hline Location & INDOT Monticello Sub-District \\
\hline $\begin{array}{l}\text { Brine Production Hardware } \\
\text { and Installation }\end{array}$ & $\begin{array}{l}\text { "Do-it-yourself" } \\
\text { The facility, all of which is housed in the } \\
\text { truck washing area, includes a 750 gallon } \\
\text { brine manufacturing tank and a 2,200 gallon } \\
\text { brine storage tank. }\end{array}$ \\
\hline Brine Production Capacity & $\begin{array}{l}\text { Depending on the wash water/fresh water } \\
\text { flow rate and the availability of water in the } \\
\text { underground storage tank, the rate of } \\
\text { production of salt brine is up to } \\
\text { approximately 1,000 gallons per hour. }\end{array}$ \\
\hline 2000-2001 Brine Use & $\begin{array}{l}\text { About 3,600 gallons of salt brine was used } \\
\text { for pre-wetting. }\end{array}$ \\
\hline Brine Use with Deicing & $\begin{array}{l}\text { Four out of 23 trucks within the Monticello } \\
\text { Sub-District (which includes INDOT yards } \\
\text { at Flora and Logansport) are equipped with } \\
\text { the 200 and 150 gallon pod pre-wetting } \\
\text { system. }\end{array}$ \\
\hline Brine Use with Anti-Icing & None. No anti-icing unit is available. \\
\hline Brine Storage & One 2,200 gallon brine storage tank. \\
\hline Oil-Water Separator & Yes \\
\hline Brine System Cost & \$3,055 \\
\hline Truck Wash Water Collection & Yes \\
\hline Truck Wash Water Reuse & Yes \\
\hline
\end{tabular}

\section{0-2001 Brine Use}

A total of about 3,600 gallons of salt brine produced with this $1^{\text {st }}$-generation experimental system was used during the 2000-2001 winter season. The salt brine was used to pre-wet salt directly on the truck load at the yards, and during spreading operations using the on-board prewetting system. The salt brine manufactured at Monticello Sub-District was shared between two additional INDOT yards, located at Logansport and Flora, which are 22 miles and 37 miles away respectively from the Monticello Sub-District.

\section{Equipment and Facilities}

The INDOT yard at Flora has a 2,500 gallon storage tank available for salt brine storage. The yard at Logansport do not have a brine storage tank and the saddle tanks on trucks have to be refilled at the Monticello Sub-District. A 1,500 gallon tank mounted on trailer was available to haul the salt brine to Flora at the time of evaluation. 
An on-board strainer for the pre-wetting system was found to be clogged by solids within brine produced from truck wash water. Subsequent addition of a finer, 100 mesh strainer to the brine storage tank delivery line was made to prevent the likelihood of any such future problem occurring.

According to Gary Kelly from the INDOT Monticello Sub-District, the amount of salt brine that should have been used for pre-wetting was affected by the malfunctioning of one of the Muncie pre-wetting system, which has taken a couple months to repair in Indianapolis. In the beginning, brine manufactured in the Monticello Sub-District had not been used for anti-icing because of the lack of on-board anti-icing units within the district. Since the winter of 20022003, the Sub-District has managed an aggressive anti-icing program utilizing the brine.

\section{Brine Production Rate}

During the winter season of 2000-2001, the majority of brine was manufactured with fresh water. Truck wash water was used in several occasions.

Data obtained from the National Weather Service Forecast Office at Northern Indiana and the National Climate Center indicates that about 10 severe snow and ice storm events occurred between the period of November 2000 and February 2001 in Northern Indiana. At the Monticello Sub-District, salt trucks are washed after every storm event and it takes approximately 40 minutes to wash one truck. The wash water flow rate is about 4 gallons per minute, thus it will take approximately 160 gallons of water per truck.

Assuming that all of the 23 salt trucks in the area (Monticello, Flora and Logansport) will be deployed for each storm event and all trucks are washed in the Monticello Sub-District unit, a total of 3,680 gallons of wash water would be generated after each storm event.

From Section 5.2.2.2, it was suggested that the total brine required during a storm for prewetting will be about 3,600 gallons. It is thus reasonable to predict that the Monticello SubDistrict yard will generate enough salt truck wash water to make brine solution for pre-wetting. Assuming that all 23 salt trucks within the district would be washed in the Monticello SubDistrict yard, additional storage volume will need to be added to the current brine making and storage setup to accommodate the salt brine generated.

\section{Wash Water and Brine Quality}

Table 6.3 illustrates the characteristics of water samples taken from different parts of the brine manufacturing setup at the INDOT Monticello and LaPorte Sub-Districts.

Table 6.3 Water characteristics from Monticello, IN and LaPorte, IN (Year 2001)

\begin{tabular}{|l|l|l|l|l|}
\hline & & COD $(\mathrm{mg} / \mathrm{l})$ & BOD $(\mathrm{mg} / \mathrm{L})$ & Oil and Grease $(\mathrm{mg} / \mathrm{l})$ \\
& Detection limit & 100 & 2 & 5 \\
\hline Location & Sample & COD $(\mathrm{mg} / \mathrm{l})$ & BOD $(\mathrm{mg} / \mathrm{L})$ & Oil and Grease $(\mathrm{mg} / \mathrm{l})$ \\
\hline Monticello & Brine & 14,000 & 14 & Below detection limit \\
Monticello & Underground storage & 1,500 & 240 & 8.8 \\
Monticello & Effluent from O/W separator & 1,200 & 12 & 7.5 \\
LaPorte & Brine & 9,900 & BDL & Below detection limit \\
LaPorte & Underground storage & 3,500 & 3 & Below detection limit \\
\hline
\end{tabular}


The wash water from truck washing operations in Monticello first flows through the floor grate in the wash bay into the underground storage tank, and then pumped through the oil-water separator before using to make salt brine. Comparing the oil and grease level of the underground storage and that of the effluent from oil-water separator, the concentration of oil and grease decreased by only $1.3 \mathrm{mg} / \mathrm{l}$ after passing through the oil-water separator. This suggests that the oil-water separator had not been very efficient in removing oil and grease.

Comparing the water samples from underground storage in Monticello with that from LaPorte, it is observed that the water sample from LaPorte had a higher COD value, while the water sample from Monticello had a higher BOD content and oil and grease concentration than that from LaPorte. It is speculated that the higher COD value in LaPorte was due to the higher concentration of salt in the wash water (9\%), compared to 4-6\% in Monticello.

The higher BOD and oil and grease concentration in the Monticello underground storage samples may be due to the presence of crud and debris that may include anti-freeze, which is an organic compound and biodegradable. In comparison, the underground storage in LaPorte was relatively new (built less than a year ago as of winter 2000) and hence there was less accumulation of crud and debris.

The final brine solution from Monticello was found to contain very little oil and grease, which may be because of two reasons: firstly, the oil and grease formed crud with other impurities in the wash water and settled to the bottom of both the underground sedimentation tank and the brine manufacturing tank. Secondly, the lighter oil and grease may accumulate on the surface of the water, away from where the water sample was taken.

\subsection{Other Experimental Brine Production and Usage Systems}

INDOT has aggressively worked to provide brine manufacturing and spraying at their operational units, with nearly a three-fold increase in brine manufacturing sites over just the past three years. As of this report's September 2004 publication date, there are thirty-three (33) brine manufacturing systems in the state of Indiana, six of which (Gary, LaPorte, Monticello, Princeton, Bainbridge, and Bluffton) are now set up to use truck wash water to make brine. Three of these six sites are using "do-it-yourself" brine manufacturing system (LaPorte, Winamac and Monticello) with the rest using commercial brine making system. An INDOT district map is given in Figure 6.3, and Figure 6.4 shows locations of the brine manufacturing systems in the state.

The Monticello brine manufacturing system has already been discussed in detail from the previous sections. This part of the report will give an overview of the other five brine manufacturing systems in the state, excluding the two most recently equipped installations (i.e., Bainbridge@ Crawfordsville and Bluffton @ Fort Wayne) whose operations were started in early 2002.

Additional information dealing with another 'do-it-yourself' brine production system located in Hannibal, Missouri will also be presented. 


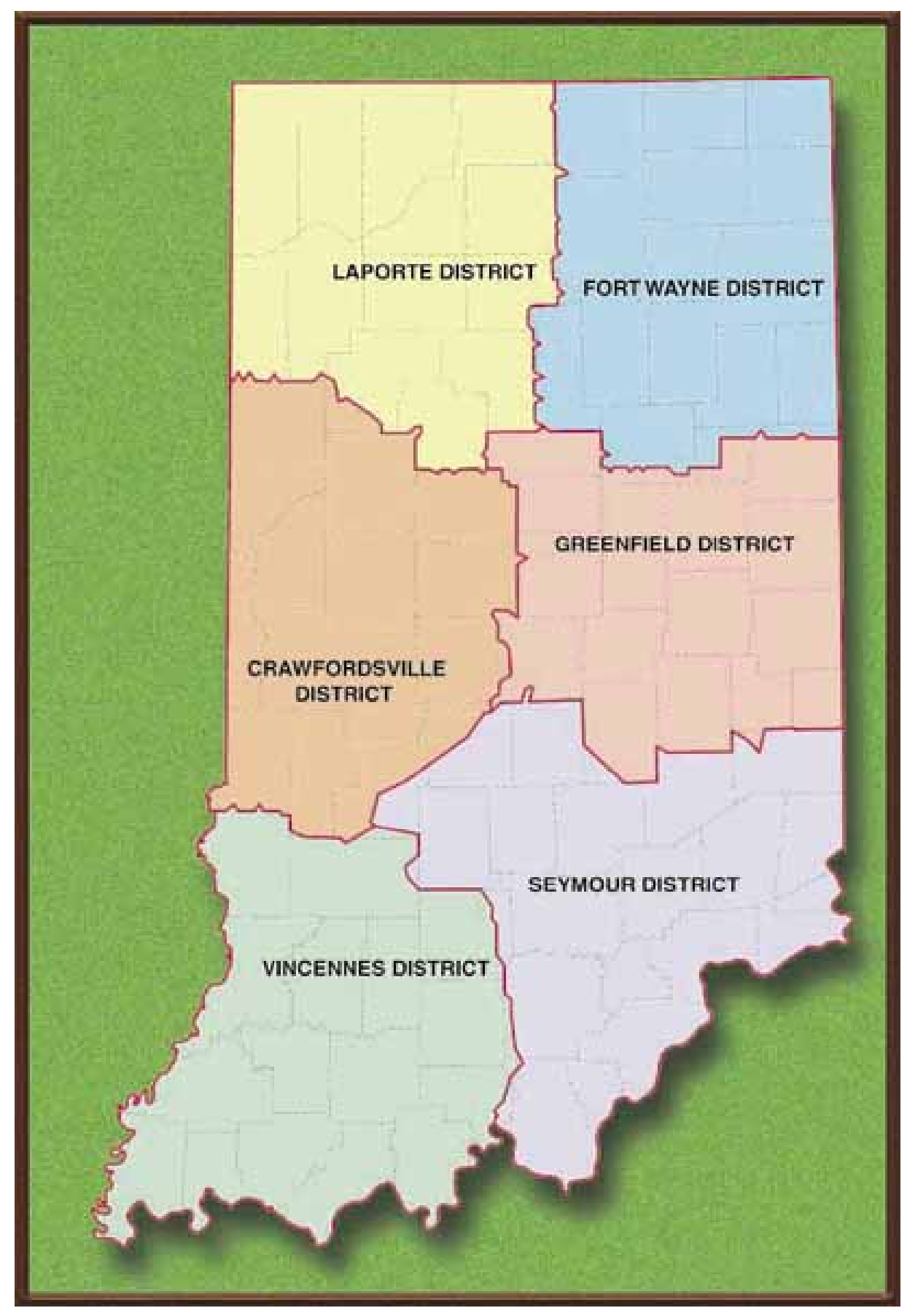

Figure 6.3: INDOT district map 

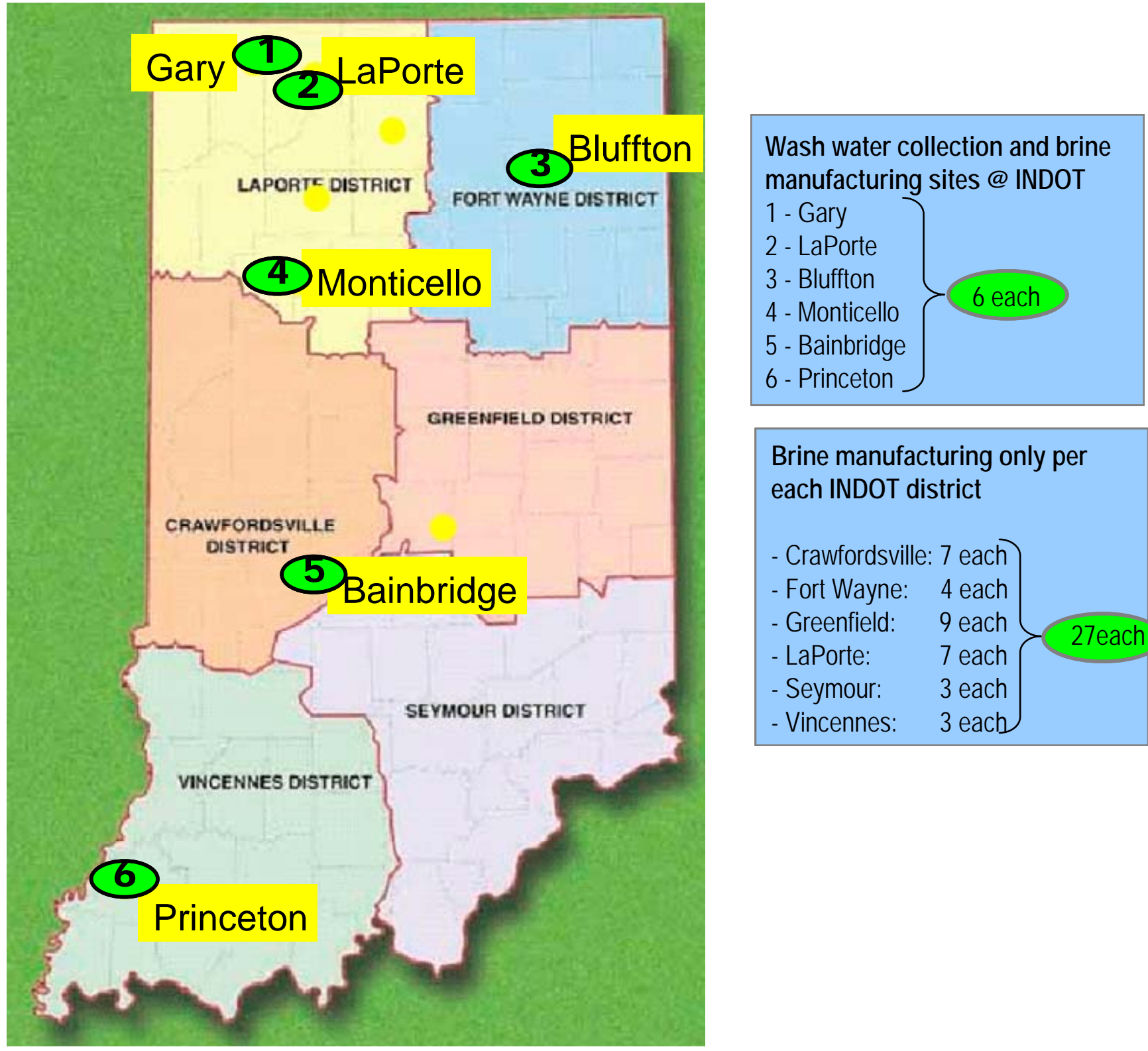

\section{Brine manufacturing only per each INDOT district}

- Crawfordsville: 7 each

- Fort Wayne: 4 each

- Greenfield: 9 each

- LaPorte: 7 each

27each

- Seymour: 3 each

- Vincennes: 3 each

Figure 6.4: Current 2004 INDOT locations with 'wash water collection and brine manufacturing' verus 'brine manufacturing only' 


\subsubsection{INDOT LaPorte Sub-District Unit}

\begin{tabular}{|c|c|}
\hline Location & INDOT LaPorte Sub-District \\
\hline \multirow{3}{*}{$\begin{array}{l}\text { Brine Production } \\
\text { Hardware and Installation }\end{array}$} & “Do-it-yourself” \\
\hline & \\
\hline & $\begin{array}{l}\text { The facility, part of which is housed in the truck } \\
\text { washing area, includes a } 300 \text { gallon galvanized horse } \\
\text { tank, two } 1,025 \text { gallon polyethylene tanks. }\end{array}$ \\
\hline $\begin{array}{l}\text { Brine Production } \\
\text { Capacity }\end{array}$ & $\begin{array}{l}\text { Rate of production of salt brine is approximately } \\
2,000 \text { gallons per hour. }\end{array}$ \\
\hline 2000-2001 Brine Use & $\begin{array}{l}\text { Salt brine produced from truck wash water was used } \\
\text { regularly throughout the winter of } 2000-2001.5,000 \\
\text { to } 6,000 \text { gallons of salt brine was used for both pre- } \\
\text { wetting and anti-icing. }\end{array}$ \\
\hline Brine Use with Deicing & $\begin{array}{l}15 \text { out of } 54 \text { trucks within the LaPorte Sub-District } \\
\text { (which include units in LaPorte, Michigan City and } \\
\text { Gary) are equipped with the } 125 \text { gallon pod pre- } \\
\text { wetting system. }\end{array}$ \\
\hline Brine Use with Anti-Icing & A 2,000 gallon tanker is available for anti-icing. \\
\hline
\end{tabular}




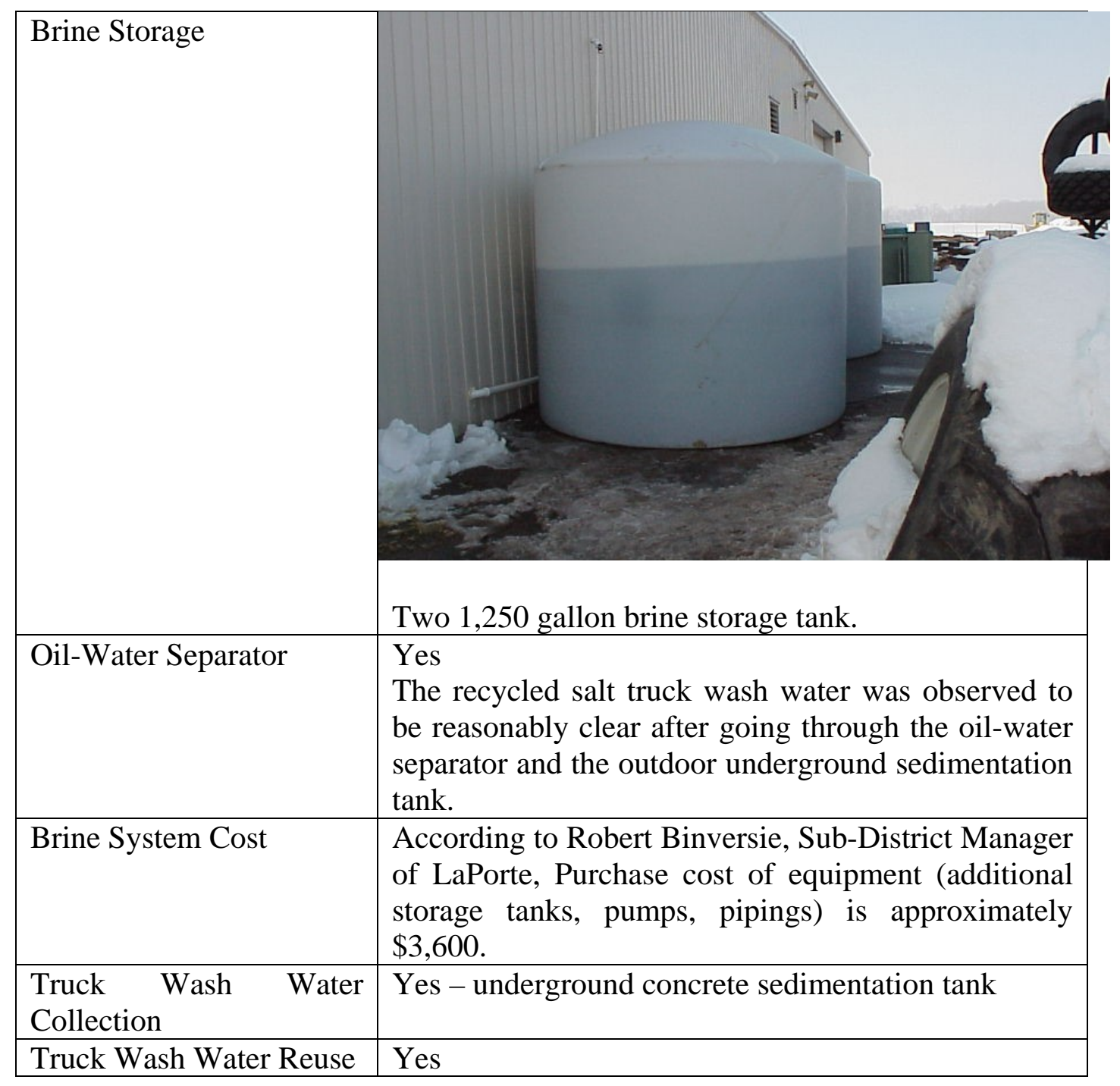


Figure 6.5

LaPorte Subdistrict brine production equipment layout

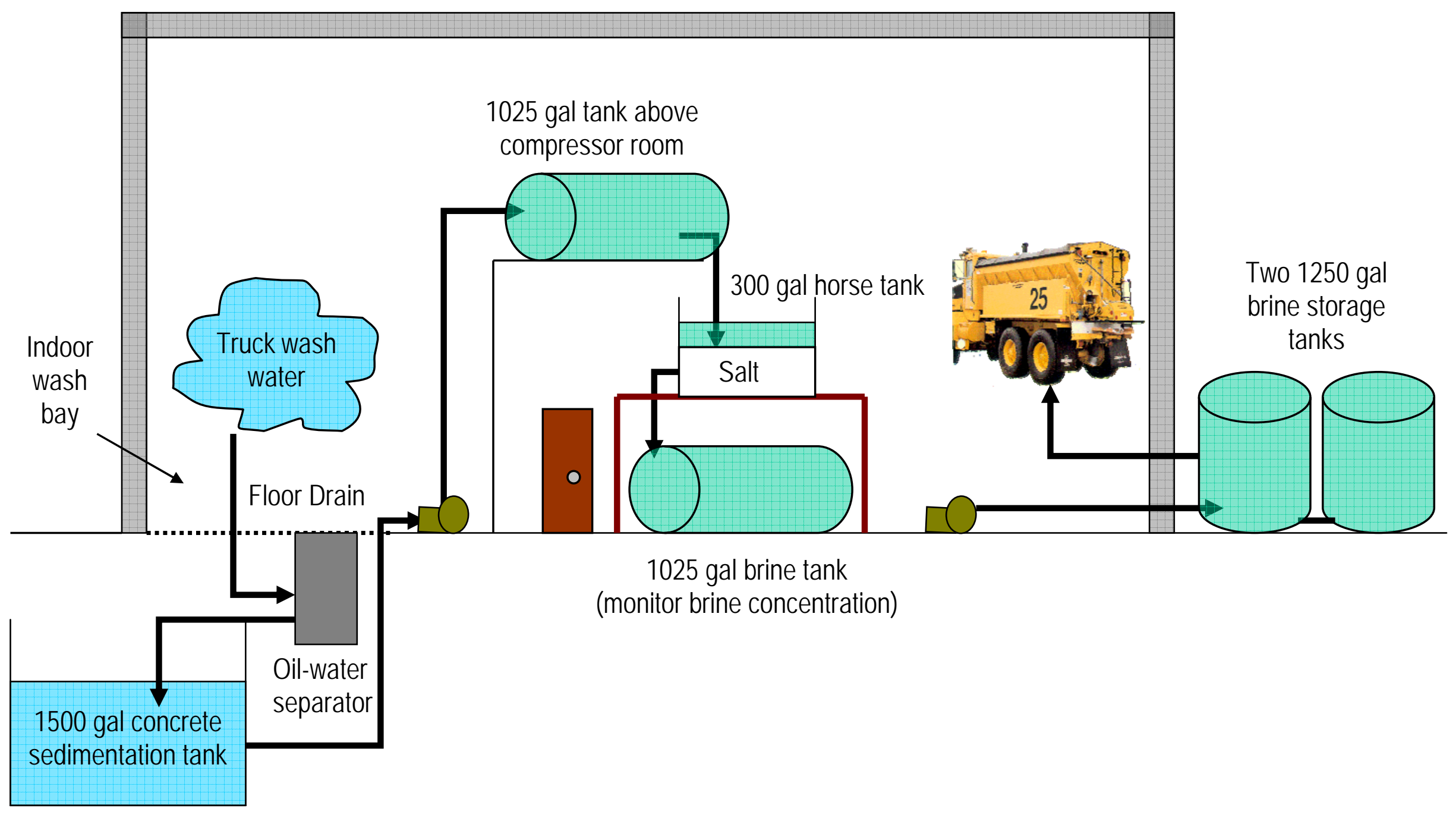




\subsubsection{INDOT Plymouth Sub-District Unit}

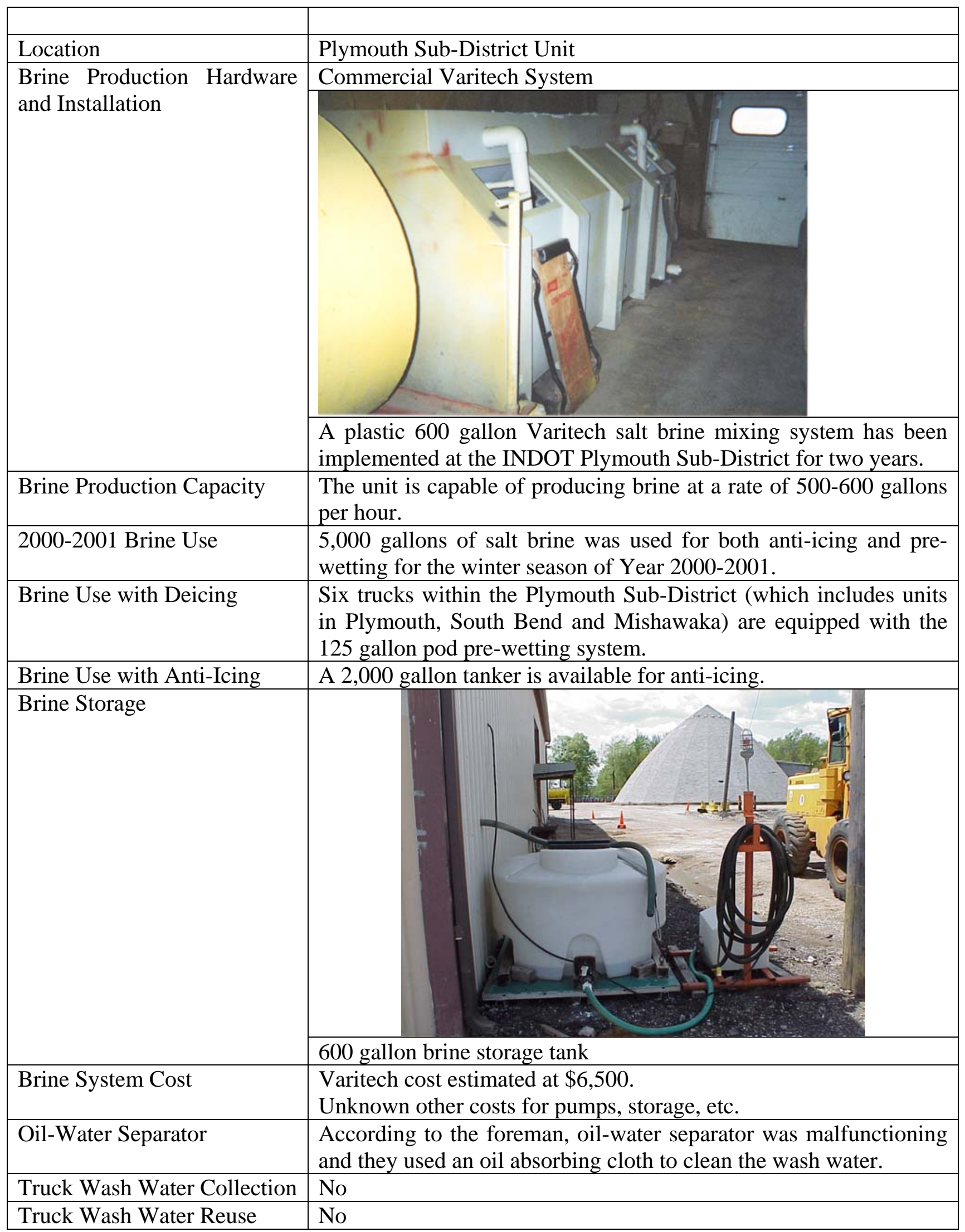




\subsubsection{INDOT Winamac Sub-District Unit}

\begin{tabular}{|c|c|}
\hline Location & INDOT Winamac Sub-District Unit \\
\hline \multirow{3}{*}{$\begin{array}{l}\text { Brine Production } \\
\text { Hardware and } \\
\text { Installation }\end{array}$} & "Do-it-yourself" \\
\hline & \\
\hline & galvanized horse tank \\
\hline $\begin{array}{l}\text { Brine Production } \\
\text { Capacity }\end{array}$ & $\begin{array}{l}\text { The rate of production of salt brine is approximately } \\
500 \text { gallons per hour. }\end{array}$ \\
\hline 2000-2001 Brine Use & $\begin{array}{l}\text { For the winter period of Year 2000-2001, } 1,000 \\
\text { gallons of salt brine is used for pre-wetting only. }\end{array}$ \\
\hline $\begin{array}{l}\text { Brine Use with } \\
\text { Deicing }\end{array}$ & $\begin{array}{l}6 \text { out of } 25 \text { trucks in the Sub-District, which include } \\
\text { Winamac, Rochester and Medaryville are equipped } \\
\text { with a } 125 \text { and } 150 \text { gallon pod for pre-wetting. }\end{array}$ \\
\hline $\begin{array}{l}\text { Brine Use with Anti- } \\
\text { Icing }\end{array}$ & No, but building their own anti-icing truck. \\
\hline \multirow[t]{2}{*}{ Brine Storage } & \\
\hline & 2,500 gallon brine storage tank \\
\hline Brine System Cost & Unknown \\
\hline
\end{tabular}




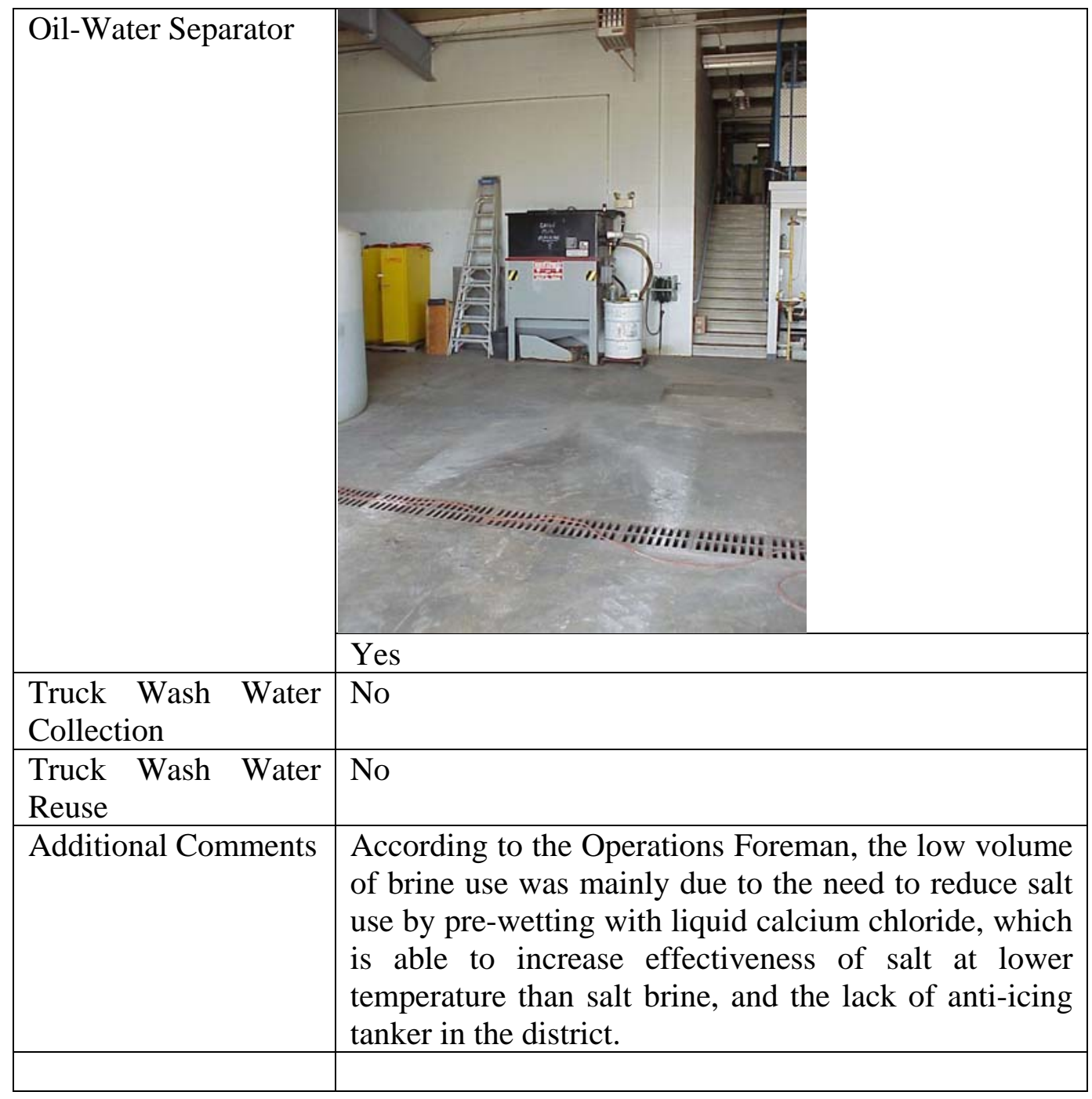




\subsubsection{INDOT Greenfield Sub-District Unit}

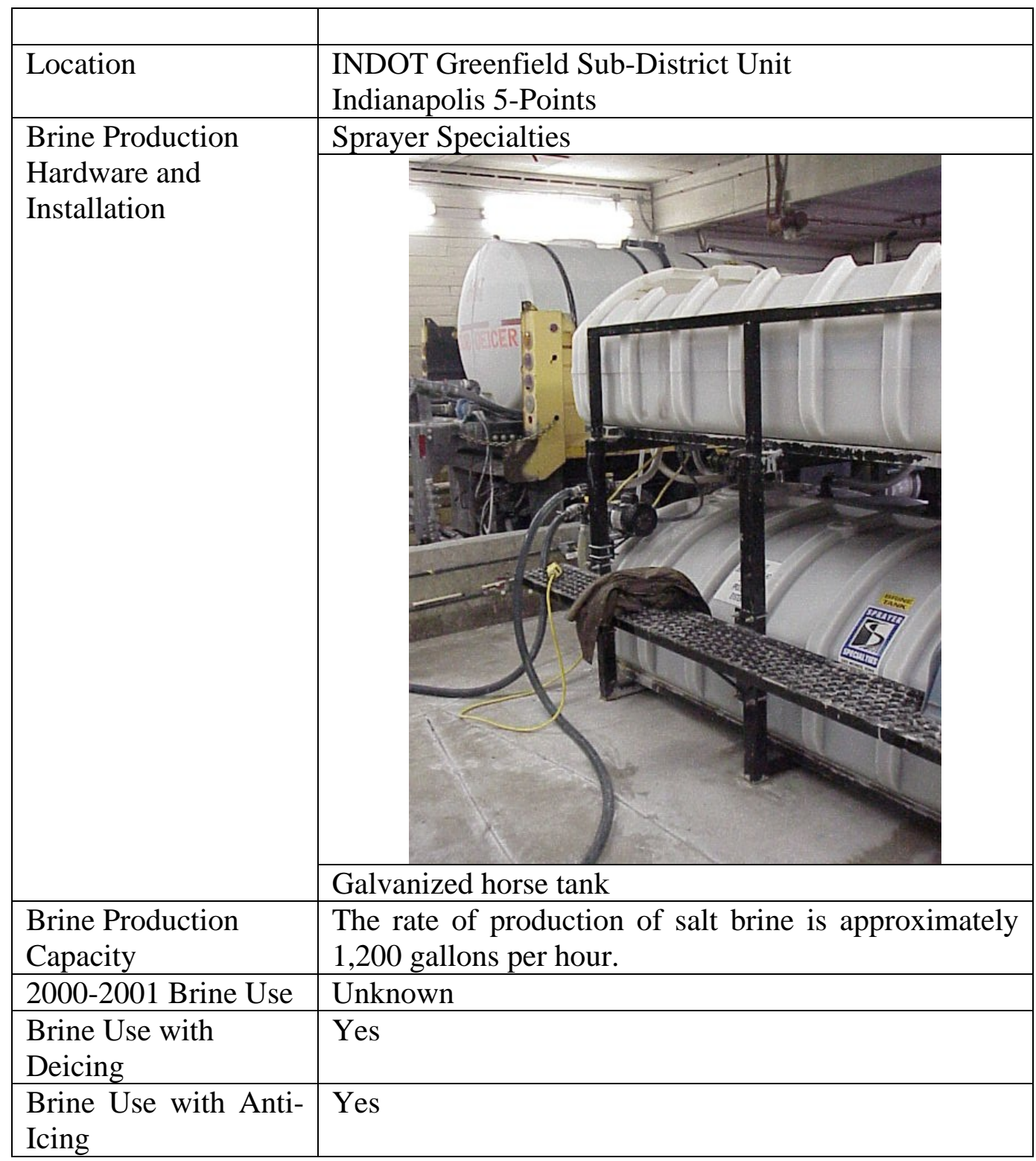




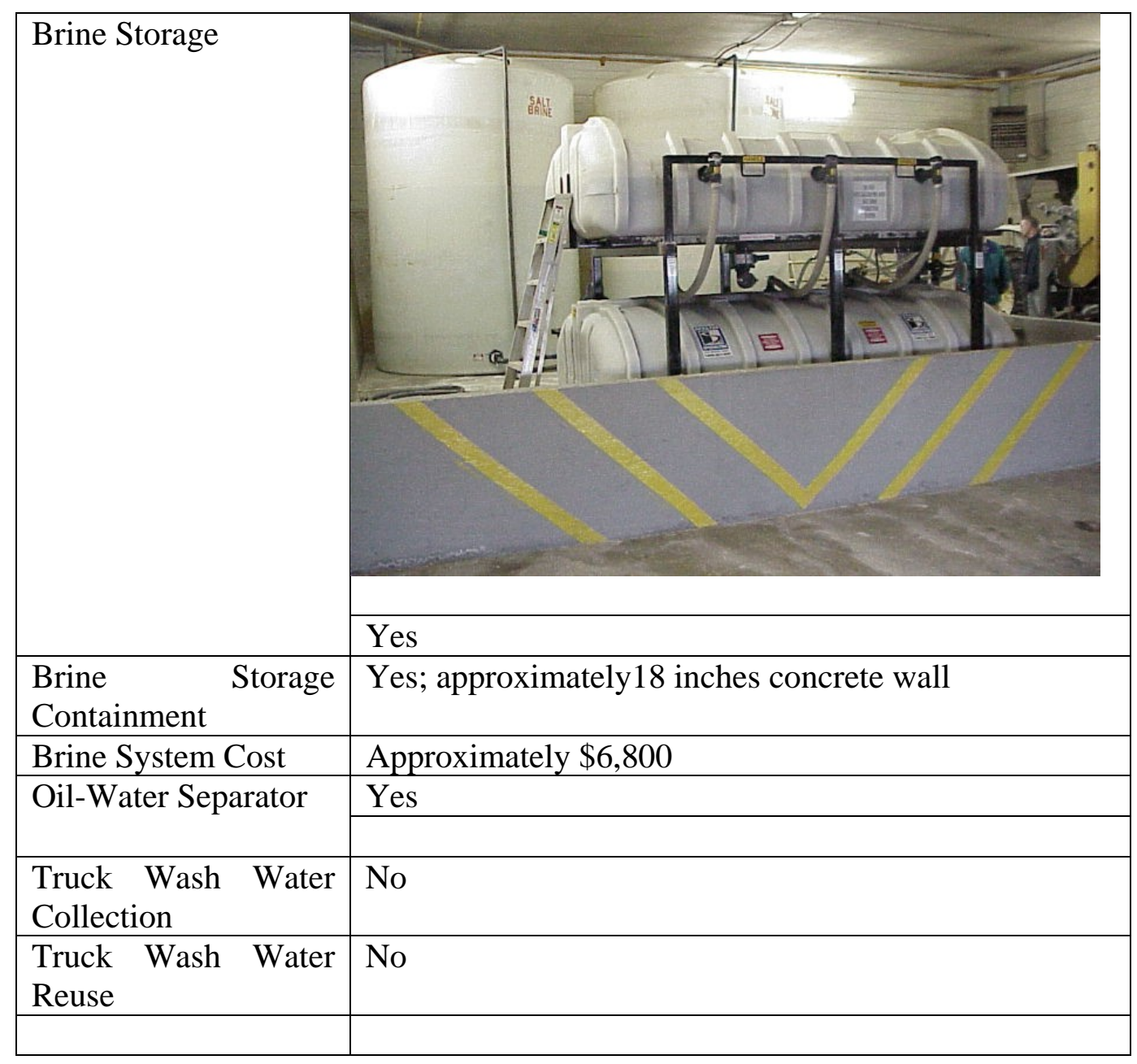




\subsubsection{INDOT Princeton Sub-District Unit}

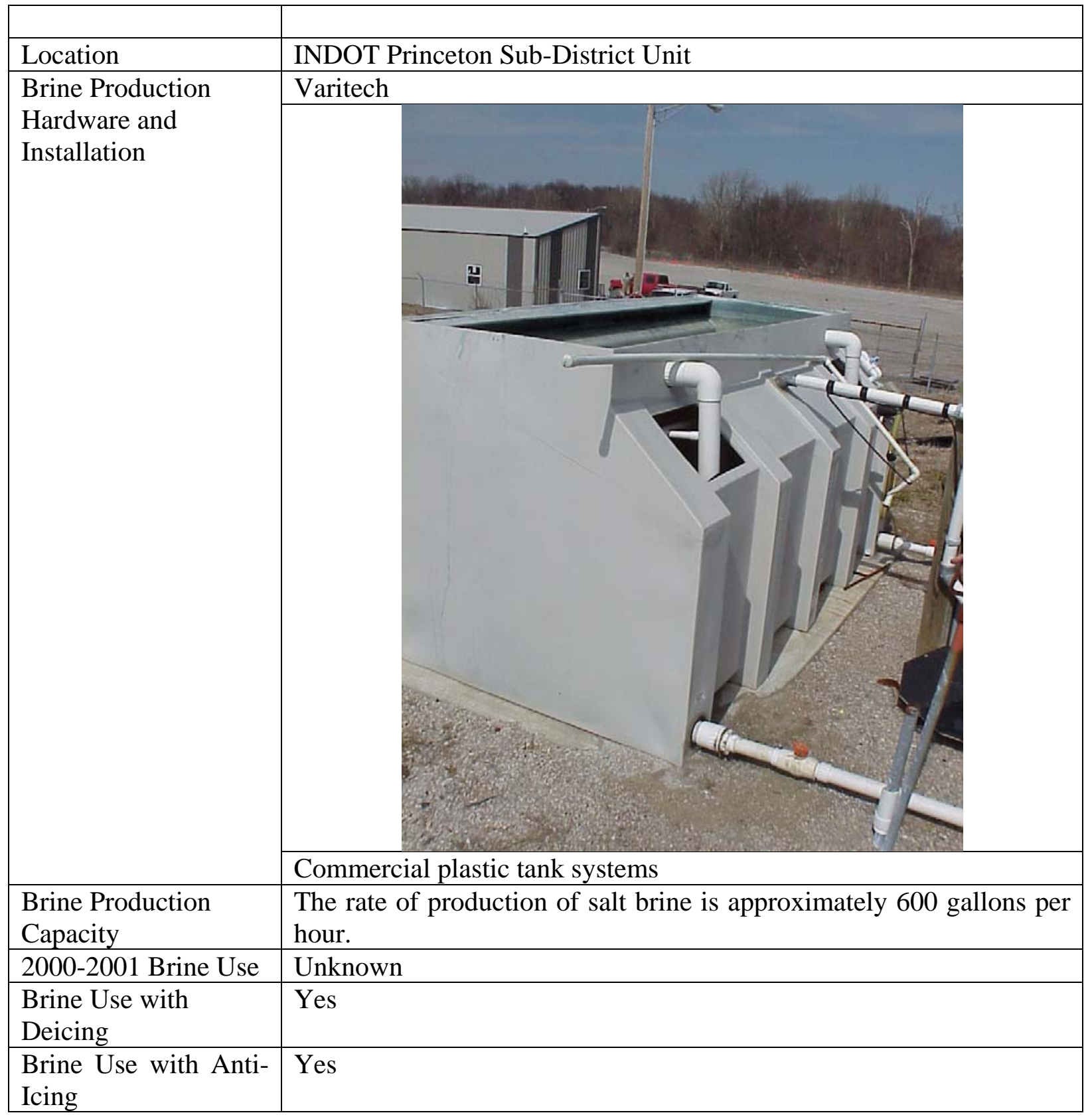




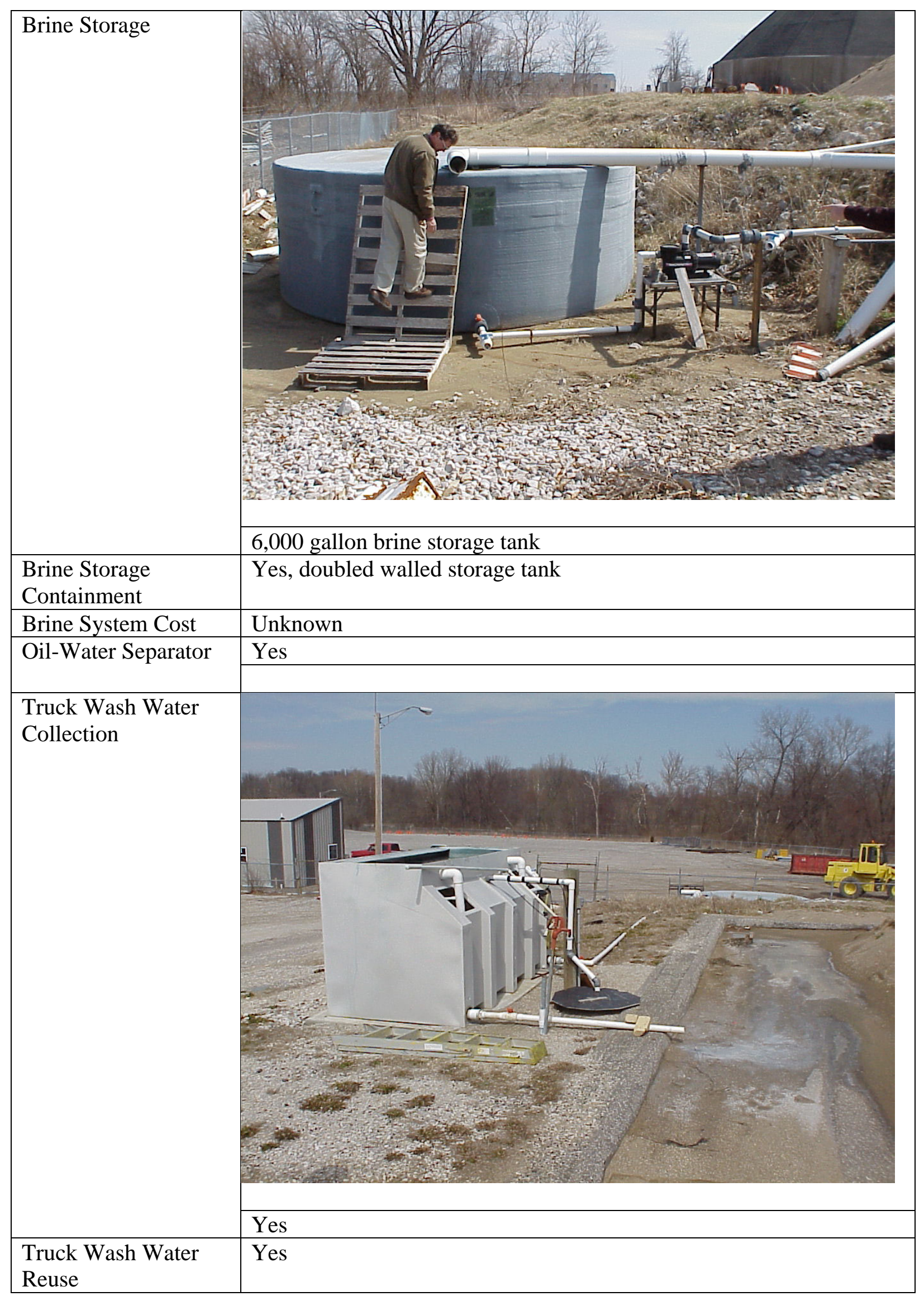




\subsubsection{Missouri DOT Hannibal Sub-District Unit}

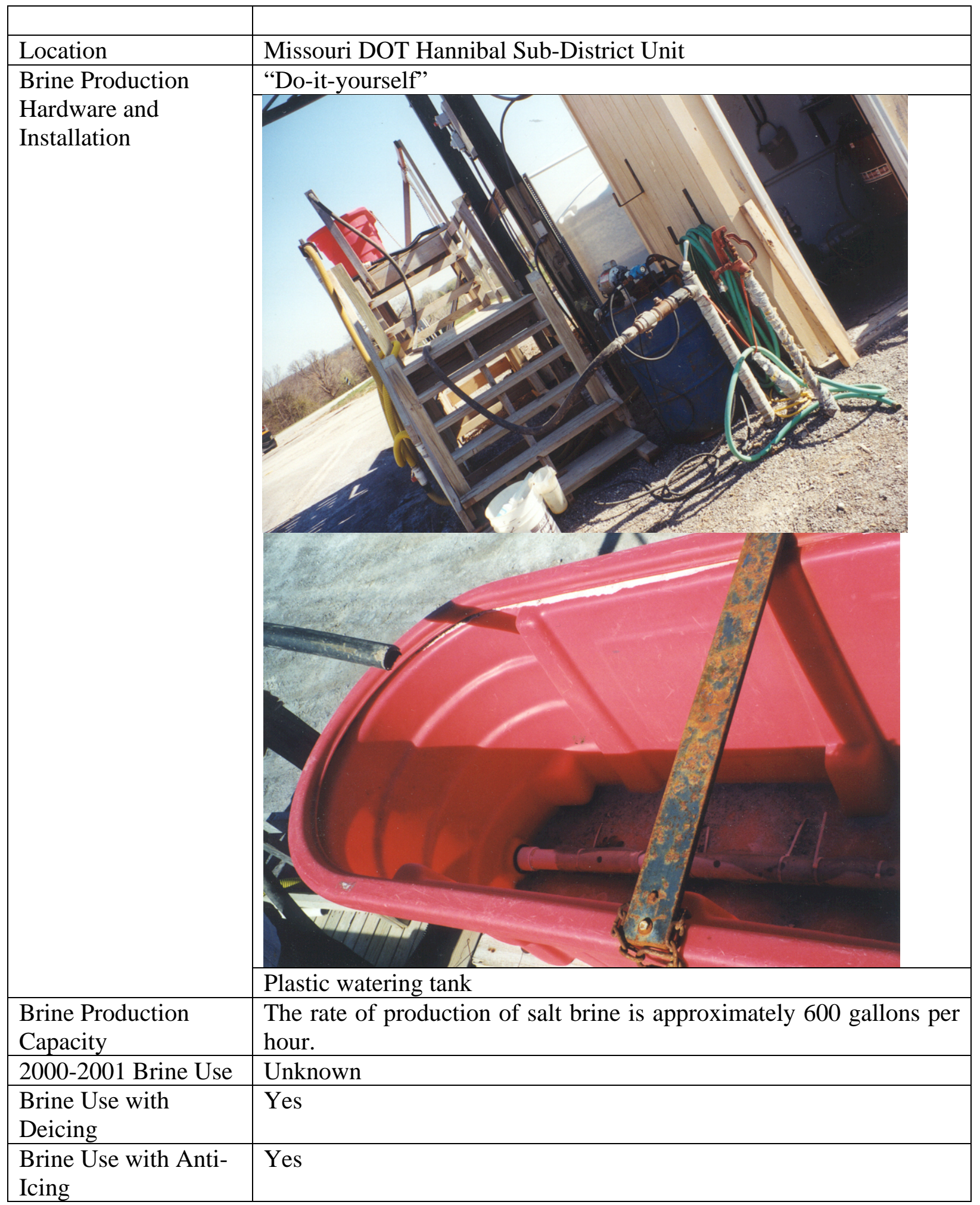




\begin{tabular}{|l|l|l|}
\hline Brine Storage & \\
\hline
\end{tabular}




\title{
7. ENVIRONMENTAL AND REGULATORY CONCERNS
}

Maintenance related activities in INDOT yards, include salt truck washing and deicing chemical handling, may generate significant quantities of salt-laden wastewater. Stormwater runoffs from these facilities may be polluted with salt from truck wash water and salt spilled during handling operations. Contaminants of concern include sodium chloride, anti-caking agents, oil and grease, and anti-freezes.

According to INDOT Field Operations Manual, Operating Procedure No. 22 (Appendix G), there have been cases where private properties and ground water located adjacent to salt storage facilities undergone pollution damage from runoffs of brine solution. Thus stormwater contaminated with salt may pose a significant environmental problem for INDOT yards. Applicable local and federal environmental laws may impose sanctions and penalties as a deterrent to lax controls on the handling of salt and deicing chemical that may have a negative impact on water quality. This section will present environmental and regulatory concerns for runoffs originating from INDOT yards. A survey of INDOT maintenance facilities will also be examined.

\subsection{Environmental Impacts of Salt and Brine Runoff}

\subsubsection{Salt Storage and Handling}

\begin{abstract}
Although dry salt is typically stored within dedicated, controlled access enclosures, it is necessary that good housekeeping practices must be employed while loading and removing salt from these locations in order to negate serious salt spillage. Careful operation of loaders will be extremely helpful in this regard, and an effort should be made to collected spilled materials rather than allowing this material to migrate away to adjacent lands and waters.
\end{abstract}

\subsubsection{Road Salt}

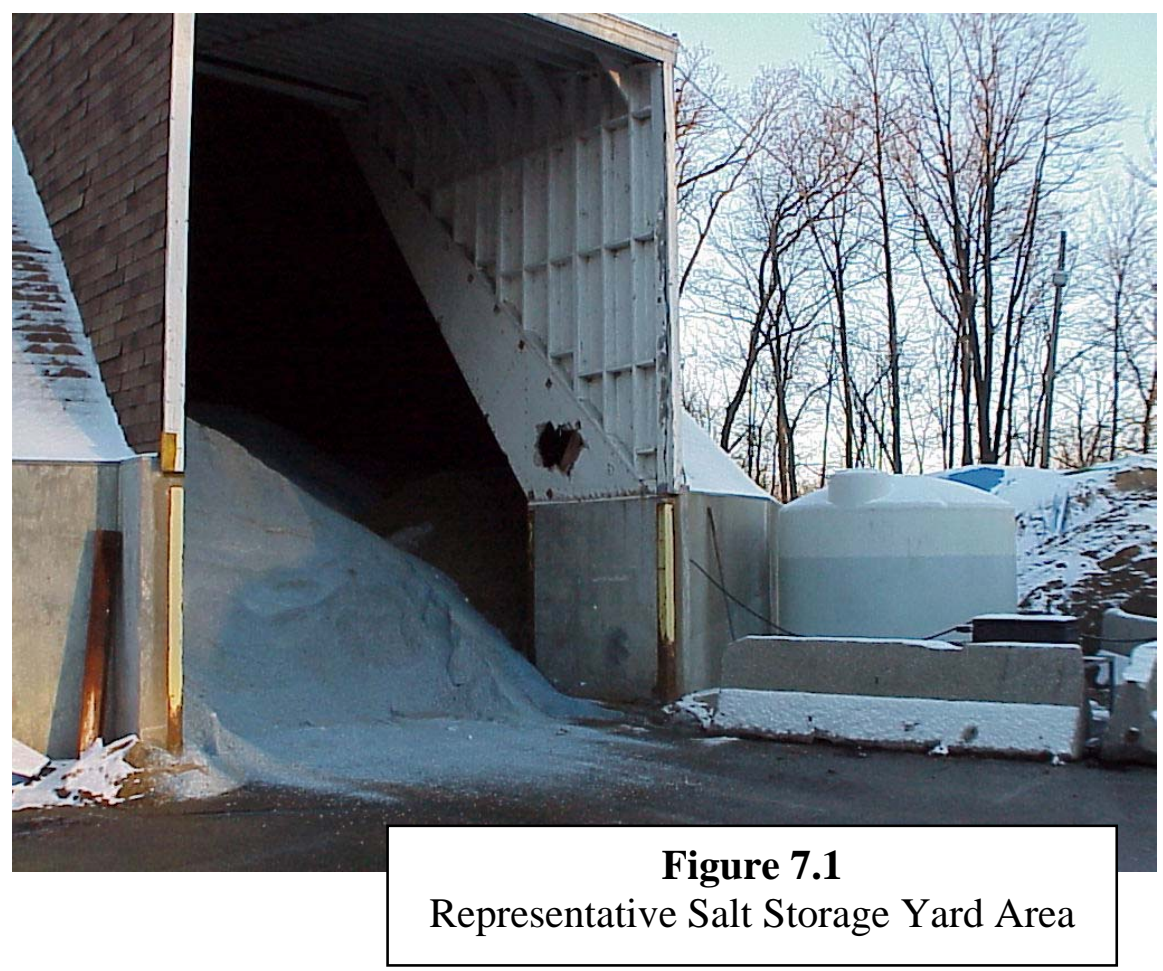

Potential environmental impacts of road salt include damage and loss of vegetation, increased salt concentrations in soils, lakes, rivers and streams, increased salt concentrations in ground water supplies, introduction of ferrocyanide into soils, ground water, lakes, rivers and streams, and increased salt loadings to wastewater treatment plants. 
In general, salt loadings are temporary and normal dilution may be enough to reduce the immediate problem. However, surface water which lack an outlet or have long flushing times may experience continually increasing salt concentration which may influence aquatic organisms.

\subsubsection{Anti-Caking Agent in Road Salt}

One of the chemicals of concern contained in road salt is cyanide. The chemical is added routinely as an anti-caking agent. The two agents added are:

- Ferric ferrocyanide (Prussian Blue), generally added to road salt at 40-50 ppm

- Sodium ferrocyanide (Yellow Prussiate of Soda), generally added at 40-50 ppm

The Food and Drug Administration has approved Yellow Prussiate of Soda for use in food products up to levels of $13 \mathrm{ppm}$. This cyanide is considered 'bound' because it resists degradation into its primary forms under normal salt handling conditions. Because of the strong chemical bondage between the cyanide groups and the iron, ferrocyanides have a low order of toxicity. However once exposed to sunlight it may react, albeit slowly, to form free cyanide which is highly toxic (Paschka, Rajat \& Dzombak 1999). Waste ferrocyanide in streams and lakes should not exceed 2 ppm because irradiated solutions become toxic to fish. In a study conducted by Blackburn Architects, Inc, the measured cyanide levels at all 18 of the INDOT sites investigated was found to be insignificant because of dilution by melting snow and water (Indiana Nonpoint Source Task Force, 1998). However there is a possibility that ferrocyanide will accumulate in ground and surface water and consideration should likely be given to conducting further research on the topic relative to its potential environmental impacts. Further details regarding this issue can be obtained from the Salt Institute (www.saltinstitute.org).

\subsubsection{Oil and Grease}

Oil and Grease are present in gasoline residue washed from the salt truck. Gasoline often contains components such as benzene, which are known human carcinogens and can contaminate ground water. Oil and grease are also oxygen demanding or consuming pollutants which will decrease the amount of dissolved oxygen in water, thus limiting a receiving water's ability to sustain aquatic life. These contaminants can migrate to stormwater drains after rainfall if vehicles are washed outside.

\subsubsection{Anti-Freeze}

The main component in most anti-freeze is ethylene glycol (or less toxic propylene glycol), which is toxic to humans and deadly to small animals. In addition to ethylene glycol, virgin anti-freeze also consists of corrosion inhibitors and foam controllers. Used anti-freeze may also contain heavy metals and other contaminants that are picked up as anti-freeze circulates through the engine, particularly in older vehicles that have metal radiators with soldered joints.

Some of the metals commonly found in used anti-freeze include lead, mercury, cadmium, chromium, copper, and zinc (U.S.EPA, 2001a). These contaminations may make used anti-freeze a hazardous waste. Anti-freeze residue washed off from salt truck may cause environmental problems if entered into a river or stream. 


\subsection{Pertinent Regulations}

\subsubsection{Intermodal Surface Transportation Efficiency Act of 1991}

In the 1987 amendments to the Clean Water Act, Congress directed the EPA to establish a permitting framework under the National Pollutant Discharge Elimination System (NPDES) program to address stormwater discharges associated with urban areas and certain industrial activities, including transportation facilities. However, in 1991, provisions within the Intermodal Surface Transportation Efficiency Act of 1991 temporarily exempted storm water discharges associated with industrial activities at facilities operated by municipalities with populations of less than 100,000 from the need to obtain an NPDES storm water discharge permit. Congress extended the permitting deadline for these facilities and sites to allow small municipalities additional time to comply with other NPDES requirements, but this extended deadline has now been reached.

\subsubsection{NPDES Stormwater Phase II Regulations}

The NPDES Stormwater Phase II regulation states that transportation agencies will fall under operators of “municipal separate storm sewer systems” (MS4). According to 40 CFR 122.26(b)(8), "MS4 means a conveyance or system of conveyances (including roads with drainage systems, municipal streets, catch basins, curbs, gutters, ditches, man-made channels, or storm drains): owned or operated by a State, city, town, borough, county, parish, district, association, or other public body...”.

Phase II regulated MS4s will be required to apply for NPDES general permit and implement storm water discharge management controls (often referred to as best management practices (BMPs) that effectively reduce or prevent the discharge of pollutants into receiving waters.

\subsubsection{Current Status in Indiana Regarding Stormwater Discharges from MS4}

Indiana's response to the national stormwater regulations was to adopt their own rule, 327 IAC 15-13 “Storm Water Runoff Associated with MS4s” in late 2002. Full implementation of their permit system must then occur within 5 years of this date, or approximately 2007.

Under Phase I, this general permit rule was not relevant to DOT-related operations. Phase I dealt with the MS4 areas serving an urbanized population greater than 100,000 people. Only the City of Indianapolis met Phase I criteria, and was issued an individual permit under Phase I.

Indiana's Department of Environmental Management (IDEM) has confirmed that stormwater sewer systems located within DOT facilities, along with their stormwater drainage systems onto adjacent roads, will fall under the MS4 definition. Thus state transportation facilities that discharge to a state highway drainage system will need to be permitted for their implementation of stormwater control measures. As of this report's date (September 2004), IDEM is still in the process of writing this permit for Indiana DOT operations, as well as establishing an overall level of control appropriate for the DOT facilities to be regulated. In the meantime, IDEM continues to conduct workshops for Phase II stormwater regulations and it is recommended that personnel from INDOT responsible for implementation of MS4 regulations attend similar workshops in the future. 
The bottom-line circumstance, though, is that INDOT facilities, as MS4s operators, are now specifically responsible for the quality of discharges from truck washing facilities, and salt runoffs from roads. Given the current absence of a formal stormwater permit and/or specific quantitative limits on effluent quality, therefore, it is not exactly clear what criteria constraints might be specified by IDEM relative to this contaminant streams. What appears to be a likely regulatory scenario, though, is that the permit restrictions will identify specific (i.e., chloride) or generic (i.e., total dissolved solids) contaminant levels which will have to adhere to the Indiana Water Quality Standards (327 IAC 2-1-6).

The most stringent criteria will likely be that of the 'total dissolved solids' limit, with a stipulated maximal value of $750 \mathrm{mg} / \mathrm{l}$ in natural State waters. By comparison, chloride has a higher $860 \mathrm{mg} / \mathrm{l}$ criterion maximum concentration (CMC) for a point-source effluent, and a 230 $\mathrm{mg} / \mathrm{l}$ criterion continuous concentration (CCC) limit. The standards for oil and grease in Indiana

are narrative rather than quantitative, stipulating only the absence of visual "sheen" and "turbidity."

In reviewing the latter regulated limits, it is important to note that these values are lower than those identified within INDOT's so-called 'Field Operations Manual on Snow and Ice Chemicals - Pollution Control Guidelines’ (i.e., Operations Procedure \#22, Revised June 1998), which lists a maximal limit for chloride of $1000 \mathrm{mg} / \mathrm{L}$ (Note: a full copy of this Operations Procedure \#22 is provided in Appendix G of this report).

\subsubsection{Current Statues in Other State Regarding MS4-Type Brine Runoffs from DOT Maintenance Facilities}

In Ohio, their State EPA has designated ODOT operations as a 'non-traditional' MS4, and their issuance of final permit requirements under the Phase II rule (in December 2002) identified six (6) minimum control measures that ODOT must address, including:

- Public Education and Outreach

- Public Involvement/Participation

- Illicit Discharge Detection and Elimination

- Construction Site Storm Water Run-off Controls

- Post Construction Storm Water Management in New Development and Redevelopment

- Pollution Prevention/Good Housekeeping

In turn, ODOT has already completed their development of a full 'Stormwater Management Plan' (URS, 2003) and has submitted this plan to the Ohio EPA to meet the aforementioned SWMP requirement. This SWMP will then be implemented during a five year period beginning on the date that Ohio EPA issues its related notice of coverage. However, even prior to this notice ODOT has already started working on their plan's implementation activities (i.e., as of last March 2003).

In reviewing this latter ODOT SWMP plan, it is also interesting to note that it specifically identifies the following chemicals of concern in relation to highway runoff: TSS, VSS, TOC, COD, NO3/NO2, TKN, PO4, TCu, TPb, TZn, Fecal Coliforms, Chloride, and Oil and Grease. Relative to salt wash water release, therefore, it would appear that 'chlorides' would represent the most stringent limit to be faced (as opposed to focusing on total dissolved solids). However, what is more important is that either of these contaminant forms (i.e., whether chloride at $~ 860$ $\mathrm{mg} / \mathrm{L}$ or TDS at $750 \mathrm{mg} / \mathrm{L}$, based on Indiana Water Quality Standards) would be considerably 
lower than the expected wash water concentrations, at which point remedial efforts such as that promoted by this report's 'collection and reuse' strategy would become absolutely necessary.

According to Blair Ballou, Engineer-Manager of the Eaton County Road Commission in the state of Michigan, the Michigan department of Natural Resources/Environmental quality (MDNR/DEQ) has issued salt and brine storage guidelines for road agencies in Michigan. This document is available in Appendix $\mathrm{H}$. So far the MDNR/DEQ wants containment of at least 1.5times largest single tank size.

In the state of Utah, according to Lynn Bernhard, Methods Engineer at Utah DOT, concrete containments have been installed at maintenance facilities where they store salt brine. There are currently no laws, policies or rules requiring secondary containment. Utah DOT does not obtain additional permitting for construction of liquid anti-icing chemical storage and handling at existing maintenance stations, they operate within the terms of previously issued surface water runoff permits. On new construction they provide $100 \%$ containment on-site for bulk salt storage and brine systems. All runoffs are captured to insure no discharge of oils or chemicals.

According to Russell Morin from the Connecticut DOT, they are not required to acquire construction permits pertaining to the brine storage tanks. However, DOT is held responsible for any spills or problems associated with the tanks. In addition, the pollution prevention plans should have spill prevention and best management practices for the tanks and drainage areas associated with them.

In the Province of New Brunswick, Canada, according to Richard Scott, General Manager of the MRDC Operations Corporation, the requirements for a permanent brine storage tank were fairly stringent and included among other things secondary containment and the submission of an approved spill contingency plan. The requirements were even more demanding for a buried storage tank. However there are no requirements for a mobile brine applications truck. Accordingly, they use their application truck as temporary storage and only produce brine on an as needed basis.

\subsubsection{Secondary Containment and Spill Contingency Plan}

According to 327 IAC 2-10 "Secondary Containment of Aboveground Storage Tanks Containing Hazardous Materials,” secondary containment of non-petroleum products is required when such storage exceeds 660 gallons or 275 gallons in a well-head protection area. The owner or operator of facilities subjected to this rule must also prepare a spill response plan for the facility. "Hazardous materials" includes "hazardous chemicals" that are defined in the OSHA Hazard Communication Standard as those that have health hazards, such as irritants. Referring to Section 7.3.1 and Section 7.3.2, deicing chemicals may satisfy the definition of health hazard and be considered as hazardous materials.

According to Don Arnold of the INDOT Environmental Division, some INDOT yards are already implementing secondary containment measures as stipulated in the above mentioned IAC Rule. These include double walled storage tanks for deicing chemical and the construction of concrete dikes around the storage tanks. INDOT facilities with these measures include Greenfield, Seymour and Vincennes. A spill contingency and response plan are also stipulated in some of the yards.

INDOT may be held responsible for any spills or problems associated with storage tanks containing brine and other deicing chemical. Thus it is imperative that formal preventive measures and good housekeeping be implemented in the INDOT yards. 


\subsubsection{Drinking Water Standards}

Salt brine discharges from transportation maintenance facilities may enter ground water and surface water, which may be sources of public water supplies. Municipal treatment works may not be equipped with expensive technologies, such as reverse osmosis and distillation, for the removal of sodium chloride. Salt brine discharges may thus negatively impact drinking water.

National Secondary Drinking Water Regulations (NSDWR's or secondary standards) are non-enforceable guidelines regulating contaminants that may cause cosmetic effects (such as skin or tooth discoloration) or aesthetic effects (such as taste, odor, or color) in drinking water (U.S. EPA, 2001b). A search on documents on IDEM's Drinking Water Branch - Compliance Section shows that EPA recommends secondary standards to water systems but does not require systems to comply. As stipulated by EPA, the secondary maximum contaminant level (SMCL) of chloride is $250 \mathrm{mg} / \mathrm{l}$ (Code of Federal Regulations, 2000a). This is the level above which the taste of the water may become objectionable. It is in comparison to $860 \mathrm{mg} / \mathrm{l}$ criterion maximum concentration (CMC) and $230 \mathrm{mg} / \mathrm{l}$ criterion continuous concentration (CCC) established by Indiana's water quality standards.

High chloride concentrations may also be associated with the presence of sodium in drinking water. High level of salt intake can be associated with hypertension in some individuals. However, sodium levels in drinking water are unlikely to be a significant contribution to adverse health effects. EPA's advised $20 \mathrm{mg} / \mathrm{l}$ of sodium in drinking water may also be considered too low and need revision (Federal Register, 1998). Sodium is thus listed in the EPA's contaminant candidate list (CCL) as a regulatory determinations priority (RDP) to allow time to evaluate and revise the agency guidance.

\subsubsection{Ground Water Standards}

Indiana's Water Pollution Control Board adopted the drinking water MCLs as ground water quality standards on August 8, 2001 (327 IAC 2-11). The "narrative” criteria (in Section 5) with this document lists a $250 \mathrm{mg} / \mathrm{l}$ limit for chloride in drinking water class ground water. INDOT officials should therefore carefully review their current practice of discharging salt-laden runoffs from salt storage and salt truck washing facilities to ensure compliance.

\subsection{Safety Issues}

\subsubsection{OSHA Hazard Communication Standard}

The OSHA Hazard Communication Standard, also know as the Worker's Right-to-Know Law, was enacted to ensure that hazards in the workplace are identified and communicated to all employees. Compliance with the Hazard Communication Standard will require, among other measures:

- providing employees with information and training on chemical found in the workplace so that employees are aware of the chemical

- maintaining an updated inventory of Material Safety Data Sheets (MSDS) for all chemicals in the workplace.

- $\quad$ ensuring that all containers, tanks, pipes, etc. are properly labeled. 
Deicing chemical stored in INDOT yards will thus be subjected to the rules in the Hazard Communication Standards.

\subsubsection{Safety and Handling of Deicing Chemicals}

Reasonable handling, care and cleanliness should be sufficient to prevent injurious contact under normal operating conditions. Since deicing chemicals such as brine, calcium chloride and magnesium chloride are concentrated inorganic salt, it may cause moderate to severe eye irritation with possible corneal injury. Liquid chemicals stored in unheated tanks will also reach temperatures much less than freezing, and will result in instant frostbite if in contact with skin.

Goggles or face shield and rubber gloves with long gauntlets should be worn. All storage and dispensing tanks should be labeled. All loading and off-loading should be performed in a safe manner, as close to the ground level as possible.

It should be emphasized that in dissolving solid or diluting concentrated liquid calcium chloride, considerable heat will be generated. Thus one is cautioned against building up pressure in a closed container and advised to avoid contact with hot equipment or hot solution.

\subsection{INDOT Yards Survey}

A survey of INDOT yards conducted by INDOT's environmental division in 1997-1998, with updates in 2001 by Lynn Corson from Purdue's CMTI was examined. A summary of the findings is given in Appendix I. 158 INDOT facilities were included in the survey. Excluding rest areas, field offices, facilities that are to be closed or moved, or facilities where no processing or washing is done, a total of 145 yards may be involved in transportation maintenance activities with deicing/anti-icing chemicals on-site. 71 facilities out of the 145 do not have connections to POTWs (publicity owned treatment works). Among these 71 facilities, 4 are in the process of hooking up to POTW, and 2 of which discharges (except sanitary) are refused by POTWs.

Of the remaining 74 facilities that do have connections to POTWs, 54 are approved to discharge both shop floor drain effluent and truck wash water to the POTWs, with the other 20 only accept sanitary sewage. Three subdistricts (LaPorte, Monticello and Gary) do not allow saltladen wash water into the POTWs at the time of survey.

Yet another approach to evaluating possible options for disposal of winter salt truck wash water can be developed on the basis of INDOT yard proximity relative to currently operating publicly-owned treatment works (i.e., wastewater) facilities (i.e., POTWs). Mapping of the INDOT yard sites in relation to POTW locations already been completed by Dr. Lynn Corson with Purdue University's CMTI program (Corson, 2004). In turn, by cross-referencing this information (subdivided per each INDOT district) against the site listings given in Appendix I, it can be seen that there are only about six INDOT yards within a 2-mile proximity to a local POTW who are not currently discharging to that site, including: Lizton (10.6 miles)@ Crawfordsville, Markel (0.26 miles) and Waterloo @ Fort Wayne, Rushville (1.23 miles) @ Greenfield, Flora (1.24 miles) and Wanatah (1.25 miles) @ LaPorte, and Aberdeen (1.72 miles) @ Seymour. A full synopsis of all INDOT yards within 2 miles of a local POTW has been given in Appendix J, including sites already connected, and it should also be noted that the latter 2-mile distance was arbitrarily selected as an approximate cutoff for an affordable piping distance. As such, the results obtained with this latter approach suggest that are only a few remaining sites

which might yet be connected to POTWs, and even then there is no certainty that all waste 
streams generated at these INDOT yards (i.e., including both human and operating wastes such as salt truck wash waters, etc.) would be acceptable by the wastewater treatment operations.

In this context, it should also be mentioned that a number of INDOT yards also conduct outside washing of trucks and may have off-site discharges of wash water. These sites, including those facilities without POTW connections, will have to obtain NPDES permits unless outside washing is stopped and all wash water connected to a POTW. Reusing salt truck wash water to make brine solution may significantly reduced harmful off-site runoffs and discharges to POTWs. Good house keeping procedures in handling salt are also needed to ensure compliance to environmental regulations.

\subsection{Future Stormwater Control Direction: The TMDL Program}

The National total maximum daily load (TMDL) is the amount of pollutant a water can receive and still meet water quality standards. As enacted in 1972, 303 (d) of the Clean Water Act requires states to identify waters not meeting state water quality standards (termed “impaired” water), set priorities for TMDL development and develop a TMDL for each pollutant for each listed water. The pollutant may come from point sources or non-point sources, with point sources regulated by the NPDES. Under the new federal rules (40 CFR 130, Subpart C) effective on October 31, 2001, states are required to list impaired water bodies and a schedule must insure that TMDLs are established no later than 10 years after the water was listed. Currently there are only 3 "impaired" waters in Indiana, however there are many more "sensitive waters” that INDOT might needs to be concerned of discharge affecting these waters.

Historically, stormwater controls for municipalities has been based upon the implementation of BMPs. With the advent of the TMDL program, rather than relying on BMPs, states, EPA, and citizen groups now increasingly seek to impose numerical concentration and mass limits on stormwater discharges. The implications in terms of pollution control costs may be unprecedented. In a national precedent-setting case, EPA recently imposed numeric limits for oil and grease in an NPDES permit for stormwater discharges from the District of Columbia to a receiving water with a TMDL for oil and grease in effect (ICPRB, 2001). This action is significant because EPA jumped right to numeric permit limits rather than give the district the opportunity to develop a BMP program to address oil and grease issues.

IDEM is also believed to be collaborating with the State of Minnesota and Region 5, EPA, to establish TMDL for chloride, and dischargers such as INDOT yards may be able to contribute to TMDL development process. INDOT environmental and stormwater managers may need to scrutinize state lists of "impaired" and "sensitive" waters to ensure a sound technical basis for listings that may impact their discharges. 


\section{COST BENEFIT ANALYSIS}

\subsection{Deicing}

It is a known fact that deicing promotes highway safety. A study, Accident Analysis of Ice Control Operations, released in 1992 by Marquette University's Department of Civil and Environmental Engineering further concluded that. It is quoted as saying "as a winter maintenance service, deicing pays for itself within the first 25 minutes after the first hour that salt is spread on two-lane highways. ..” The study found that costs related to accidents, including medical expenses, emergency services, workplace costs, travel delay, property damage, and administration and legal expenses decrease by $88.3 \%$ after application of deicing salt.

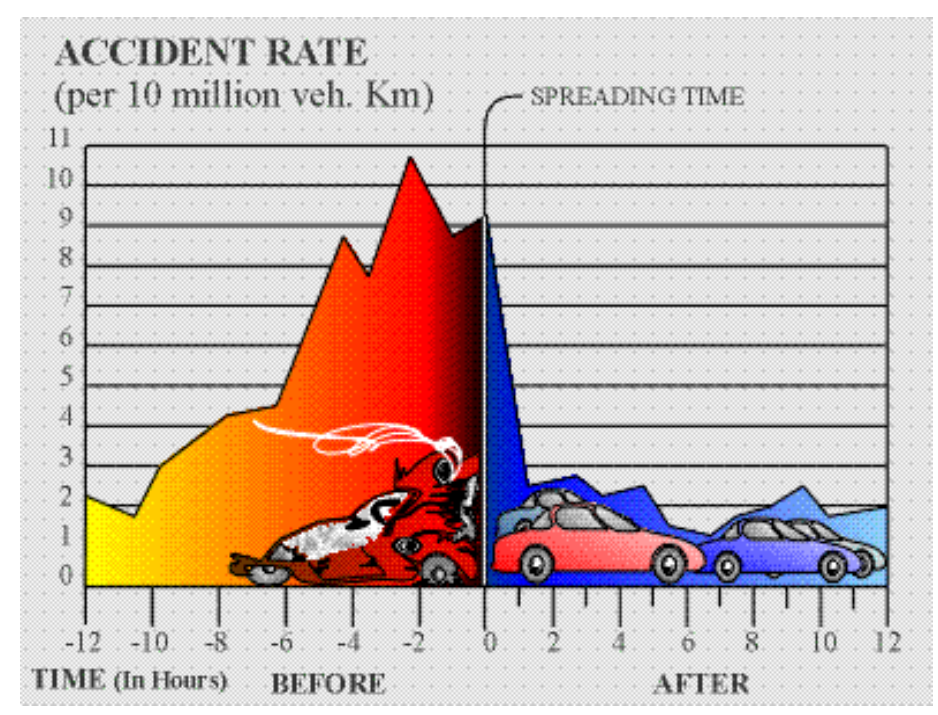

Figure 8.1: Accident rate before and after salt spreading (Source: Salt Institute, 1999b)

\subsection{Anti-icing}

The practice of anti-icing has proven to be cost effective according to many agencies. A study was completed by the Insurance Corporation of British Columbia (ICBC) on the number of claims reduction as a direct result of using anti-icing agents and technology. The results showed a $6 \%$ reduction in the number of claims reported or a total of 83 claims for the four months testing period. The average cost of a winter claim to ICBC which includes property damage, injury and fatality claims was $\$ 16,040$ on a city street and $\$ 20,506$ on a highway. The estimated savings to ICBC was then calculated at 1.37 million dollars for the 83 claims (Gilfillan, 1999).

Focus, a monthly newsletter published by FHWA which acts as the primary communications vehicle for FHWA's infrastructure research and technology program, noted the following examples of cost savings with regard to anti-icing strategies:

- Data from an RWIS station has enabled North Dakota DOT to reduce the use of sand on a bridge on I-94 near Fargo, saving $\$ 10,000$ to $\$ 15,000$ in just four storms. 
- On the 153-km (95-mi) West Virginia Parkway, data collected by an RWIS network leads to savings of about $\$ 2,300$ per storm in labor costs and $\$ 6,500$ per storm in materials costs.

- Maryland DOT predicts labor savings resulting from reduced crew standby times can pay for the State's RWIS stations in just 5 to 7 years.

A report from the Idaho Transportation Department also found that by utilizing liquid magnesium chloride as an anti-icing agent on a section of US Highway 12 in the northern part of the states, a reduction of $62 \%$ average labor hours, $83 \%$ abrasives and $83 \%$ average accidents are achieved. It is noted that these success are achieved even without the use of RWIS roadside weather observation sites. The crews rely on the Internet to obtain area forecast and have developed their own set of indicators that enable them to treat and re-treat the road before the chemical concentration drops too low to be effective (Breen, 2001)

\subsection{Cost Benefit Analysis of Deicing/Anti-icing Chemicals}

Each year \$1.5 billion are spent on highway snow and ice control (Smithson, 1997). Chemicals used for deicing account for about one-third of these expenses (Transportation Research Board, 1991). There is no doubt that the first criteria in choosing a deicer is effectiveness, however the large amount of deicing/anti-icing materials to be used will warrant a careful weighing of the cost of different deicing/anti-icing material.

In general, deicing/anti-icing products with a lower working temperature cost more. Working temperature is the lowest temperature in which the cost of application is justified by the results obtained. As an example solid calcium chloride, with a working temperature of $-20^{\circ} \mathrm{F}$ cost \$260/ton, while rock salt (sodium chloride), the most common deicing chemical with a working temperature of $15{ }^{\circ} \mathrm{F}$ cost about $\$ 30 /$ ton, depending on seasonal availability. The cost of using salt rises when 30 to $50 \%$ of the load is lost due to bounce and scatter or the salt being blown off the road. Pre-wetting salt with brine solution has been proven to save salt use by 20 to $30 \%$. Cost can be further reduced when state agencies produce their own brine at the low cost of $\$ 0.05 / \mathrm{gal}$. A further illustration of the cost benefit of pre-wetting will be given in Section 8.4.

Some alternative deicers/anti-icers have emerged in recent years. An example is Ice Ban, a by-product of corn. Ice Ban is found to be less corrosive and more "environmental friendly" than conventional chemical deicers. However comparing to the cost of salt brine, Ice Ban is considerably more expensive at $\$ 1.25 /$ gal as a pre-wetting agent. Inconsistencies in the quality of the product have also been experienced by some of the INDOT yards which use Ice Ban. Only a side-by-side cost benefit analysis of the various deicing/anti-icing products, their effectiveness, cost and the needs of the individual district will truly be useful.

\subsubsection{Corrosiveness and Environmental Concerns}

It is noted that $\$ 5$ billion in indirect costs of deicing - corrosion, water quality degradation, and other environmental consequences are impose in snow and ice operations (Smithson, 1997). Environmental effects and corrosiveness of deicing chemicals should be taken into consideration in the cost benefit analysis of deicing products. 
Sodium chloride is the most common and the cheapest of the deicing products. However, it is also the most corrosive. Organic deicers such as Ice Ban and calcium magnesium acetate (CMA) are found to have little or no effect on steel or concrete (TRB, 1991).

Calcium chloride, another common deicing chemical, can have corrosion inhibitor added to it. According to Dow Chemical, manufacturer of Dow Flakes (calcium chloride with corrosion inhibitor), it was found that the corrosiveness of calcium chloride will be decreased by $70 \%$ as a result of adding the corrosion inhibitor. However, the cost will be significant higher at $\$ 445 /$ ton, compared to $\$ 200 /$ ton without corrosion inhibitor. There is no known corrosion inhibitor for sodium chloride to date.

To examine the environmental impacts of liquid deicers/anti-icers, a report was commissioned by the Pacific Northwest Snowfighters (PNS) and the Insurance Corporation of British Columbia (ICBC) (Gilfillan, 2001). Graham Gilfillan, a member of PNS and the manager of Material Damage Loss Prevention of ICBC, reported that their research resulted in the basic conclusion that all deicers pose some type of environmental concerns, depending on the application and specific circumstances of use. Organic deicers such as Ice Ban and CMA were found to have high values of biochemical oxygen demand, which will temporarily deplete streams or ponds of oxygen during microbial breakdown of these products should they be released in high concentration in the environment. However, at the normal rates of application of the liquid deicers, oxygen depletion may not be a significant factor.

The only product which had the least toxic effect for all tests was salt brine solution, but it must be noted that sodium chloride may persist in the environment, while organic deicers are readily biodegradable. Considering the fact that organic deicers are usually more expensive than inorganic deicers such as sodium chloride and calcium chloride, transportation agencies need to pick the best option for their specific needs in order to be cost effective while minimizing environmental damage.

\subsection{Cost Benefit of Pre-wetting: Using Salt Brine Manufactured with the "Do-it- yourself” Brine Maker}

To illustrate the cost benefit of using salt brine in snow and ice operations, the following sections will present a cost benefit study of using salt brine for pre-wetting. Although the practice of anti-icing may result in a greater level of cost savings to transportation agencies, its potential cost savings will be difficult to ascertain due to the complexity of anti-icing, which renders different anti-icing chemicals and application rates in various road conditions, and the need for other facilities such as RWIS and weather forecasting.

\subsubsection{Effect of Salt Brine when Added to Solid Sodium Chloride}

Solid salt requires energy to go into solution before any melting action can begin. When a liquid, such as salt brine, is added to the surface of dry salt, the time over which the material will travel into solution will be decreased.

It has long been realized that pre-wetting solid abrasives or deicing chemicals can provide a marked benefit to the user. Sodium chloride (salt brine), magnesium chloride and calcium chloride are the most commonly used liquid chemicals for pre-wetting purposes.

As previously shown in the "do-it-yourself" brine making system in the INDOT Monticello Sub-District, salt brine can be manufactured at the DOT yards at a relatively low cost. Experiences from DOTs in Illinois, Iowa and Minnesota show that pre-wetting dry salt with 
salt brine is effective down to $20^{\circ} \mathrm{F}$ pavement temperature, and a salt saving of $20-30 \%$ is typically achieved.

\subsubsection{Effect of Salt Brine when Added to Sand}

The use of sand alone as a winter road maintenance technique, by definition, does not assist in melting snow or ice. In other words, sand alone is not an anti-icer or deicer, rather it is a traction enhancer. According to the Michigan DOT, when sand is applied to the road surface with a conventional spreader, $30 \%$ bounces off the traveled portion of the lane. It was found that if sand is pre-wetted with an anti-icing liquid, less solid material can be used to ensure the same amount of coverage on the road surface (Leggett, 2000). Furthermore, as sand requires cleanup typically in the spring, less solid material dispersed will likely results in less material cleanup at the end of the winter period.

\subsubsection{Cost Analysis of Using “Do-it-yourself” Brine Manufacturing System for Pre- wetting} from INDOT.

The following cost saving analysis is based on "real life numbers" that were obtained

Over the two year winter period of 1999-2001, INDOT used on average of 372,915 tons of salt per year (refer to Table 3.3 and Table 3.4), and the amount of abrasive used was estimated to be 60,000 tons per year. The average cost per ton of salt and sand are $\$ 30$ and $\$ 10$ respectively. The total number of snow trucks is 1,141 and the number of maintenance facilities is 123 from Table 3.3 .

Simple division indicates that the average truck consumes 327 tons of salt per year and 53 tons of sand per year, and the average number of trucks per facility is 9 trucks.

Thus, without pre-wetting:

The annual cost of salt per facility per year = 327 ton/year*9 trucks/facility*\$30/ton $=\$ 88,290 /$ facility/year

The annual cost of sand per facility per year

= 53 ton/year*9 trucks/facility*\$10/ton $=\$ 4,770 /$ facility/year

With Pre-wetting (assume 10\% salt and sand saving):

Average truck consumes 294 tons salt/year

Annual amount of salt/facility/year $=294 /$ ton/year $* 9$ trucks/facility $=2,646$ tons salt/facility/year

Average truck consumes 48 tons sand/year

Annual amount of sand/facility/year $=48$ ton/year*9 trucks/facility $=432$ tons sand/facility/year

Pre-wet amount is assumed to be: 10 gal salt brine/ton salt

$\mathrm{Gal} /$ truck/year $=10$ gals/ton*294 tons/year $=2,940$ gals/truck/year

$\mathrm{Gal} /$ facility/year $=$ 2,940 gals/truck/year $* 9$ trucks/facility $=26,460$ gal/facility/year 
Table 8.1 illustrates the estimated cost of pre-wetting, using the Monticello "do-ityourself" brine making unit as an example. It is assumed that each INDOT maintenance facility will have a home-built brine maker and all trucks will be retrofitted with on-board spraying units.

Table 8.1 Estimated cost for pre-wetting

\begin{tabular}{|c|c|c|c|c|}
\hline CAPITAL COST & COST/UNIT & UNIT & QUANTITYIFACILITY & $\begin{array}{l}\text { ESTIMATED } \\
\text { COST }\end{array}$ \\
\hline Salt brine production system & $\$ 3,055$ & EA & 1 & $\$ 3,055$ \\
\hline $\begin{array}{l}\text { Retrofitting trucks with } \\
\text { spreader and saddle tank }\end{array}$ & $\$ 1,000$ & EA & 9 & $\$ 9,000$ \\
\hline & & & SUBTOTAL & $\$ 12,055$ \\
\hline \multicolumn{5}{|l|}{ ANNUAL O \& M COST } \\
\hline Salt Brine & $\$ 0.05$ & GALS & 26460 & $\$ 1,323$ \\
\hline Sand & $\$ 10$ & TONS & 432 & $\$ 4,320$ \\
\hline Salt & $\$ 30$ & TONS & 2646 & $\$ 79,380$ \\
\hline & \multicolumn{3}{|c|}{ TOTAL ESTIMATED O \& M COST } & $\$ 85,023$ \\
\hline
\end{tabular}

Table 8.2 illustrates the potential cost savings of using pre-wetting over a 5-year planning period. It is estimated that $\$ 20,034$ can be saved per facility over this period, and $\$ 2,464,223$ can be saved for the whole fleet of trucks in the state.

Table 8.2 Cost comparison with and without pre-wetting

\begin{tabular}{|l|l|l|}
\hline & With Pre-wetting & Without Pre-wetting \\
\hline Capital Cost & $\$ 12,055$ & $\$-$ \\
\hline Annual O \& M Cost & $\$ 85,023$ & $\$ 93,060$ \\
\hline Present Worth Costs & $\$ 12,055$ & $\$-$ \\
\hline Capital Cost & $\$ 339,471$ & $\$ 371,561$ \\
\hline O \& M Cost* & $\$ 351,526$ & $\$ 371,561$ \\
\hline Total Present Worth Cost & \\
\hline & $\$ 20,034$ \\
Savings over 5-yr period/facility & $\$ 2,226$ \\
Savings over 5-yr period/truck & $\$ 2,464,223$ \\
Savings over 5-yr period for whole fleet &
\end{tabular}

*Based on an 8\% annual interest, and a 5-yr planning period. Present worth factor is 3.9927

A conservative estimate of $10 \%$ reduction in salt and sand has been assumed, since most DOTs have reported a salt and sand savings of $20-30 \%$ using the pre-wetting method. Thus the benefits and savings will potentially be far greater. However, this significant benefit of salt saving will only be realized if operators and managers follow through and modify their spread rates when using pre-wetted salt as oppose to dry salt. 


\section{CONCLUSIONS AND RECOMMENDATIONS}

The increased public concern about the environment, more stringent environmental laws and regulations, and a goal of promoting increased operational efficiency has prompted transportation agencies such as INDOT to review their operations and reduce environmental impacts. This report provided background information on cold-weather deicing and anti-icing, the pertinent regulations, and the factors involved in setting up a successful brine manufacturing system with recycled truck wash water. A detailed proof-of-concept study was conducted at the INDOT Monticello Sub-District using an experimental brine manufacturing setup.

A Web-based synopsis of this project, detailing both the technical challenge of salt truck wash water disposal and a pro-active strategy for its beneficial reuse, is available at the following URL: http://rebar.ecn.purdue.edu/Salt-Wash-Reuse/

Based on the report, the following recommendations are made:

Collection of wash water:

- Incorporate proper drainage systems and wash bays in construction plans for new yards, while modifying older yards to comply with current stormwater regulations and avoid discharge to "waters of the state".

- Configure oil-water separator to allow direct side-stream capture of wash water.

Pretreatment of wash water:

- Increase the frequency of preventative maintenance efforts applied to oil-water separators to several times a year (e.g., twice per year) to maintain their effectiveness.

- Underground sedimentation tank for truck wash water collection should also be cleaned periodically on an as-needed basis

- Districts should develop appropriate preventative-maintenance plans on an individual, asneeded basis

Storage of wash water:

- Procure and install wash water storage capacity as necessary per local rates of operation

- Likely wash volumes can be estimated on the basis of truck routes and truck numbers, with $\sim 200$ gallons wash per truck per route

Pumping wash water to brine maker:

- Use pumps made with non-corrosive "Viton" plastics, which are more affordable than stainless steel.

Brine making:

- When selecting brine manufacturing hardware, the following considerations should be made:

- Future need for additional capacity

- Adequate water supply capacity

- Suitability of proposed site from an operational and environmental standpoint

- Pump capacity requirement 
- Overflow control requirement

- Containment of spill

- Use of non-corrosive parts and materials in the plant construction

Brine storage:

- Install brine storage with a capacity suited to local needs relative to project brine application volumes and rates

- Use INDOT personnel to build concrete dikes as secondary containment for brine storage.

- For exterior storage applications, the observations made during this study were that heattracing and double walled storage was not necessary, but further validation of this circumstance should be secured.

Brine usage:

- Ensure the availability of proper deicing/anti-icing equipment, for example, anti-icing trucks, pre-wetting system and pavement temperature sensors.

- Designate and train responsible "brine production” operators at each site.

Other recommendations:

- INDOT environmental personnel should attend workshops conducted by IDEM, such as the MS4 stormwater regulations to obtain proper knowledge of the stormwater regulations.

- Encourage communications with transportation officials from other states to facilitate exchange of ideas and expedite the testing of new technologies. 


\section{REFERENCES}

Aurora Program (2001). About RWIS. http://www.aurora-program.org/what_is_rwis.cfm

Breen, B.D. (2001). Anti-icing Success Fuels Expansion of the Program in Idaho. Maintenance Division, Idaho Transportation Department.

Boselly, III, S, Dore, G., Tnornes, J., Ulbery, C. and Ernest, D. (1993) Road Weather Information Systems, Volume I and II. SHRP-H-350, SHRP, National Research Council, Washington, DC.

Code of Federal Regulations (2000a), 40 CFR 122, EPA Administrated Permit Programs: NPDES. http://www.access.gop.gov/nara/cfr/waisidx_00/40cfrv14_00.html

Code of Federal Regulations (2000b), 40 CFR 143, National Secondary Drinking Water Regulations.

http://www.epa.gov/safewater/regs/cfr143.pdf

Corson, Lynn (2001). INDOT Facilities Survey of POTW Discharges and Brine Making. Indiana Clean Manufacturing Technology and Safe Materials Institute (CMTI).

http://www.ecn.purdue.edu/CMTI/INDOT/

Corson, Lynn (2004). Calculation of Highway Mileage Between INDOT Facilities NOT Currently Connected to a POTW and the Three Nearest POTWs for Purposes of Estimating Costs of Pumping and Hauling Brine as an Alternative to Direct Discharge to a POTW, Indiana Clean Manufacturing Technology and Safe Materials Institute (CMTI). http://www.ecn.purdue.edu/CMTI/INDOT/

Dow Chemical Company (2000). Manual of Good Practice for Snow and Ice Control with Dow Calcium Chloride Products. Form No. 173-01638

Dow Chemical Company (2000). Calcium Chloride Handbook: A Guide to Properties, Forms, Storage, and Handling,. Form No. 173-01534-600XAMS.

Federal Highway Administration (FHWA) (2000) Winter Road Maintenance Products and Technologies, Publication No. FHWA-OP-00-012, Washington, D.C.

Federal Highway Administration (FHWA) (1996) Manual of Practice for an Effective Anti-icing Program: A Guide for Highway Winter Maintenance Personnel, Report No. FHWA-RD-95-202, Washington, D.C.

Federal Register (1998). Part III, Environmental Protection Agency. Announcement of the Drinking Water Contaminant Candidate List. Vol. 63, No. 40.

http://www.epa.gov/safewater/ccl/ccl_fr.pdf 
Gilfillan, Graham (1999). Road Safety Benefits of Liquid Anti-icing Strategies and Agents. Winter Road Research and Development, Insurance Corporation of British Columbia, Canada.

Gilfillan, Graham (2001). Environmental Impacts of New Technology in Winter Maintenance. Insurance Corporation of British Columbia.

Hyman, W. and Vary, D. (1999). Best Management Practices for Environmental Issues Related to Highway and Street Maintenance. Synthesis of Highway Practice, Series 272. National Academy Press, Washington D.C.

Illinois Department of Transportation (1998). Guidelines for Liquid Chemical Applications for Snow and Ice Control.

Indiana Administrative Code: Title 327 Water Pollution Control Board. http://www.state.in.us/legislative/iac/title327.html

Indiana Code: IC 13-11-2 http://www.in.gov/legislative/ic/code/title13/ar11/ch2.html

Indiana Department of Environmental Management (1998). Compliance Manual for Indiana's Vehicle Maintenance Shop. Compliance and Technical Assistance Program http://www.state.in.us/idem/ctap/vehicle/vmmanual/toc.html

Indiana Department of Environmental Management (2001). Office of Water Management, Wastewater Permit Program. http://www.state.in.us/idem/owm/npdes/guide/index.html

Indiana Department of Transportation (1998). INDOT Yards Survey, 1997-1998.

Indiana Department of Transportation (1998). Snow and Ice Chemicals - Pollution Control Guidelines. Field Operations Manual, Operating Procedure No. 22

Indiana Department of Transportation (2000) Winter material use by state, 1999-2000.

Indiana Nonpoint Source Task Force (1998). Findings of the Indiana Nonpoint Source Pollution Management Task Force, 1995-1998.

Interstate Commission on the Potomac River Basin (ICPRB) (2001). Anacostia River Toxics Management Action Plan. http://www.potomacriver.org/artmap.htm

Iowa Department of Transportation (1997). Hand-out-Iowa Winter Maintenance Expo, 1997

Leggett, Tim (2000) Cost Benefit Analysis of an Automatic Granular Reduction Device for Prewetted Solid Delivery. Wisconsin Department of Transportation.

Michigan Department of Environmental quality (1997). Salt and Brine Storage Manual.

Missouri Department of Transportation (1999). Mirror Mounted Pavement Sensors. Research, Development and Technology Division Quarterly, Vol.3, No.2 
National Climate Data Center (2001). Storm Events Database.

http://www4.ncdc.noaa.gov/cgi-win/wwcgi.dll?wwEvent Storms

National Weather Service Forecast Office at Northern Indiana (2001). Severe Weather Data Storm Data. http://www.crh.noaa.gov/iwx/program_areas/severe/stormdata/storm_data.html

URS (2003). 'Ohio Department of Transportation Storm Water Management Plan (2003): Authorization for Small Municipal Separate Storm Sewer Systems to Discharge Storm Water Under The National Pollutant Discharge Elimination System,' Small MS4 Plan Submitted to the Ohio Environmental Protection Agency, March 10, 2003, 70 pgs.

Paschka, M.G., Rajat S. G. and David A. D. (1999). Potential Water-Quality Effects form Iron Cyanide Anticaking Agents in Road Salt. Water Environment Research 71:6. pp. 1235-1239.

Salt Institute (1999a). The Snowfighter’s Handbook. Alexandria, Virginia.

Salt Institute (1999b). Highway Deicing and Anti-icing for Safety and Mobility. Alexandra, Virginia.

Smithson, L (1997). Winter Maintenance Technology and Practices — Learning from Abroad. Road Management and Engineering Journal, March 1997

Transportation Research Board (TRB) (1991). Highway Deicing: Comparing Salt and Calcium Magnesium Acetate. Special Report 235, National Research Council, Washington D.C

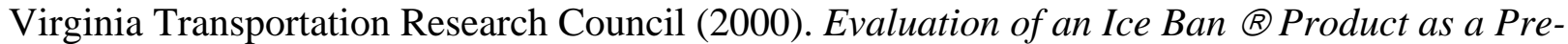
wetting Agent for Snow Removal and Ice Control Operations. (VTRC 00-R12).

U.S. EPA (2001a). Pollution Prevention Template "Vehicle Maintenance"

http://es.epa.gov/oeca/fedfac/cfa/templates/p2frame.html

U.S. EPA (2001b). Current Drinking Water Standards

http://www.epa.gov/safewater/mcl.html

Wisconsin Department of Transportation and County Highway Departments (WisDOT) (1999). Test and Evaluation of Pre-wetting of Sodium Chloride with Magnesium Chloride or Ice-Ban, 1997/1998 and 1998/1999 Winter Seasons. 
APPENDICES 
Appendix A: Contact List 


\section{INDOT SUB-DISTRICT}

$\begin{array}{llll}\text { Tom Konieczny } & \text { Operations Engineer } & \text { LaPorte } & 219-325-7560 \\ \text { Robert Binverse } & \text { Manager } & \text { LaPorte } & 219-325-7592 \\ \text { Michael Fraze } & \text { Operations Foreman } & \text { LaPorte } & 219-325-7591 \\ \text { Wayne Dittelberger } & \text { Engineer } & \text { Vincennes } & 812-882-8330 \text { ext. 314 } \\ \text { Steve Geise } & \text { Operations Foreman } & \text { Plymouth } & 574-936-4057 \\ \text { Mike Hardiman } & \text { Operations Foreman } & \text { Gary } & 219-939-3900 \\ \text { Tom Kasten } & \text { Operations Foreman } & \text { Winamac } & 574-936-4581 \\ \text { John McIntire } & \text { Operations Foreman } & \text { Monticello } & 574-583-4171 \\ \text { Sonja Heishman } & \text { Manager } & \text { Monticello } & 574-583-4171 \\ \text { John Myers } & \text { Foreman } & \text { Monticello } & 574-583-4171 \\ \text { Jim Miller } & \text { Foreman } & \text { Logansport } & 574-753-3592 \\ \text { Alan Lester } & \text { Foreman } & \text { Flora } & 574-967-3796\end{array}$

\section{INDOT DISTRICT OPERATIONS ENGINEERS}

Larry Vaughan

Todd Johnson

Eryn Hays

Tom Konieczny

Terry Byrns

Jerry Thompson

Sam Wolfe
Operations Engineer

Operations Engineer

Operations Engineer

Operations Engineer

Operations Engineer

Operations Engineer

Operations Engineer
Crawfordsville

Fort Wayne

Greenfield

LaPorte

Seymour

Vincennes

Toll Road
$765-361-5240$

260-969-8206

$317-467-3417$

219-325-7560

812-524-3708

812-895-7325

$574-651-2440$

\section{INDOT ENVIRONMENTAL \& RESEARCH STAFF}

Don Arnold

Dennis Belter

Tom Duncan

Barry Partridge
Environmental Manager

Management Support Manager

Operations Support Division

Environmental Service Manager

Chief, Research Division
317-233-1165

$317-232-5424$

$317-232-5512$

317-463-1521 ext. 215

\section{INDIANA DEPARTMENT OF ENVIRONMENTAL MANAGEMENT (IDEM)}

$\begin{array}{lll}\text { Martha Clark Mettler } & \text { Planning \& Restoration } & 317-232-8706 \\ \text { Bruno Pigott } & \text { Permits Branch } & 317-233-6725 \\ \text { Steve Roush } & \text { Industrial NPDES } & 317-232-8704 \\ \text { Catherine Hess } & \text { Municipal NPDES } & 317-232-8637\end{array}$

INDIANA FIRE PREVENTION AND BUILDING SAFETY COMMISSION

John Hibner

Building and Fire Code Specialist

317-232-1413

John Weesner

Fire Code Specialist

317-232-6312 


\section{NON-INDIANA DEPARTMENTS OF TRANSPORTATION}

Blair Ballou

Lynn Bernhard

Dennis Burkheimer

Kelly Moores

John Tarnowski
Engineer-Manager Eaton County

Road Commission, Michigan

Methods Engineer, Utah DOT

Winter Operations Administrator, Iowa DOT

Highway Maintenance, Iowa DOT

Maintenance Department, Minnesota DOT
$517-543-1630$

801-964-4597

515-239-1355

$515-225-3322$

651-297-1843

\section{OTHER CONTACT}

Bruce Bertam

Lynn Corson

Graham Gilfillan

Wilfrid Nixon
Technical Director, Salt Institute

703-549-4648

Director, Indiana Clean Manufacturing Technology and Safe Materials Institute (CMTI)

Manager, Materials Damage and

Lost Prevention, Insurance Corporation

of British Columbia, Canada

Professor, Civil and Environmental Engineering, 319-335-5166

University of Iowa

\section{VENDORS AND MANUFACTURES}

Sprague Controls Varitech Industries

Sprayer Specialities

SynTech Products

Ulrich Chemical

Dultmeier Sales

Pacer Pumps

Park Plastics Products

Rule Industries

KTH Sales

Grainger

Fisher Scientific

American Process

Technology

Biggs Plumbing
"RoadWatch” Pavement Temp. Sensor

Commercial Salt Brine System

Commercial Salt Brine System

Caliber Deicers

Dow Flake

Little Giant Sewage Sump Pump, Banjo Valves, Storage Tanks

Pacer Polyester Pump

Contractor for Gary Sub-District Brine System

Sump/Utility Pump

Sewage Sump Pump

NEMA Type I Enclosures

Hydrometers

Rectangular Polyethylene Tank

PVC Pipes, Fittings
1800-441-2048

320-834-2595

1800-351-1587

$1800-537-0288$

$317-898-8632$

1800-553-6975

1800-233-3861

219-459-1074

978-281-0440

219-736-0060

765-446-0423

1-800-766-7000

1-800-537-9444

765-447-1141 
Appendix B: Salt Brine Properties 
Appendix B.1: Eutectic Diagram of Sodium Chloride 


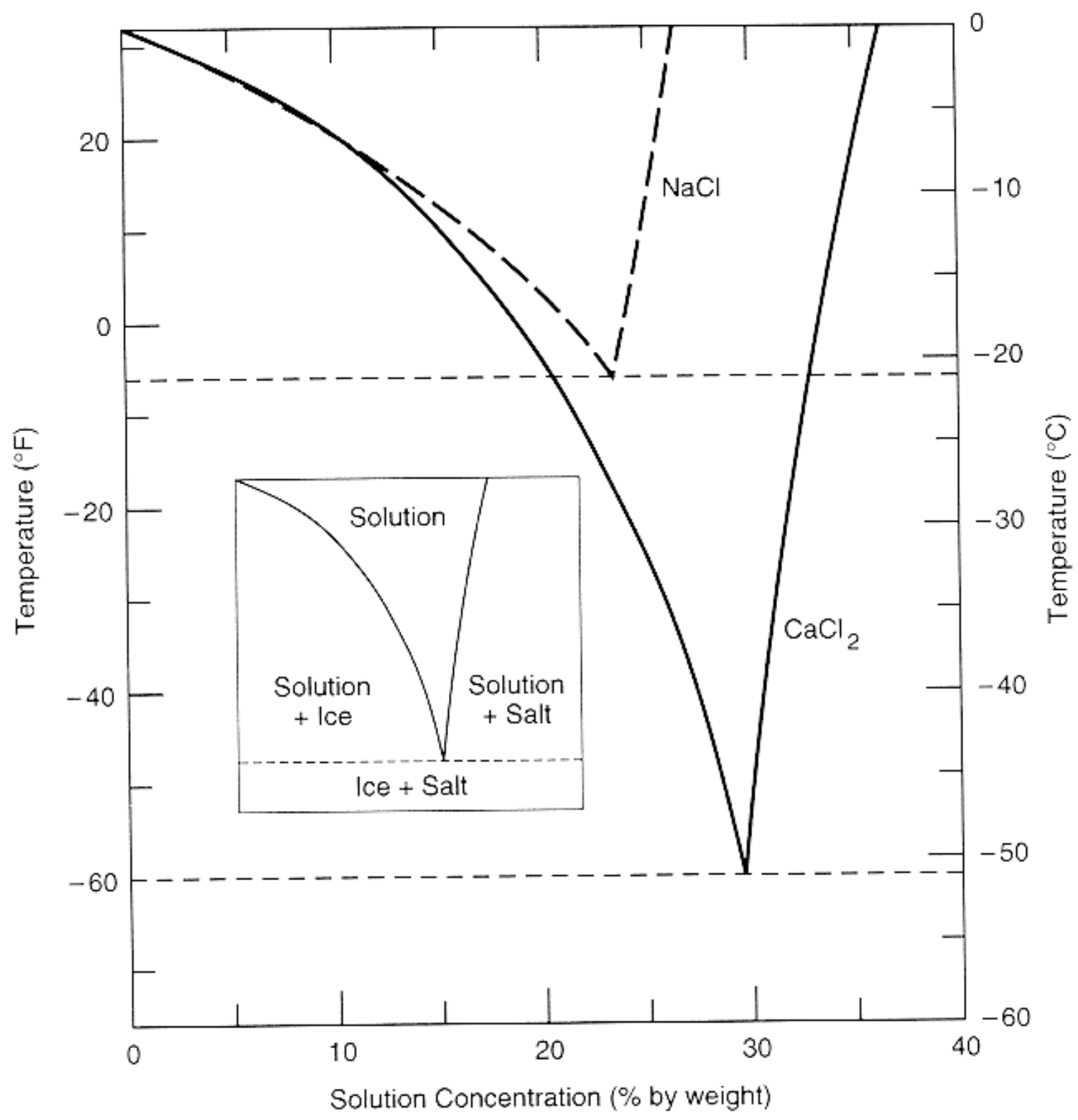


Appendix B.2: Hydrometer Readings and the Corresponding Salt Concentration for a Solution with Temperature of $15{ }^{\circ} \mathrm{C}\left(59^{\circ} \mathrm{F}\right)$. 
Pure salt concentration and corresponding specific gravity (measured by a hydrometer) at $15^{\circ} \mathrm{C}\left(59^{\circ} \mathrm{F}\right)$

\begin{tabular}{|c|c|c|c|}
\hline $\begin{array}{l}\text { Percent } \\
\text { salt }\end{array}$ & $\begin{array}{l}\text { Specific gravity } \\
\text { at } 15^{\circ} \mathrm{C}\left(59^{\circ} \mathrm{F}\right)\end{array}$ & $\begin{array}{l}\text { Percent of } \\
\text { saturation }\end{array}$ & $\begin{array}{l}\text { *Weight of salt } \\
\mathrm{kg} / \mathrm{m}^{3} \text { (lb/gal) }\end{array}$ \\
\hline 0 & 1.000 & 0 & $0(0)$ \\
\hline 5 & 1.035 & 20 & $51.8(0.432)$ \\
\hline 6 & 1.043 & 24 & $62.7(0.523)$ \\
\hline 7 & 1.050 & 28 & $73.5(0.613)$ \\
\hline 8 & 1.057 & 32 & $84.6(0.706)$ \\
\hline 9 & 1.065 & 36 & $95.9(0.800)$ \\
\hline 10 & 1.072 & 40 & $107.2(0.895)$ \\
\hline 11 & 1.080 & 44 & $118.9(0.992)$ \\
\hline 12 & 1.087 & 48 & $119.8(1.000)$ \\
\hline 13 & 1.095 & 52 & $131.8(1.100)$ \\
\hline 14 & 1.103 & 56 & $154.7(1.291)$ \\
\hline 15 & 1.111 & 60 & $166.8(1.392)$ \\
\hline 16 & 1.118 & 63 & $178.9(1.493)$ \\
\hline 17 & 1.126 & 67 & 191.5 (1.598) \\
\hline 18 & 1.134 & 71 & $204.3(1.705)$ \\
\hline 19 & 1.142 & 75 & $217.2(1.813)$ \\
\hline 20 & 1.150 & 79 & $230.1(1.920)$ \\
\hline 21 & 1.158 & 83 & $243.4(2.031)$ \\
\hline 22 & 1.166 & 87 & $256.8(2.143)$ \\
\hline 23 & 1.175 & 91 & $270.3(2.256)$ \\
\hline 24 & 1.183 & 95 & $284.1(2.371)$ \\
\hline 25 & 1.191 & 99 & $293.3(2.448)$ \\
\hline 26 & 1.200 & 100 & \\
\hline
\end{tabular}


Appendix B.3: 23\% Salt Brine Concentration Conversion Chart 
Original Concentration

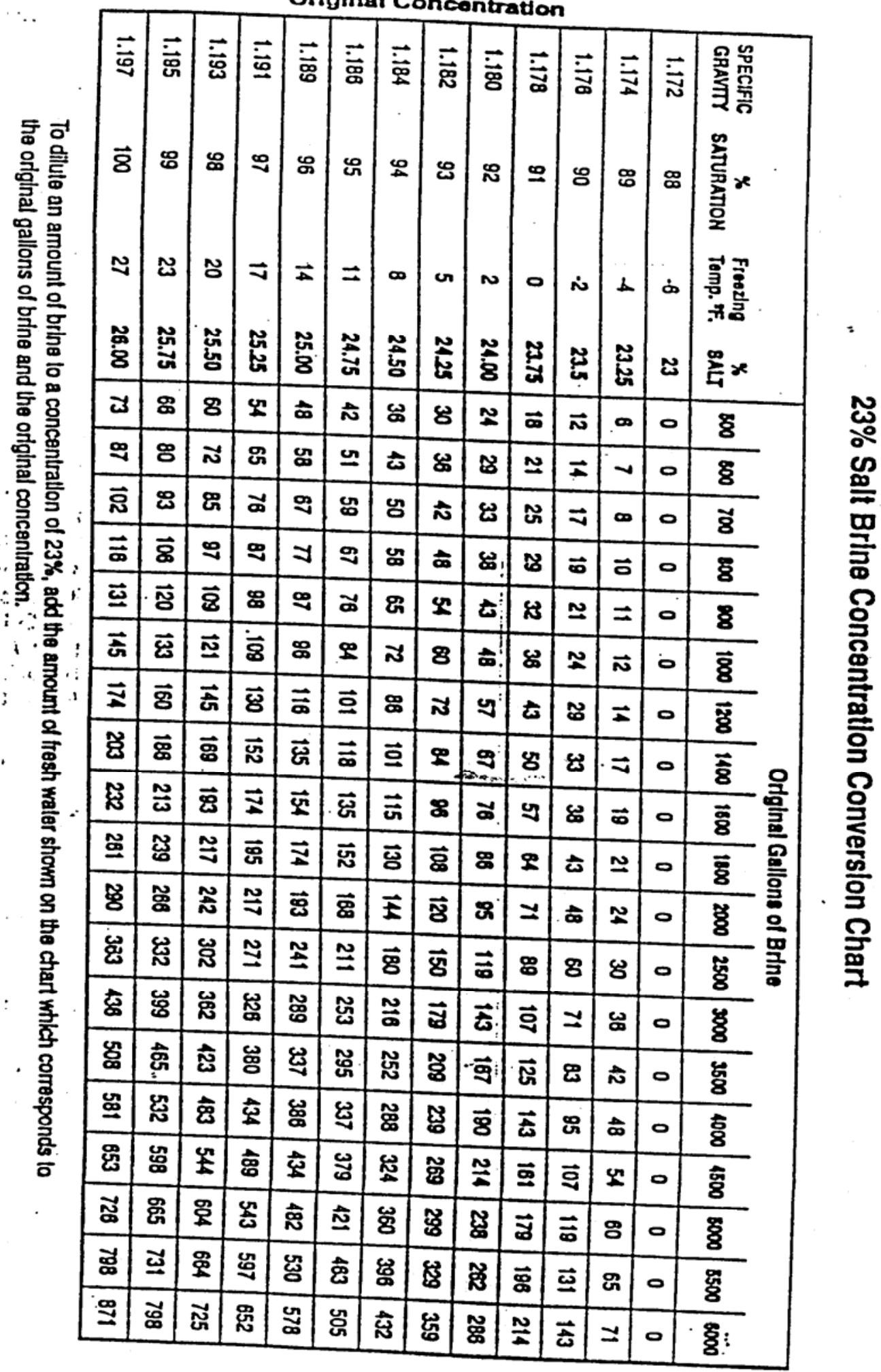




\section{Appendix C: Water Quality Data for the Truck Washing Facility Located in Greenfield, IN}




\section{WATER QUALITY DATA FOR ROAD SALT TRUCK WASHING FACILITIES LOCATED AT GREENFIELD, INDIANA}

\begin{tabular}{|c|c|c|c|c|c|c|}
\hline $\begin{array}{c}\text { Sample Collection } \\
\text { Date }\end{array}$ & Location & $\begin{array}{c}\text { TSS } \\
(\mathrm{mg} / \mathrm{l})\end{array}$ & \begin{tabular}{|c|} 
Chloride \\
$(\mathrm{mg} / \mathrm{l})$
\end{tabular} & $\begin{array}{l}\text { BOD5 } \\
(\mathrm{mg} / \mathrm{l})\end{array}$ & \begin{tabular}{c|}
$\mathrm{pH}$ \\
\\
(Std. \\
Units) \\
\end{tabular} & $\begin{array}{l}\text { Oil and } \\
\text { Grease } \\
(\mathrm{mg} / \mathrm{l})\end{array}$ \\
\hline 1/20/99 & Greenfield 636031 & 2,360 & 79,000 & 21 & 7.4 & -- \\
\hline 1/19/99 & Greenfield 633041 & 137 & 4,200 & 9.1 & 7.5 & -- \\
\hline 1/19/99 & Greenfield 632032 & 259 & 12,400 & $<6.7$ & 7.3 & -- \\
\hline 1/19/99 & Greenfield 632031 & 1,834 & -- & 25 & 7 & -- \\
\hline 1/19/99 & Greenfield 631031 & -- & 22,300 & 17 & 7.6 & -- \\
\hline 1/19/99 & Greenfield 633011 & 673 & 31,800 & 22 & 7.3 & -- \\
\hline $1 / 15 / 99$ & Greenfield 633031 & 348 & 315 & 3.4 & 7.8 & -- \\
\hline $1 / 15 / 99$ & Greenfield 636021 & 1,136 & 24,800 & 9.4 & 7.5 & -- \\
\hline $1 / 15 / 99$ & Greenfield 631011 & -- & 6,600 & 4.3 & 7.6 & -- \\
\hline $1 / 15 / 99$ & Greenfield 635031 & 128 & -- & -- & 7.8 & -- \\
\hline 2/16/99 & Greenfield 63104 & 390 & 27,500 & 110 & 7.3 & 218 \\
\hline 2/17/99 & Greenfield 63301 & 3,110 & 42,900 & 45 & 7.6 & 103 \\
\hline 2/17/99 & Greenfield 63303 & 140 & 42,000 & 24 & 7.8 & 13 \\
\hline 2/25/99 & Greenfield 63605 & 960 & -- & 10 & 6.9 & 25 \\
\hline 2/25/99 & Greenfield 63501 & 616 & 47,500 & 4.8 & 7.4 & 12 \\
\hline 2/24/99 & Greenfield 63604 & 4,170 & 8,400 & 34 & 7.1 & 25 \\
\hline 2/24/99 & Greenfield 63601 & 4,970 & 24,600 & 26 & 7.6 & 75 \\
\hline 2/15/99 & Greenfield 63502 & 3,230 & 47,000 & 40 & 7.4 & 47 \\
\hline 2/15/99 & Greenfield 63100 - 3 & -- & -- & -- & 7.2 & -- \\
\hline 3/8/99 & Greenfield 63102 - 1 & 111 & 31,300 & 4.8 & 7 & 4 \\
\hline 3/8/99 & Greenfield 63102 - 2 & 118 & 20,100 & 6.4 & 7.1 & -- \\
\hline 3/8/99 & Greenfield 63204 - 1 & 126 & 20,600 & 9.7 & 6.9 & 9 \\
\hline 3/8/99 & Greenfield 63204 - 2 & 424 & 10,800 & 93 & 7 & 80 \\
\hline 3/12/99 & Greenfield 635-01-1 & -- & 4,100 & -- & 7.4 & -- \\
\hline 3/12/99 & Greenfield 635-01-2 & 370 & 4,100 & -- & 7.5 & -- \\
\hline 3/12/99 & Greenfield 635-02-1 & 1,410 & 31,300 & 18 & 7.6 & 86 \\
\hline 3/12/99 & Greenfield 635-02-2 & 528 & 24,000 & 31 & 7.7 & 84 \\
\hline \multicolumn{2}{|l|}{ Average } & 1,198 & 24,679 & 25.8 & 7.4 & 60 \\
\hline
\end{tabular}


Appendix D: Flow Meter Data for the INDOT Bluffton Truck Washing Facility 
Flow Meter Data for the INDOT Bluffton Truck Washing Facility

\begin{tabular}{|c|l|l|c|}
\hline Month & $\begin{array}{l}\text { Flow } \\
\text { (gal) }\end{array}$ & $\begin{array}{l}\text { Cumulative flow } \\
\text { (gal) }\end{array}$ & $\begin{array}{r}\text { Flow } \\
\text { (gpd) }\end{array}$ \\
\hline Apr-98 & 2430 & 2430 & 81 \\
May-98 & 1,176 & 3,606 & 39 \\
Jun-98 & 1,463 & 5,069 & 49 \\
Jul-98 & 1,076 & 6,145 & 36 \\
Aug-98 & 11,280 & 17,425 & 376 \\
Sep-98 & 2,389 & 19,814 & 80 \\
Oct-98 & 1,935 & 21,749 & 65 \\
Nov-98 & 10,619 & 32,368 & 354 \\
Dec-98 & 5,220 & 37,588 & 174 \\
Jan-99 & 45,536 & 83,124 & 1,518 \\
Feb-99 & 5,955 & 89,079 & 199 \\
Mar-99 & 24,879 & 113,958 & 829 \\
Apr-99 & 3,690 & 117,648 & 123 \\
\hline Sum: & 117,648 & Average: & 302 \\
\hline
\end{tabular}




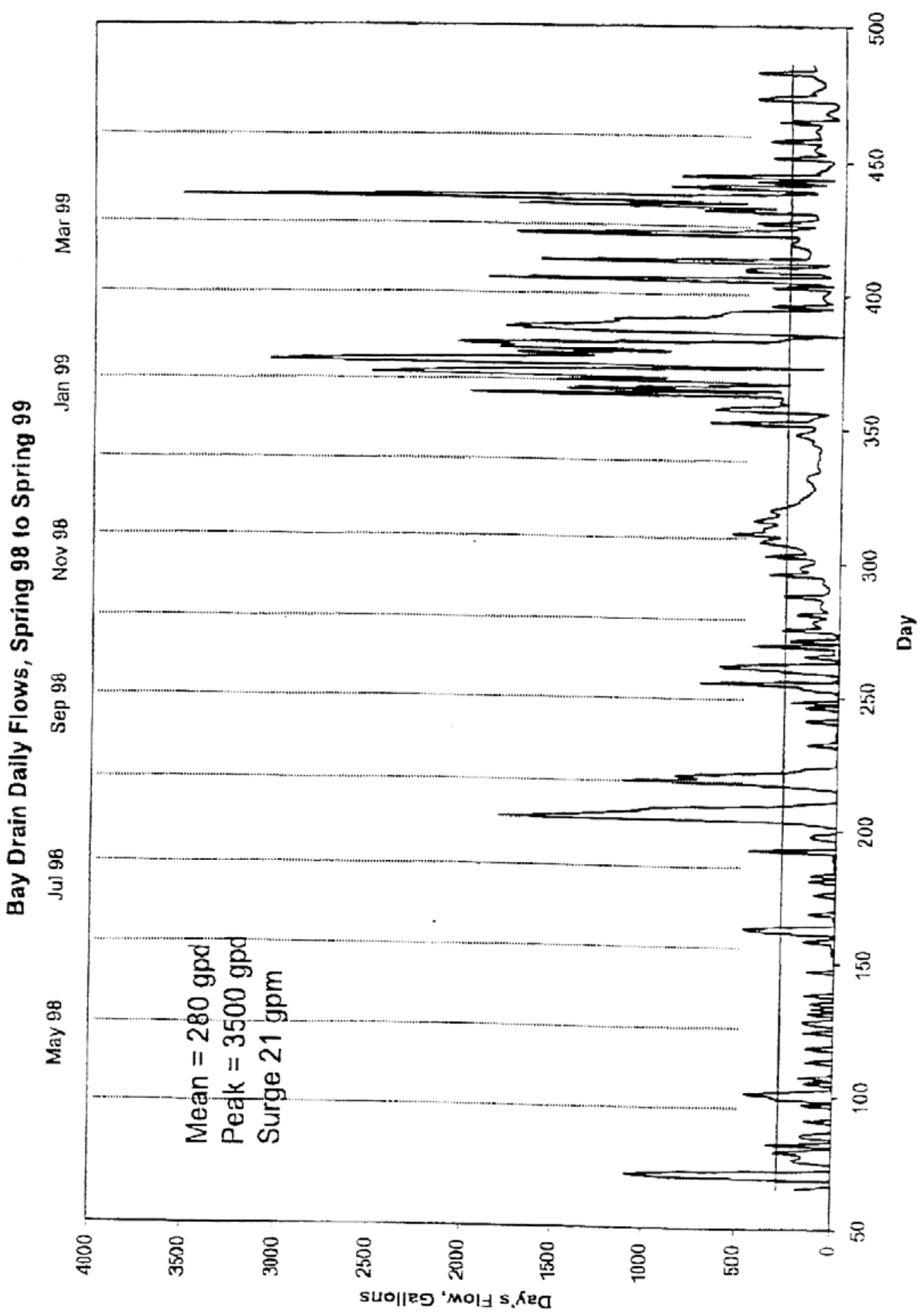




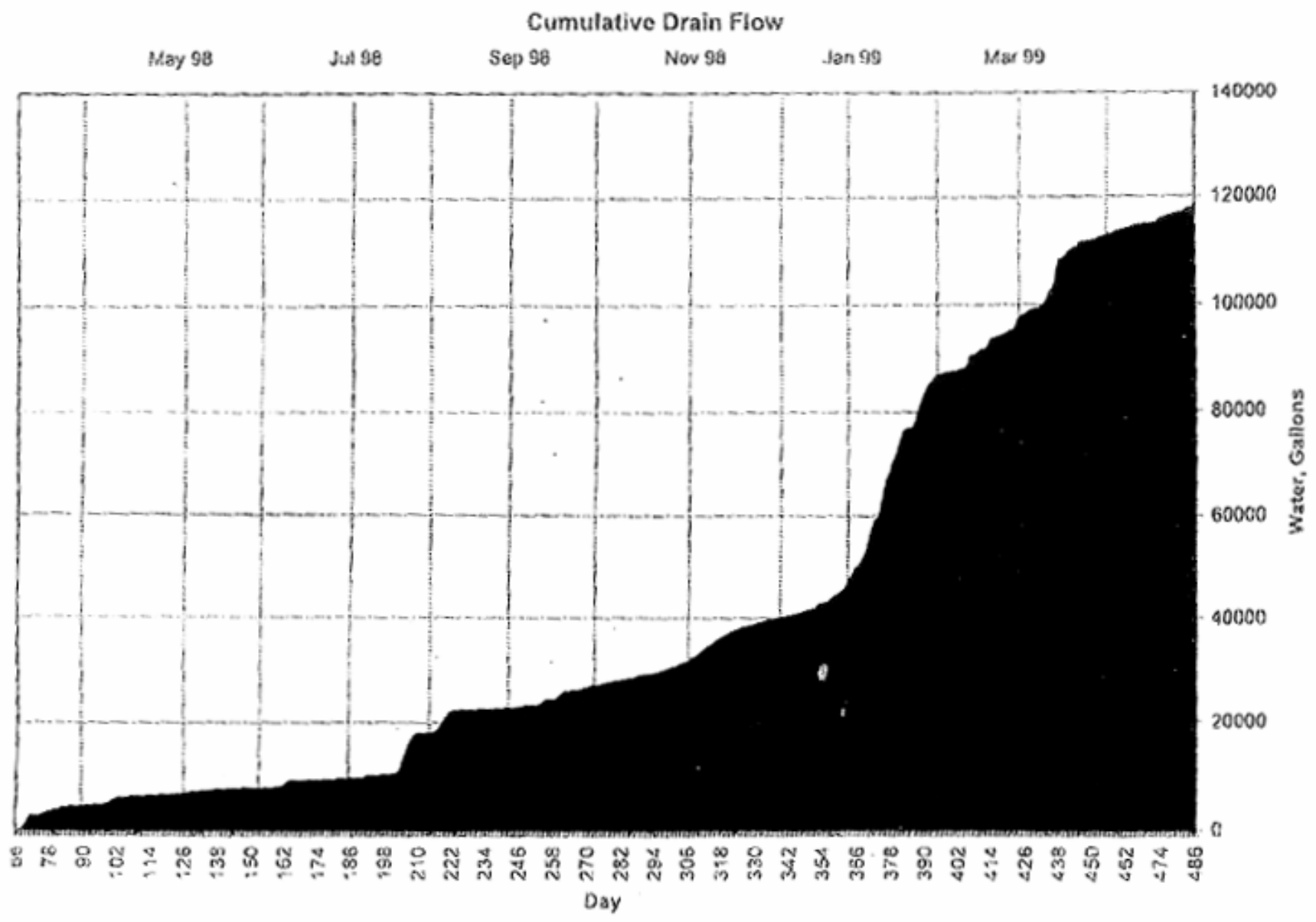

INDOT Operations Support FAX: 317-232-5551 / 14 May '99 / 15:11 / P. 02 
Appendix E: Brine Making Procedure with Do-it-yourself Brine Manufacturing System at Monticello, IN 

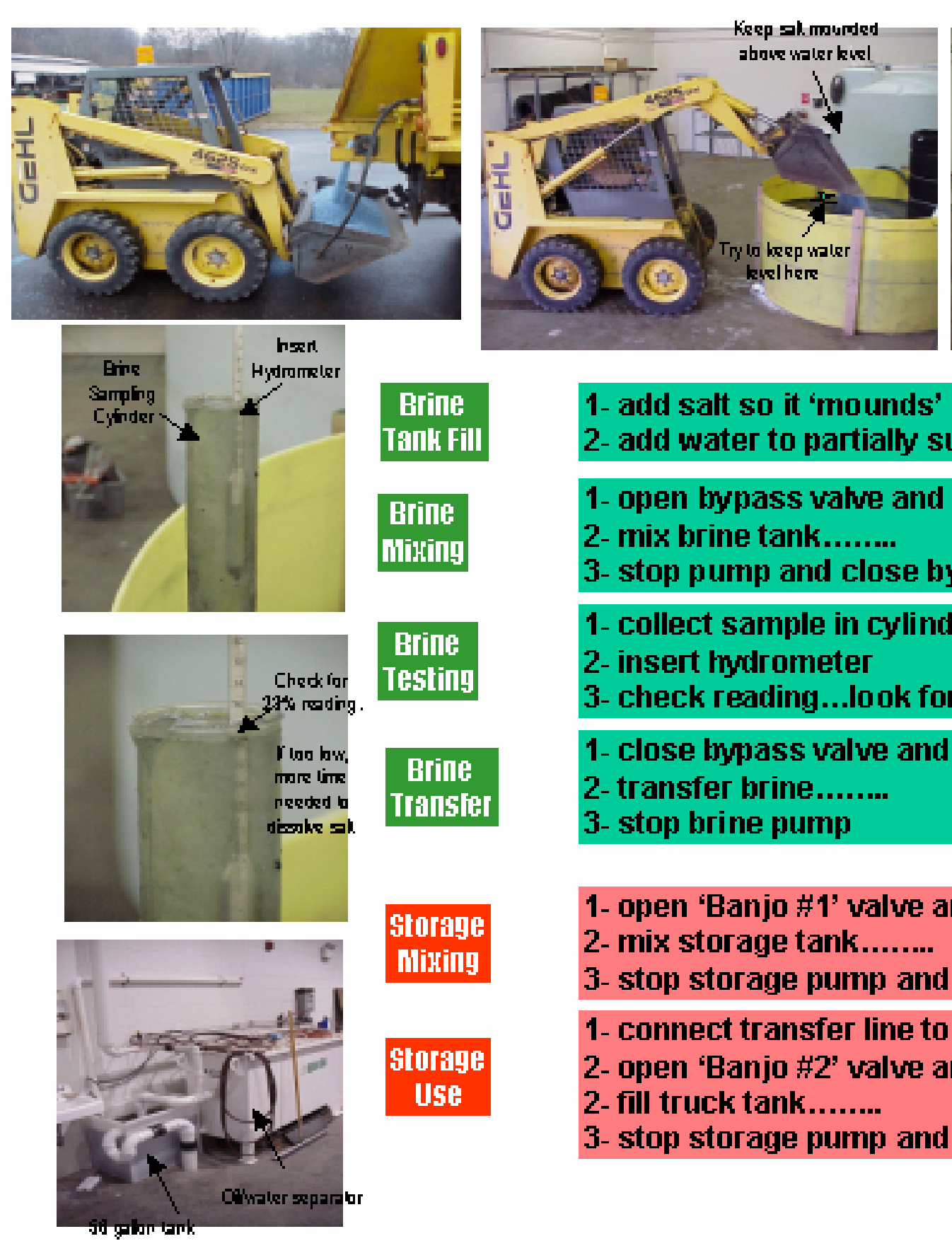

Brine

Iank Fill

\section{Brine}

niking

1- add salt so it 'mounds' inside tank

2- add water to partially submerge mound

1- open bypass value and start brine pump

2- mix brine tank.

3- stop pump and close bypass valve

1- collect sample in cylinder

2- insert mydrometer

3- check reading...look for '23'!!

1- close bypass valve and start brine pump

2- transfer brine........

3- stop brine pump

\section{storige} niking

storage

Use
1- open 'Banjo \#1' valve and start storage pump

2- mix storage tank.........

3- stop storage pump and close 'Banjo \#1' valve

1- connect transfer line to truck fitting

2- open 'Banjo \#2' valve and start storage pump

2- fill truck tank.........

3- stop storage pump and close 'Banjo \#2' valve
On-gil suinges Top - Gine pump

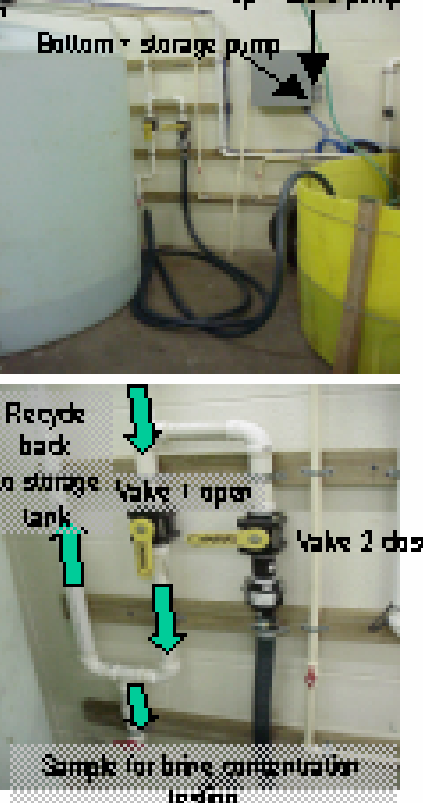

Bampk for bine oprixnteitur

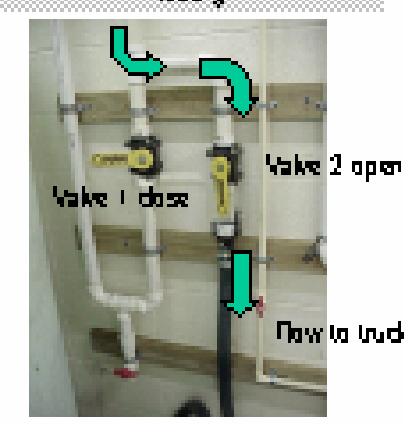

Selling in

Ing ni

Indkank

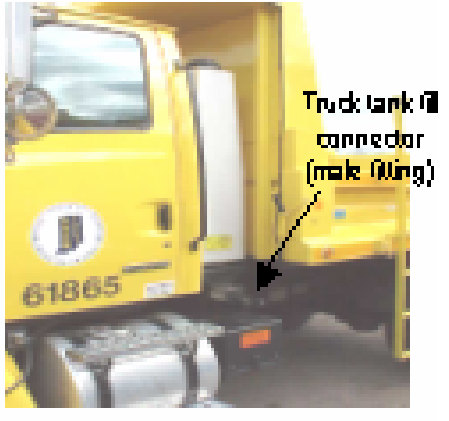


Appendix F: Laboratory Results for Water Samples Taken from Monticello and LaPorte, IN 
CERTIF I CATE OF ANALYSIS

\begin{tabular}{|c|c|c|c|c|}
\hline \multirow{3}{*}{$\begin{array}{l}\text { Service Location } \\
\text { HERITAGE ENVIRONMENTAL SERVICES, LLC } \\
\text { COMMERCIAL LABORATORY OPERATIONS } \\
\text { 7901 W. MORRIS ST. } \\
\text { INDIANAPOLIS, IN } 46231 \\
(317) 243-8304\end{array}$} & & \multirow{2}{*}{\begin{tabular}{|c|} 
Received \\
$10-A P R-01$ \\
Complete \\
$17-A P R-01$ \\
\end{tabular}} & Project & $\begin{array}{c}\text { Lab ID } \\
\text { A549662 }\end{array}$ \\
\hline & & & \multicolumn{2}{|c|}{ PO Number } \\
\hline & & $\begin{array}{l}\text { Printed } \\
18-A P R-01\end{array}$ & \multicolumn{2}{|c|}{$\begin{array}{c}\text { Sampled } \\
09-A P R-01 \quad 09: 00\end{array}$} \\
\hline Report To & \multicolumn{4}{|c|}{ Bill To } \\
\hline $\begin{array}{l}\text { LEE YEUNG } \\
\text { PURDUE UNIVERSITY } \\
\text { SCHOOL OF CIVIL ENGINEERING } \\
1284 \text { CIVIL ENGINEERING BUILDING } \\
\text { WEST LAFAYETTE, IN } 47907-1284\end{array}$ & \multicolumn{4}{|c|}{$\begin{array}{l}\text { ACCOUNTS PAYABLE } \\
\text { PURDUE UNIVERSITY } \\
\text { FREH } \\
\text { BUSINESS OFFICE } \\
\text { WEST LAFAYETTE, IN } 47907\end{array}$} \\
\hline \multicolumn{5}{|c|}{ Sample Description } \\
\hline $\begin{array}{l}\text { CHEMICAL OXYGEN DEMAND (COLORIMETRIC) EPA } 410 . \\
\text { Analyst: } E \text {. SotKIEwICZ }\end{array}$ & & & Test: 6301 & $\begin{array}{l}\text { NELAC: } Y \\
.1 .0\end{array}$ \\
\hline $\begin{array}{l}\text { Parameter } \\
\text { CHEMICAL OXYGEN DEMAND }\end{array}$ & $14000^{\text {Result }}$ & & \begin{tabular}{r|r} 
Det. Limit \\
1000 \\
\end{tabular} & $\begin{array}{l}\text { Units } \\
\mathrm{mg} / \mathrm{L}\end{array}$ \\
\hline 1:100 DILUTION & & & & \\
\hline $\begin{array}{l}\text { BIOCHEMICAL OXYGEN DEMAND EPA } 405.1 \\
\text { Analyst: L. STUBBLEFIELD } \\
\text { Analysis Date: } 11 \text {-APR-01 13:45 }\end{array}$ & & & Test: 6801 & $\begin{array}{l}\text { NELAC: }: Y \\
.4 .0\end{array}$ \\
\hline $\begin{array}{c}\text { Parameter } \\
\text { BIOCHEMICAL OXYGEN DEMAND }\end{array}$ & Result & & \begin{tabular}{r|r} 
Det. Limit \\
\end{tabular} & $\begin{array}{l}\text { Units } \\
\mathrm{mg} / \mathrm{L}\end{array}$ \\
\hline The CCV is biased low. & & & & \\
\hline $\begin{array}{l}\text { HEXANE OIL AND GREASE (SOLID PHASE EXTRACTION) } \\
\text { Analyst: E. SOTKIENICZ }\end{array}$ & EPA 1664 A & & Test: 6166 & $\begin{array}{l}\text { NELAC:N } \\
.0 .0\end{array}$ \\
\hline $\begin{array}{c}\text { Parameter } \\
\text { HEXANE EXTRACTABLE MATERIAL ( OIL AND GREASE }\end{array}$ & BDL Result & & \begin{tabular}{r|r} 
Det. Limit \\
5.0
\end{tabular} & $\begin{array}{l}\text { Units } \\
\mathrm{mg} / \mathrm{L}\end{array}$ \\
\hline $\begin{array}{l}\text { BDL Below Detection Limit } \\
\text { Sample was received on ice at temperature } 10.7 \\
\text { All aqueous samples are reported on a wet weig } \\
\text { Sample chain of custody number } 104319 \text {. } \\
\text { This Certificate shall not be reproduced, exce } \\
\text { without the written approval of the lab. } \\
\text { The sample results relate only to the analytes } \\
\text { or to the sample as received by the lab. } \\
\text { Heritage Environmental Services, LLC certifies }\end{array}$ & $\begin{array}{l}\text { C. } \\
\text { ht basis unl } \\
\text { of in full, } \\
\text { that the te }\end{array}$ & $\begin{array}{l}\text { ested } \\
\text { results }\end{array}$ & se noted. & \\
\hline
\end{tabular}


C ERT I F I C A T E OF ANALYSIS

\begin{tabular}{|c|c|c|c|c|}
\hline \multirow{3}{*}{$\begin{array}{l}\text { Service Location } \\
\text { HERITAGE ENVIRONMENTAL SERVICES, LLC } \\
\text { COMMERCIAL LABORATORY OPERATIONS } \\
\text { 7901 W. MORRIS ST. } \\
\text { INDIANAPOLIS, IN } 46231 \\
\text { (317)243-8304 }\end{array}$} & & $\begin{array}{l}\text { Received } \\
10-A P R-01\end{array}$ & Project & $\begin{array}{c}\text { Lab ID } \\
\text { A549665 }\end{array}$ \\
\hline & & $\begin{array}{l}\text { Complete } \\
17-A P R-01\end{array}$ & \multicolumn{2}{|c|}{ PO Number } \\
\hline & & $\begin{array}{l}\text { Printed } \\
18-A P R-01\end{array}$ & \multicolumn{2}{|c|}{$\begin{array}{c}\text { Sampled } \\
\text { 09-APR-01 09:00 }\end{array}$} \\
\hline Report To & \multicolumn{4}{|c|}{ Bill To } \\
\hline $\begin{array}{l}\text { LEE YEUNG } \\
\text { PURDUE UNIVERSITY } \\
\text { SCHOOL OF CIVIL ENGINEERING } \\
1284 \text { CIVIL ENGINEERING BUILDING } \\
\text { WEST LAFAYETTE, IN } 47907-1284\end{array}$ & \multicolumn{4}{|c|}{$\begin{array}{l}\text { ACCOUNTS PAYABLE } \\
\text { PURDUE UNIVERSITY } \\
\text { FREH } \\
\text { BUSINESS OFFICE } \\
\text { WEST LAFAYETTE, IN } 47907\end{array}$} \\
\hline \multicolumn{5}{|c|}{$\begin{array}{l}\text { CLIENT ID: MONTICELLO UNDERGROUND ST } \\
\text { MATRIX TYPE: NON-SPECIFIC WATER } \\
\text { PROJECT: INDOT YARDS MANAGEMENT(SALT) } \\
\text { Submitter Code : } 7992\end{array}$} \\
\hline
\end{tabular}

\begin{tabular}{|c|c|c|c|}
\hline $\begin{array}{l}\text { CHEMICAL OXYGEN DEMAND (C } \\
\text { Analyst: E. SOTKIEWICZ }\end{array}$ & & Test: 630 & $\begin{array}{l}\text { NELAC: }: \\
.1 .0\end{array}$ \\
\hline $\begin{array}{c}\text { Parameter } \\
\text { CHEMICAL OXYGEN DEMAND }\end{array}$ & $1500^{\text {Result }}$ & $\begin{array}{r}\text { Det. Limit } \\
100\end{array}$ & $\begin{array}{l}\text { Units } \\
\mathrm{mg} / \mathrm{L}\end{array}$ \\
\hline
\end{tabular}

\begin{tabular}{|c|c|c|c|}
\hline \multicolumn{2}{|l|}{$\begin{array}{l}\text { BIOCHEMICAL OXYGEN DEMAND EPA } 405.1 \\
\text { Analyst: L. STUBBLEFIELD } \\
\text { Analysis Date: } 11 \text {-APR-01 04:12 }\end{array}$} & \multicolumn{2}{|c|}{$\begin{array}{l}\text { NELAC: }: \text { } \\
\text { test: } 6801.4 .0\end{array}$} \\
\hline $\begin{array}{c}\text { Parameter } \\
\text { BIOCHEMICAL OXYGEN DEMAND }\end{array}$ & Result & Det. Limit 2 & $\begin{array}{l}\text { Units } \\
\mathrm{mg} / \mathrm{L}\end{array}$ \\
\hline
\end{tabular}

\begin{tabular}{|c|c|c|c|}
\hline $\begin{array}{l}\text { HEXANE OIL AND GREASE (SOLID PHASE EXTRACTION } \\
\text { Analyst: } E \text {. SOTKIEWICZ }\end{array}$ & EPA $1664 A$ & Test: 616 & $\begin{array}{l}\text { NELAC:N } \\
.0 .0\end{array}$ \\
\hline $\begin{array}{l}\text { Parameter } \\
\text { HEXANE EXTRACTABLE MATERIAL ( OIL AND GREASE }\end{array}$ & Result & $\begin{array}{r}\text { Det. Limit } \\
5.0\end{array}$ & $\begin{array}{l}\text { Units } \\
\mathrm{mg} / \mathrm{L}\end{array}$ \\
\hline
\end{tabular}

\footnotetext{
Sample corments

Sample was received on ice at temperature $10.7 \mathrm{C}$.

Al1 aqueous samples are reported on a wet weight basis unless otherwise noted.

Sample chain of custody number 104319.

This Certificate shall not be reproduced, except in full, without the written approval of the $7 \mathrm{ab}$.

The sample results relate only to the analytes of interest tested or to the sample as received by the lab.

Heritage Environmental Services, LLC certifies that the test results indicated as NELAC (National Environmental Laboratory Accreditation Conference) accredited (Yes for NELAC) meet all requirements of NELAC and
} 
C ERT I F I C A T E OF A N A L Y S I S

\begin{tabular}{|c|c|c|c|c|}
\hline \multirow{3}{*}{$\begin{array}{l}\text { Service Location } \\
\text { HERITAGE ENVIRONMENTAL SERVICES, LLC } \\
\text { COMMERCIAL LABORATORY OPERATIONS } \\
\text { 7901 W. MORRIS ST. } \\
\text { INDIANAPOLIS, IN } 46231 \\
(317) 243-8304\end{array}$} & & $\begin{array}{l}\text { Received } \\
10-A P R-01\end{array}$ & Project & $\begin{array}{c}\text { Lab ID } \\
\text { A549666 }\end{array}$ \\
\hline & & $\begin{array}{l}\text { Complete } \\
17-A P R-01\end{array}$ & \multicolumn{2}{|c|}{ PO Number } \\
\hline & & $\begin{array}{l}\text { Printed } \\
18-A P R-01\end{array}$ & \multicolumn{2}{|c|}{$\begin{array}{c}\text { Sampled } \\
\text { 09-APR-01 09:00 }\end{array}$} \\
\hline Report To & \multicolumn{4}{|c|}{ Bill To } \\
\hline $\begin{array}{l}\text { LEE YEUNG } \\
\text { PURDUE UNIVERSITY } \\
\text { SCHOOL OF CIVIL ENGINEERING } \\
1284 \text { CIVIL ENGINEERING BUILDING } \\
\text { WEST LAFAYETTE, IN } 47907-1284\end{array}$ & \multicolumn{4}{|c|}{$\begin{array}{l}\text { ACCOUNTS PAYABLE } \\
\text { PURDUE UNIVERSITY } \\
\text { FREH } \\
\text { BUSINESS OFFICE } \\
\text { WEST LAFAYETTE, IN } 47907\end{array}$} \\
\hline \multicolumn{5}{|c|}{$\begin{array}{l}\text { CLIENT ID: MONTICELLO 0/W SEPARATOR } \\
\text { MATRIX TYPE: NON-SPECIFIC WATER } \\
\text { PROJECT: INDOT YARDS MANAGEMENT(SALT) } \\
\text { Submitter Code :7992 }\end{array}$} \\
\hline
\end{tabular}

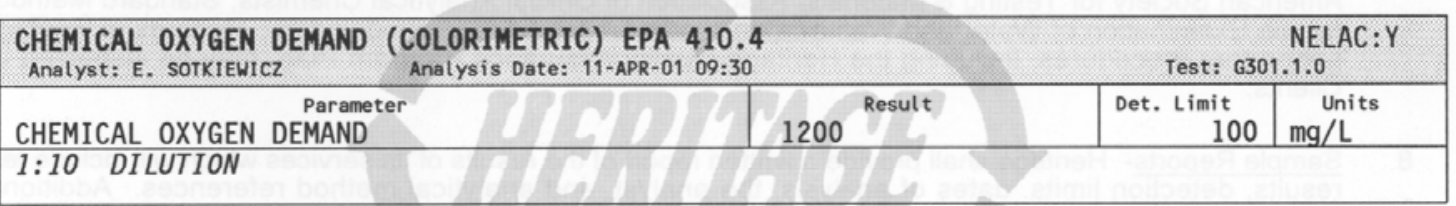

\begin{tabular}{|c|c|c|c|}
\hline $\begin{array}{l}\text { BIOCHEMICAL OXYGEN DEMAND EPA } 405.1 \\
\text { Analyst: L. STUBBLEFIELD } \\
\text { Analysis Date: } 11 \text {-APR-01 }\end{array}$ & & rest: 680 & $\begin{array}{l}\text { NELAC: } Y \text { Y } \\
1.4 .0\end{array}$ \\
\hline $\begin{array}{l}\text { Parameter } \\
\text { BIOCHEMICAL OXYGEN DEMAND }\end{array}$ & 12 Result & Det. Limit 2 & $\begin{array}{l}\text { Units } \\
\mathrm{mg} / \mathrm{L}\end{array}$ \\
\hline
\end{tabular}

\begin{tabular}{|c|c|c|c|}
\hline $\begin{array}{l}\text { HEXANE OIL AND GREASE (SOLID PHASE EXTRACTION } \\
\text { Analyst: E. SOTKIEwICZ }\end{array}$ & EPA 1664 A & Test: 616 & $\begin{array}{l}\text { NELAC }: N \\
5.0 .0\end{array}$ \\
\hline $\begin{array}{l}\text { Parameter } \\
\text { HEXANE EXTRACTABLE MATERIAL ( OIL AND GREASE }\end{array}$ & Result & $\begin{array}{l}\text { Det. Limit } \\
5.0\end{array}$ & $\begin{array}{l}\text { Units } \\
\mathrm{mg} / \mathrm{L}\end{array}$ \\
\hline
\end{tabular}

Sample was received on ice at temperature $10.7 \mathrm{C}$

All aqueous samples are reported on a wet weight basis unless otherwise noted.

Sample chain of custody number 104319.

This Certificate shall not be reproduced, except in full, without the written approval of the lab.

The sample results relate only to the analytes of interest tested or to the sample as received by the lab.

Heritage Environmental Services, LLC certifies that the test results

indicated as NELAC (National Environmental Laboratory Accreditation

Conference) accredited (Yes for NELAC) meet all requirements of NELAC and 
CERTIFICATE OF ANALYSIS

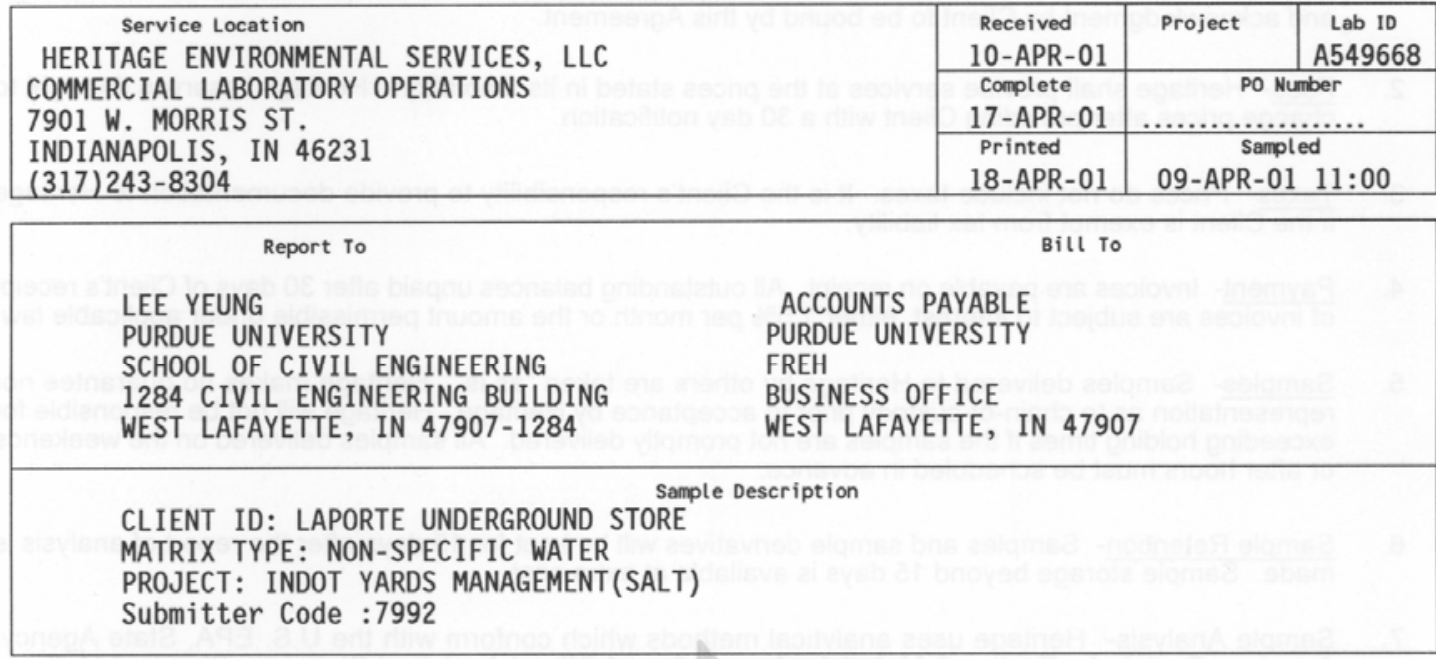

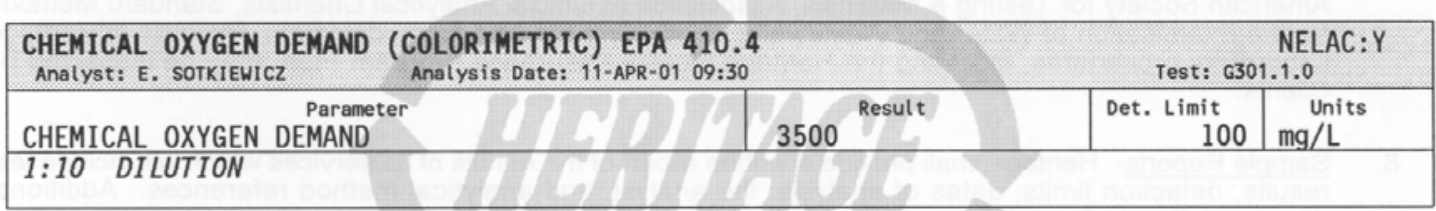

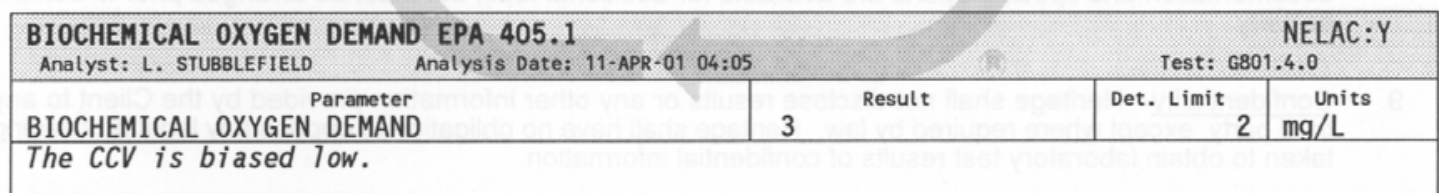

\begin{tabular}{|c|c|c|c|}
\hline $\begin{array}{l}\text { HEXANE OIL AND GREASE (SOLID PHASE EXTRACTION) } \\
\text { Anatyst: E. SOTKIEHICz }\end{array}$ & EPA 1664 A & Test: 616 & $\begin{array}{l}\text { NELAC:N } \\
.0 .0\end{array}$ \\
\hline $\begin{array}{l}\text { Parameter } \\
\text { HEXANE EXTRACTABLE MATERIAL (OIL AND GREASE }\end{array}$ & $\mathrm{BDL}$ Result & $\begin{array}{l}\text { Det. Limit } \\
5.0\end{array}$ & $\begin{array}{l}\text { Units } \\
\mathrm{mg} / \mathrm{L}\end{array}$ \\
\hline
\end{tabular}

UNPRESERVED SAMPLE WAS SPLIT AND PRESERVED WITH H2SO4 UPON RECEIPT 4-10-01.

BDL Below Detection Limit

Sample was received on ice at temperature $10.7 \mathrm{C}$.

All aqueous samples are reported on a wet weight basis unless otherwise noted.

Sample chain of custody number 104319.

This Certificate shall not be reproduced, except in full, without the written approval of the lab.

The sample results relate only to the analytes of interest tested 
C ERTIF I C A TE OF ANALYSIS

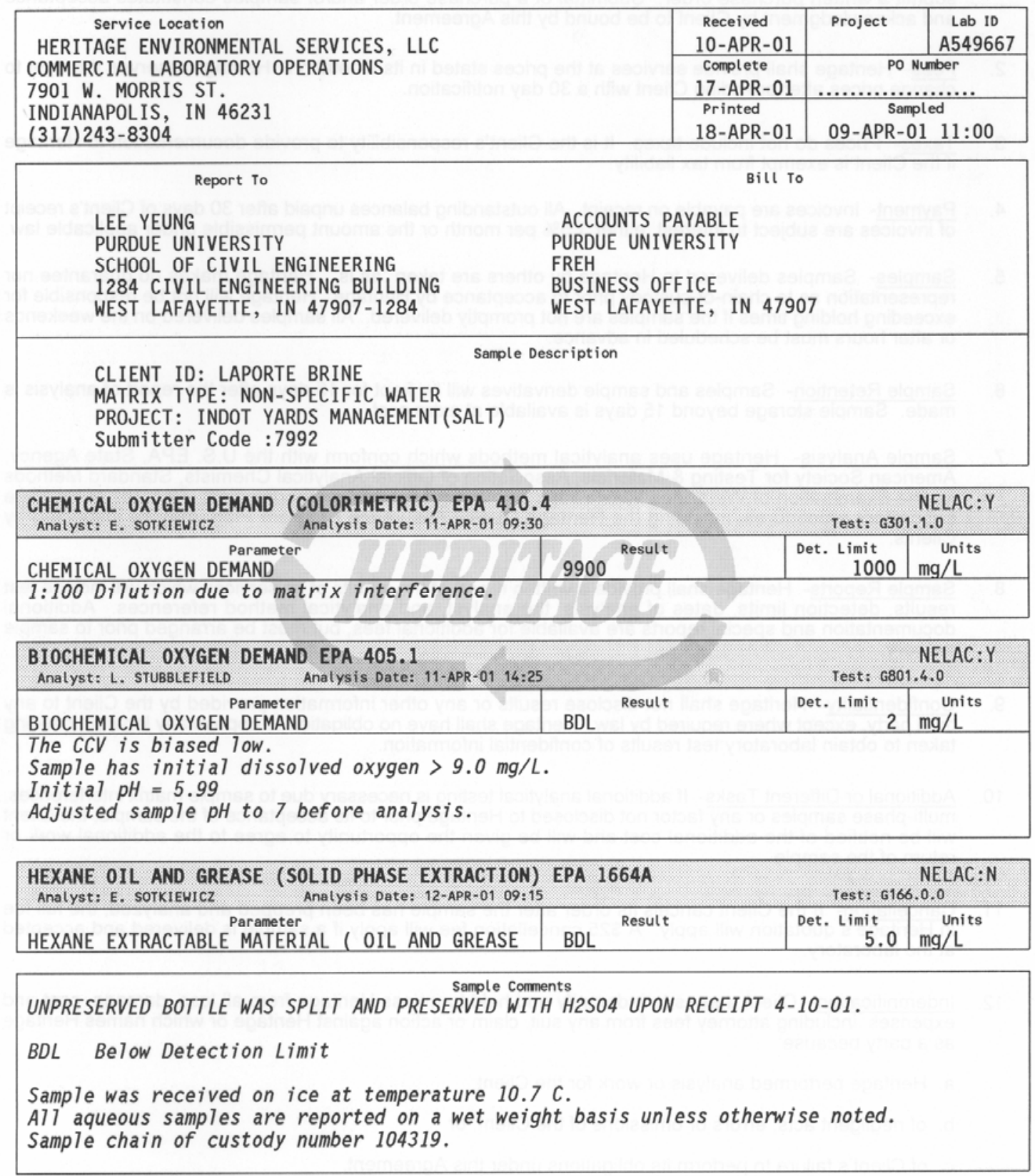


Appendix G: INDOT Operating Procedure No. 22 


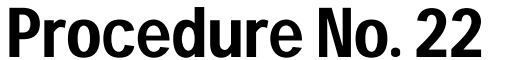

Field Operations Manual, Operating Procedure

December 1988, Revised July 1998

Snow And Ice Chemicals -Pollution Control Guidelines Statement of Problem

The Indiana Department of Transportation (INDOT) has experienced an increasing number of incidents involving salt pollution. In varying degrees, private properties and ground waters located adjacent to salt storage facilities and salt/abrasive mix locations have undergone pollution damage from the runoff of our brine solution. Environmental concerns and media coverage has increased public awareness of the problems which salt run-off has created and mandated that we take appropriate action at each and every location to create a clean environment. The extent of cleanup operations required at isolated locations may have influenced public opinion to the feeling that the problem is much more severe than actual. In this regard, it is imperative that we take every reasonable precaution to insure that we have established a course of responsible salt management and instilled a level of conscious awareness within the work force that "an ounce of prevention is worth a pound of cure".

\section{Priority}

It is our intent to establish, as one of our primary goals, that INDOT is making a sincere effort to minimize and control any and all undesirable situations, which might arise from the storage and/or handling of snow and ice chemicals. Our plan is to control runoff to the extent that we will reduce our influence on the pollution of the environment to below allowable levels. The purpose of this guideline is to establish and maintain pollution control as a top priority.

\section{IT SHALL BE THE RESPONSIBILITY OF EACH SUPERVISOR INVOLVED WITH THE ICE AND SNOW REMOVAL OPERATION TO INSURE THAT EACH EMPLOYEE IS AWARE OF THE INSTRUCTIONS CONTAINED- WITHIN THIS GUIDELINE AND THAT THEY ARE MADE KNOWLEDGEABLE OF THE RESULTS OF SLOPPY HOUSEKEEPING.}

Guidelines concerning chloride levels are established in another section, but should not exceed local standards. Acceptable contamination levels established by governing agencies will normally take priority over levels established within these guidelines if they are more stringent. We are responsible and accountable for our activities in the areas of salt storage and handling and will make a concentrated effort to promote a policy of sensible salting operations. We will promote an image of concern and make every conscious effort to address the inherent problems of each facility on an individual basis. The subsequent suggestions and instructions will attempt to highlight many of the areas, which need to be addressed, but in no way are they intended to be all-inclusive. 


\section{THE WRITTEN WORD MUST BE TEMPERED AND APPLIED WITH REASON IN EACH INSTANCE.}

\section{Administration and Supervision}

Exercising good practice and administering sound judgment in salt storage/handling requires some expertise and technical knowledge in the field. Although all administrators are not expected to be experts in the field, they should be knowledgeable of the sensible salting practices. Each district should identify individual(s), possibly the district maintenance operations engineer, who has the clear responsibility to represent the District/Subdistrict in all issues regarding pollution and the environment. This individual should be informed in this field, having the ability and expertise to address problems and also know where to seek assistance when it is required. In order to accomplish this, this person should participate in training courses, seminars and other informational sources to expand their resources and keep abreast of new techniques and technology.

The following is a list of responsibilities that this person should have knowledge about, but not be limited to:

1. The identification and assessment of the needs of salt storage facilities in regard to environmental engineering aspects.

2. The gathering of information such as groundwater sodium and chloride levels, initiation of testing procedure, and assembling of pertinent data in order to submit recommendations regarding existing or planned practices which may affect the environmental aspects of our operations.

3. Assist in design, preparation of plans, specifications, and provisions of new construction or reconstruction of existing facilities.

4. Assist in coordination of efforts between INDOT and other agencies at the local level regarding environmental or public health hazards for storage/handling.

5. Ensure proper maintenance of pollution control devices and maintain the integrity of both the structure and the ecology.

6. Assist in the instruction and training of maintenance workers in sensible salting procedures including the pra1ection of the environment during salt delivery, handling, loading, and clean up of equipment and staging areas. (Mixing and loading sites should be generally cleaned after each storm).

7. Perform spot inspections during winter storms to observe actual practice and take appropriate action to correct deficiencies that will promote sensible salting.

8. Spot-check reporting procedures on usage of de-icing chemicals to prevent excess usage of salt. Studies by various states indicate that a considerable savings could be realized if more stringent guidelines were applied to current application rates.

9. Last, but most important, is the leadership factor. Efficient, safe storage and handling of salt depends on the attitude and cooperation of the maintenance workers to achieve results. Their outlook on sensible salting and preservation of the environment will depend largely upon the attitude of their supervisors. If they receive a strong endorsement of good housekeeping practices, their efforts will be directed towards achieving the goals outlined within this guideline. In this regard, 
top management has taken a strong and determined stand to support a policy of safe and proper salt storage and handling. It is critical, however, to retain the Operations Support Division's environmental control capability at the Subdistrict level where the problems exist.

\section{$\underline{\text { Site Analysis }}$}

Although neither federal, state, nor local authorities are requiring environmental impact statements for site selection at the present time, it is only sound management practice that would dictate the consideration of the side effects of salt storage facilities upon the environment. These considerations should be given to the construction of new sites, the enlargement of existing facilities, and our operational activities at established locations.

Many problems can either be averted or created when a decision is being made regarding the location of buildings and work areas. We must, therefore, address these needs at an early stage in the development and planning of field functional maintenance operations units. Although the plan development of all facilities will continue to originate at the district level, final review and approval will be coordinated with the appropriate central office authority.

Management will continue to be involved and will provide additional expertise as may be necessary to ensure that proper coordination will occur at an early stage in order to effect a well organized, safe, functional, and environmentally acceptable operational unit. All phases of planning, design, and construction must be coordinated with the environmental aspects of salt storage and will require the review and approval of the designated individual responsible for representing the district in these matters.

\section{Drainage}

The drainage of the area, on which the building is to be located and upon which loading and mixing operations are to occur, is as important to the environment as it is to providing a suitable working area. The paving of the floor inside the building should be impenetrable and slop towards the door so as to prevent the intrusion of rainwater and to prevent contamination of the underlying soil and groundwater. A seal coat is recommended to extend life and additionally protect the pad from water intrusion. The exterior pad should be sloped away from the building to its outer limits and the water retained by means of curb or slope reversal of the pad itself in order that the runoff may be directed into a collection system. It is important to note at this juncture that collection facilities are a last resort and that "time, effort, and money, in most cases, can be better spent on avoiding or minimizing the formation of salt brine". However, it is our plan that all brine runoff is retained in some form of impervious storage and/or evaporation facility

and from that point, safely released into the environment. This is especially critical where maintenance units are located adjacent to ground water wells or near fresh water lakes or reservoirs. 
The drainage systems should be designed so that brine runoff, if any, is directed into the storage/evaporation facility, or so that unpolluted rainwater which falls on the pad after spring clean up is diverted away from the facility and allowed to resume its natural drainage course. The main objective at this point is to minimize the quantity of water collected and to not collect unpolluted runoff.

\section{$\underline{\text { Design of Brine Storage/Evaporation Facilities }}$}

The most economical design and construction principles should be used in determining what brine runoff facilities are needed. The proper design type and size can be predicated from knowing the local site conditions, available space, and the capacity of the local treatment facilities. In retrospect, however, it cannot be overemphasized that THE TOP PRIORITY IN BRINE CONTROL IS ITS MINIMIZATION and efforts in this direction will certainly alleviate the task of dealing with it once it has been formed.

Numerous brine control methods are available, and at this point, there is insufficient evidence available to determine which is the best overall solution to the problem. There is, however, some application, which is most suited for each specific situation being addressed. The alternatives must be investigated and analyzed to determine the best solution available.

The most desirable situation would be the usage of a sanitary sewer line, if available. The owner must give permission and some questions may arise as to the salt concentration of the brine. This should not present any problem as sewage treatment plants are generally capable of handling chloride concentrations in sludge of 50,000 parts per million before digestion is retarded or inhibited. In comparison seawater contains an average of $3.5 \%$ or 35,000 parts per million of salt. Sampling of the effluent at the point source of pollution may be necessary to determine that the plant will be able to successfully ingest the brine concentration.

It may be noted at this point in this guideline, that the topic of salt concentrations of brine solutions in the water and the soil has arisen. Acceptable chloride levels are easily addressed but difficult to reasonably define. What may be within reason to one agency may be unacceptable to another. In this regard INDOT has established guidelines of the most widely acceptable levels, in an effort to meet most contingencies. These levels may be set at unattainable levels, in some instances. As a target, we may use approximately 1000 parts per million (ppm) or 1000 milligrams per liter (mgil) for saltwater (brine) solution, in free form, being released from INDOT properties into the environment. There are however, exceptions to most rules. Heavier concentrations may be emitted only into sanitary sewer lines or flowing streams when the dilution level prior to leaving INDOT property would exceed $1000 \mathrm{ppm}$. In the event that the stream did not occupy state right of way but is near enough to be economically practical and large enough to be environmentally acceptable, we should investigate the possibilities of piping runoff into it. A small reservoir for temporary retention of runoff waters to allow the metering of runoff into the environment within allowable levels may be an alternate and should be considered if space is available. 
If space is not available, a large buried storage tank, series of buried storage tanks, or series of buried cement block and concrete brine storage basins may be constructed. In any case, storage facilities must be constructed that do not leak into the ground water.

Capacity shall be designed so that even during periods of heavy precipitation, overflow should not occur. Figure 1 illustrate typical brine storage basins construction in series.

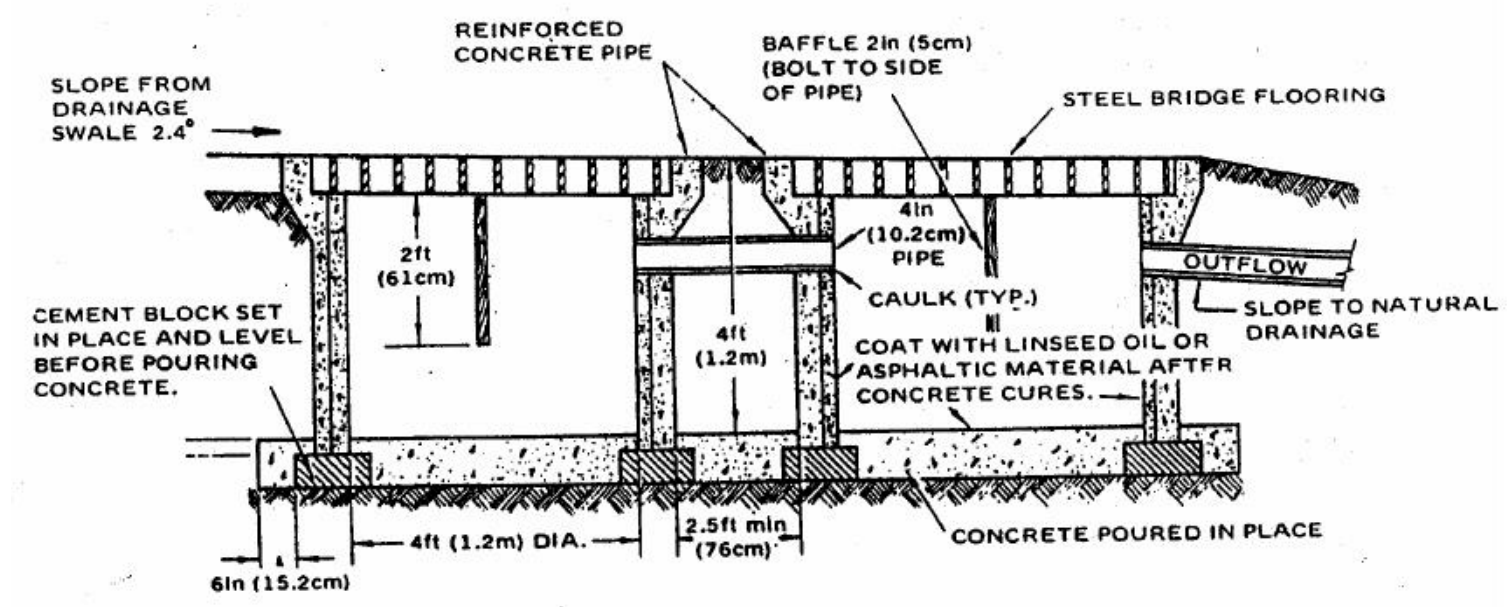

Figure 1 Salt brine storage basin Courtesy of Pennsylvania Department of Transportation

Brine may be used or disposed of as conditions warrant. Some uses may include stabilization of compacted aggregate shoulders or recycling by pumping onto abrasive stockpiles or back into the salt bins. The shoulder stabilization activity should be included in the maintenance work program. The additional equipment and crew size needed to include this application in the reconditioning or spot repair of unpaved shoulders should be identified early on and so noted in the work control category of the performance standard. Disposal operations may also include hauling to an approved dumpsite (an expensive alternative with no benefits) or spraying or spreading further diluted brine on unpaved shoulders. In this instance, application rates should be monitored to prevent excessive amounts from being spread on any particular section so that runoff and leeching do not cause vegetation kill. As mentioned previously, it may simply be metered off into the environment at approved levels.

Another viable alternative is the construction of a brine retention lagoon. Information such as average monthly rainfall, average monthly evaporation rates, soil conditions (percolation etc.) size of storage and mixing pad, number of snow/ice routes, and location and size of the equipment cleanup area are primary factors in the design of such a facility. Other, less obvious, factors must also be considered. Central Office Highways Operations will direct the plan development of such facilities with input from the district.

Collection facilities such as brine retention lagoons must be constructed with impervious liners, which may be composed dense graded bituminous mixes, geomembrane fabrics or a combination of these. They must retain their imperviousness and durability when subjected to repeated cleanup and maintenance operations. Steel and/or concrete tanks 
should be bituminous coated. This may be accomplished by hand application or by filling with liquid bitumen and subsequent emptying by pumping.

As additional information is assembled and becomes available, it will, from time to time, be distributed, as it is not the intent of these guidelines to be all-inclusive. New and innovative ideas are continuously being developed, as the sate of the art is refined. We are, therefore, attempting to maintain the instructions up to current standards and encourage the submittal of new and applicable material to be shared and reviewed for inclusion into the guidelines.

\section{Mixing/Handling of De-icing Chemicals}

In most cases and at most locations, the mixing and handling of de-icing chemicals has become a routine and familiar process. This situation has both its good and bad aspects. It is highly desirable in the fact that the "fire drill" approach certainly minimizes reaction time to the approach of a storm. In the other hand, familiarity may lead to the standardization of storm preparation, allowing the omission of detail, which may be required by a combination of varying factors. These particulars need to be addressed in individual situations and assessed so that the best approach is tailored to fit the available storm information.

Although pre-mixed piles are utilized for timely reactions to storm conditions, they are a luxury that may be causing unnecessary salt brine runoff. The department can no longer afford this luxury, in most cases. The "one round of mix" rule of thumb may no longer be appropriate, especially at locations where brine runoff is not yet under control. It is therefore recommended that pre-mixing not be performed unless where special conditions or facilities exist, or cover is provided where brine control is not yet available. Although this approach may somewhat delay reaction time to the approach of a storm, it is a positive step forward in the control of brine runoff. In the absence of pre-mixed materials, straight salt may be applied and may well be more appropriate for the particular storm conditions than mix. Pre-mix piles may be established for one round when the warning of a severe storm dictates. The re-establishment of the practice of pre-mixing of one round of mix should be considered only after an adequate brine control has been established at the location and a determination is made that the facility is capable of handling the increased concentrations of chemicals in the operation of that facility.

The snow/ice operations area should include the installation of a permanent "equipment clean and wash area" which is drained into the brine treatment facility. This area should preferable by constructed near, or adjacent to, the brine treatment area. In some instances, where existing conditions would not allow such a convenience, the drain from the wash area would be directed into the brine treatment area during the months that ice/snow chemicals are in use. Later, it would be directed away from the brine treatment facility after the final winter cleanup and during the months that chemicals are not in use. Commercial equipment washing sites, when locally available, should be considered for equipment cleanup. Under no circumstances will equipment (spreaders) be placed in permanent summer storage locations prior to final cleanup, unless the storage area has 
been constructed on the ice/snow removal operations pad and the cleanup is completed before the pad drainage is diverted away from the brine treatment facility for the summer months.

\section{Sensible Salting}

Maintenance Operations is charged with the responsibility of minimizing the harmful effects of chemical de-icers on the environment by addressing the manner in which plants, soils, and waters are affected by de-icing applications. Although chlorides are not reported to have harmful effects on soil characteristics, they have been found to exert a toxic (harmful) effect on plants. There is also an indication that the sodium ion is toxic to trees while calcium is an element commonly found in oils, and is essential to plant growth. The Public Health service has indicated an upper limiting chloride concentration in public water supplies of 250 ppm. In extreme cases, waters with 2000 ppm have been used for domestic purposes without adverse effects once the human system has adjusted to these waters. It is extreme negligence to disregard the cause and effects of our contributing any pollution to sources of drinking water and our legal responsibilities could reach catastrophic proportions.

It makes little sense to spread salt where salt is not needed, and although some studies indicate that the application of de-icing salts in rural areas is unlikely to cause water quality problems, it is within the realm of responsible management to maintain minimum applications rates for economic as well as ecology reasons. Determining the precise spreading rates necessary to attain bare pavement and to keep from causing environmental damage to the vegetation is the crux of the problem. The "bare pavement" snow and ice removal policy has led INDOT, as well as the user, into the situation in which we find ourselves. The concept of public pressure for bare pavement may have evolved simply because the public was unaware of its contribution to environmental damage, thinking that a bare pavement policy resulted only in a small increase in the cost of snow and ice removal.

Some salt may travel more than 100 feet laterally from the roadway, even when the ground is very gently sloped. Concentration levels along the roadside are on the increase. Studies have determined that sodium levels from 0-18 years of salting at distances from 0 to 45 feet from the edge of pavement vary from $30 \mathrm{ppm}$ to $488 \mathrm{ppm}$. Chloride concentrations in the same time frame and at the same distances have varied from a trace to $217 \mathrm{ppm}$. To respond to these conditions the goals of our operations must focus on the need to discontinue practices, which continue to create a pollution invasion of the environment. We must gear our operations to keep abreast of the state of the art of sensible snow and ice control management and use our current practices and equipment to elevate potentials of sensibility. Continuing education to train Operations personnel in the operation and application of these guidelines has now become a priority, which must be assessed by management. There should be greater emphasis on training drivers in the skills and usage of snow and ice removal equipment. 
In the interim, the operations manager when addressing conditions and options available in dealing with winter storms must observe attention to detail. The increase in calcium chloride as an additive to pure salt or salt/abrasive applications should be considered when conditions warrant. These conditions or characteristics may be identified by, but not limited to, the following criteria:

1. Reduction in salt usage because of a quicker, more effective use of material. (Prewetting of salt with calcium chloride may reduce the amount of salt required by $40 \%$ ). About $4 \%$ of prewetted salts leave the roadway while about $40 \%$ of dry spread salt leaves the roadway. Salt brine from a brine treatment facility is an excellent procedure at this time.

2. A quicker melt is effective because the $30-45$ minute time period required to form a brine is nearly eliminated.

3. There is less salt waste and therefore less adverse environmental effect because prewetted salt does not bounce and immediately begins to penetrate through the frozen layer.

Recommendations for use of calcium chloride from a Pennsylvania study include the following list of calcium chloride levels:

Temperature Recommended Application Rate
- $25^{\circ} \mathrm{F}+$
- use straight salt
- $15^{\circ}-25^{\circ} \mathrm{F}$
$1 / 4 \mathrm{CaCl}--3 / 4$ salt
- $5^{\circ}-15^{\circ} \mathrm{F}$
$1 / 3 \mathrm{CaCl}_{2}--2 / 3$ salt
- below $5^{\circ} \mathrm{F}$
$-1 / 2 \mathrm{CaCl}_{2}--1 / 2$ salt

Although the above chart may indicate an extensive and therefore expensive usage of $\mathrm{CaCl} 2$, the conditions warranting the use of such a treatment are infrequent and the appropriate treatment is certainly the correct treatment from an economic, ecology, and management standpoint. There are many other treatment combinations of materials and equipment that are available to the responsible manager and it would be both impossible and inappropriate to address the infinite number of possible combinations or conditions under which their usage is appropriate. Good judgment and sound management practices are essential and must preclude standardization of the snow and ice removal operations. The public expects and deserves the best effort and application of men, equipment, and materials to maintain roadways in a safe, comfortable, and environmentally acceptable condition.

\section{Cleanup of Existing Facilities}

It is a principle of physics that matter cannot be created or destroyed. Since sodium, calcium, and chlorine are all elements and are governed by the laws of nature, they can neither be created nor destroyed and must eventually be accounted for. When salt is allowed to be released from point sources in particular, it is free to inhabit the environment along pathways of least resistance, and becomes involved in many 
processes, which in many cases posses the potential of creating significant ecological alterations.

The cleanup of existing salt storage facilities begins with the evaluation and assessment of existing conditions at salt storage locations where point source pollution has adversely affected adjacent property. Salt affected soils may be classified as saline, sodic, or salinesodic depending on the kinds and amounts of soluble salts present. The difference in these soil classifications determines, to a great extent, the measures that may be under taken to reclaim these soils to their former productivity. Saline soils contain soluble salt in sufficient quantities to impair seed germination and plant growth. Sodic soils contain a relatively low amount of soluble salts but are high in levels of sodium. Saline-sodic soils contain large amounts of both sodium and salt. Concentrations of these classifications in varying amounts affect different crops to a greater or lesser degree.

The chemical exchange, as it occurs within the various soil groupings, becomes a very complicated process, and any discussion regarding this topic is beyond the scope and intent of this guideline. It is, however, important to understand that the differences in classifications as they exist in a specific soil type, determines to a great extent the factors that need to be identified and considered in the effective and economic reclamation of affected soils. Some salt affected soils cannot be economically reclaimed due to the very small soil particle-size to a depth in excess of two feet, the lack of high quality water for leaching out of salts, and the absence of good drainage.

The concept of reclaiming soils is a new and complex issue, and several workable options are available. Saline affected soils cannot be reclaimed by chemical alteration (i.e. treated with another chemical, conditioner, or fertilizer). However, some possible physical alterations are as follows. It is necessary to point out, however, that no solution would be effective without first removing the source of the pollutant.

1. Leaching out of the soil either by rainfall over a period of time or by repeated application of high quality irrigation water.

2. Construction of French drains surrounding and through affected clayey soils or highly

3. Tillage speeds up desalting by mixing the easily soluble salts deeper into the soil and loosing the dense subsoil. Subsoil tillage operations such as chiseling or moldboard or disk-plowing land with compacted, cemented, or hardpan layers will improve filtration and uniformity of water and root penetration.

4. Planting to avoid salt build-up in the immediate zone of seed placement. Salt accumulation can be avoided by planting seeds on the shoulders of the beds.

5. Germinating seeds and seedlings are usually most sensitive to salt.

6. Establishment of salt tolerant crops that add fresh organic matter, and the addition of organic matter whether from manure, compost, or sludge. If the relative salinity 
were determined to not be excessively high, perhaps dilution of the affected area by one or more of the above methods would bring it to within tolerable limits for medium or even low salt tolerance crops(See Table 9-4).

7. Complete removal of the affected soil to a depth of approximately two feet and replacement with acceptable material.

The determination of the degree of soil salinity is the preliminary step to the evaluation and assessment of existing conditions of salt polluted property that was discussed at the beginning of this section. This may be achieved by the testing of these soils. If the testing and analysis are to be true indicators of the magnitude of the problem, they must be representative of the entire soil profile that has been affected. It is generally best to sample both surface soil and subsoil to a depth of three feet. However, dense or impervious soil at depths of seven (7) to ten (10) feet below the surface may cause salt accumulation in root zones as water containing dissolved salts can be caused to move upward through the soil through capillary action.

A relatively new method for measuring soil salinity in the firled is the Four-Electrode Technique that has the potential of eliminating soil sampling and laboratory analysis. This method employs a direct measure of the soil properties and provides a measure of electrical conductivity measured in millimhos/centimeter. The ability of a soil to carry a current is called electrical conductivity and the higher the conductivity, the higher is the salt concentration. Generally a value of four plus (4+) millimhos/cm indicates a saline condition. Table 9-1 provides a summary of salt-affected soil classifications.

Table 9-1. Summary of Salt-Affected Soil Classification

\begin{tabular}{lcccc}
\hline Classification & $\begin{array}{c}\text { Conductivity } \\
\text { (mmhos/cm) }\end{array}$ & Soil $\rho H$ & $\begin{array}{c}\text { Exchangeable } \\
\text { Sodium Pertentage }\end{array}$ & $\begin{array}{c}\text { Soil } \\
\text { Physical Condition }\end{array}$ \\
\hline Saline & $>4.0$ & $<8.5$ & $<15$ & Normal \\
Sodic & 54.0 & $>8.5$ & $>15$ & Poor \\
Saline-godic & $>4.0$ & $<8.5$ & $>15$ & Normai
\end{tabular}

It becomes obvious that a general guideline cannot be issued to cover the innumerable combinations of conditions, as they exist in the field. However, it is possible to analyze and assess the existing conditions at each site when provided with the pertinent information that can be made available through a reasonable and thorough program of investigation and testing. 
Table 9-4 provides a summary of tolerance of some common crops to salt.

Table 9-4. General Salt Tolerance Ratings of Various Crops

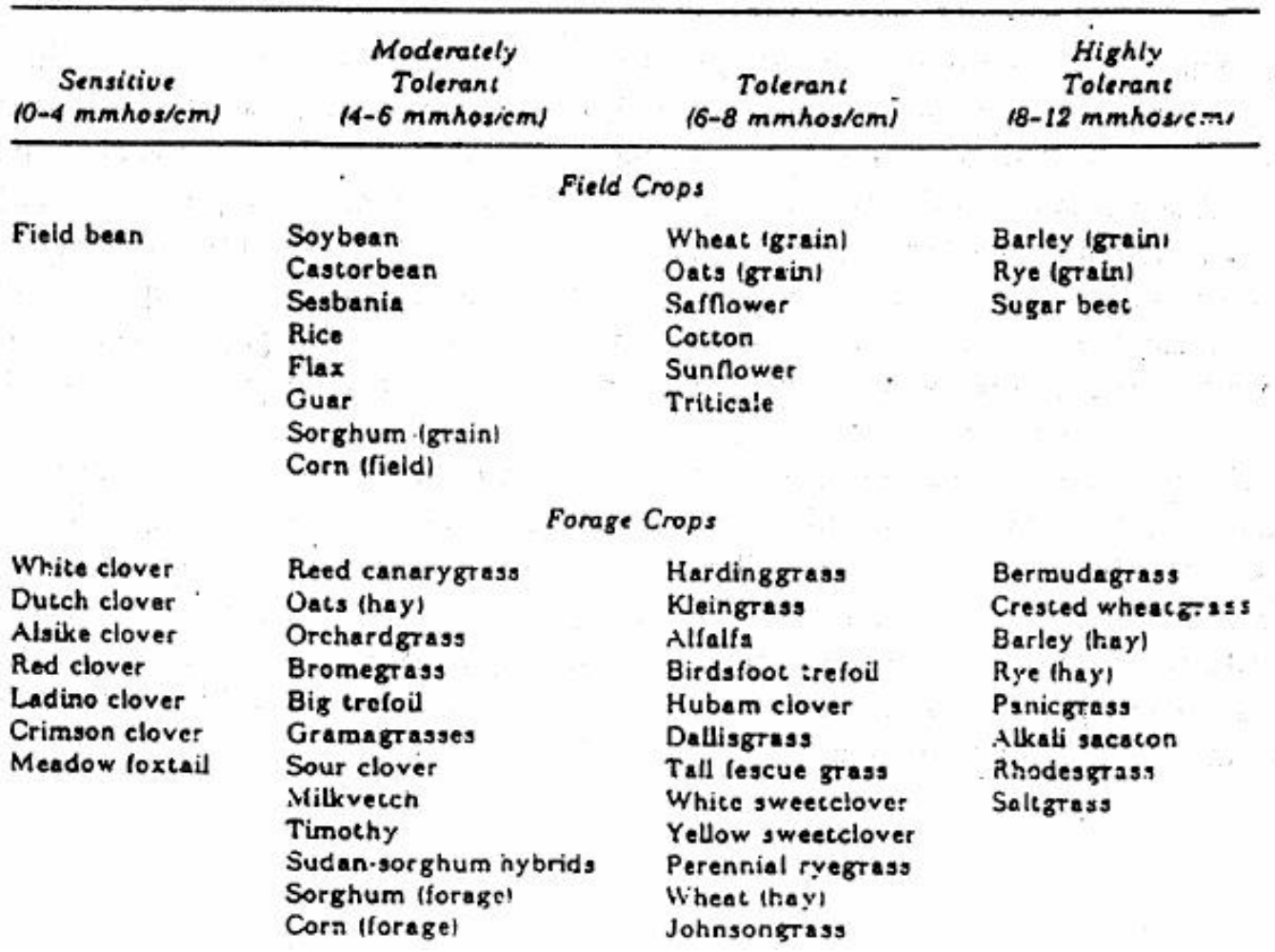

The analysis of the findings of such a program would allow engineers and supervisors to evaluate the problems inherent at the individual locations and make recommendations to management regarding a proposed plan of action.

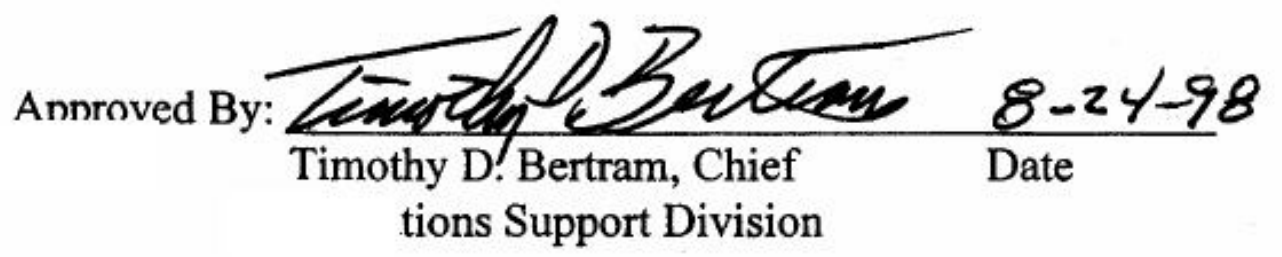


Appendix H:

Salt and Brine Storage Manual, Michigan Department of Environmental Quality 


$\left[15 \frac{\text { Eaton County CRoad Commission }}{\text { County of Eaton, Michigan }}\right.$

\footnotetext{
JOHN W. MOORE

Chairman

FAED W. MARQUAADT Vice Chairman

กMOTKY د. LAMOKEAUX Member

BLAM E. ERUOU, P.E Engineer-Managur

SHARON $X$ HICE Finance Director
}

FAX COVER SHEET

TO:

LEE YEUNG

FAX NO:

$765-496 \cdot 1101$

FROM:

B. BमLOU

EATON COUNTY ROAD COMMISSION

FAX NO: (517) 543-2608

NUMBER OF PAGES INCLUDNYG COVER SHEET 22 


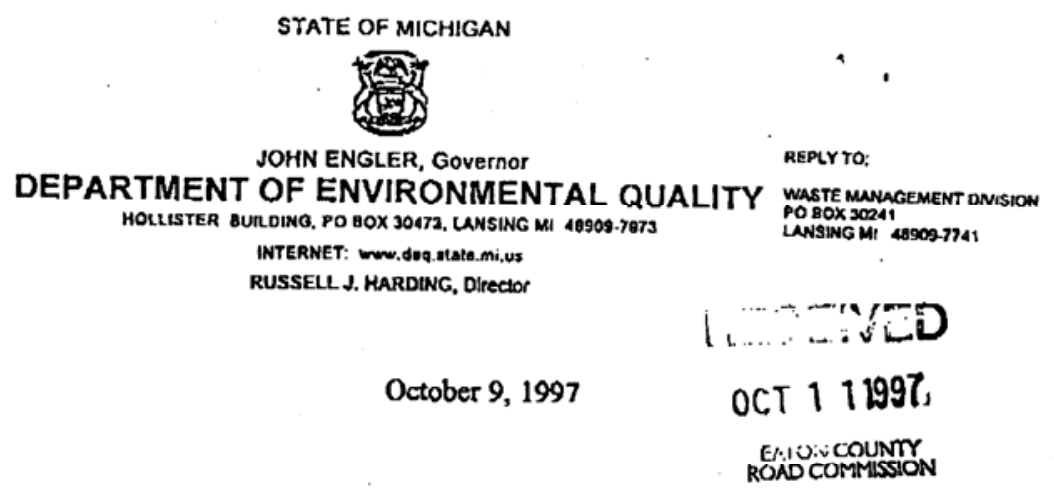

TO: . . County Raad Commissions

Department of Transportation Garages

Michigan Municipal League

Michigan Association of Townships

SUBJECT: Guidelines for the Storage of Salt and Brine

The Department of Environmental Quality has dcveloped new guidclines for the storage of salt and brine at road maintenance garagcs. The enclosed new guideline is dated September 1997 and should replace the previous guidcline distributed by the Department of Natural Resources dated April 1982.

Following these guidelines will help to assure that road maintenance garages throughout the state are compliant with the wastewater discharge and Pollution Incident Prevention Plan (PIPP) regulations of Part 31 of the Natural Resources and Environmental Protection Act (NREPA) 1994 PA 451, as amended.

If you would like additional copies of these guidelincs to distribute, please contact:

Groundwater Program Section

Michigan Department of Environmental Quality

P.O. Box 30241

Lansing, Michigan 48909

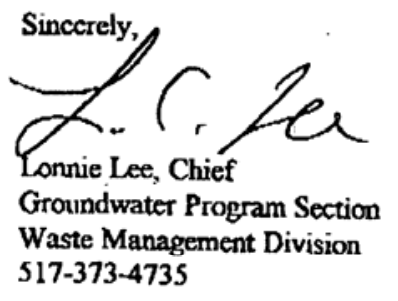




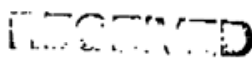

OCT 111997 :

EATOi: COUUINTY
ROAD COMMISSION

\section{SALT AND BRINE STORAGE MANUAL}

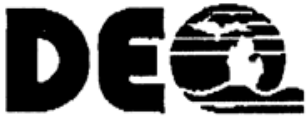

John Engler, Governor Russell J. Harding, Director

Waste Management Division Michigan Department of Environmental Quality 
The Michigan Department of Environmental Quality (MDEQ) will not discriminate against any individual or group on the basis of race, sex, religion, age, national origin, color, marital status, disability or political beliefs. Questions or concerns should be directed to the MDEQ Office of Personnel Services, P.O. Box 30473, Lansing. MI 48909.

Printed by authority

Part 31 of NREPA. 1994 PA.451, as amended

Cost per copy: . 83

Total number of copies _. 300 Total Cost:5 248.40

DEP

Michigan Department of Environmental Quality

DEQ Internet website address: http://unww.deq.state.mi.us 


\section{SALT AND BRINE STORAGE MANUAL}

\section{INTRODUCTION}

Salt storage and handling at road agency maintenance facilities has resulted in documented groundwater problems in Michigan. Most of these problems involve the contamination of drinking water wells. Part 31, Water Resources Protection, of the Natural Resources and Environmental Protection Act, 1994 PA 451 (Part 31), formerly The Michigan Water Resources Commission Act, 1928 PA 24S, and Part 5 of the Administrative Rules of Part 31 prohibit injurious discharges to the waters of the state and require containment measures to prevent pollution from oil, salt in liquid form (brine), salt in solid form (including sand-salt), and other polluting materials.

This manual has been prepared to offer the more than 400 Michigan road agency facilities in the state suggested methods for preventing pollution incidents and achieving compliance with Part 31 and the Part 5 Rules. The Part 5 Rules require facilities storing salt or brine, or other polluting materials to prepare and submit a Pollution Incident Prevention Pian (PIPP) describing procedures to prevent contamination and for responding to spills. This manual is directed to the storage of salt, brines, and sand mixtures (hereafter referred to as sand-salt). For solid deicing chemicals other than solid salt and sand mixtures, the guidelines for storage of solid salt and sand mixtures applies. For liquid deicing chemicals other than brine, the guidelines for storage of brine must be followed.

Incorporation of the concepts outlined in this manual will assist in the development of a PIPP that meets the requirements of the Part 5 Rules and Part 31. Copies of Part 31 and the Part 5 Rules can be obtained from the Waste Management Division (WMD), Michigan Department of Environmental Quality (DEQ), P.O. Box 30241, Lansing, Michigan, 48909 or by calling $517-373-2730$.

This manual does not address the storage of oil, gasoline, and/or other polluting materials which are also addressed by the Part $S$ Rules or other state or federal regulations. If you have any questions with regard to storage of these materials, please contact the WMD District Office in your area (see Appendix C).

For the purposes of this manual the following words and their usage are defined as follows:

"impervious" - incapable of being passed through or penetrated.

"compatible" - capable of being mixed with, or coming in contact with another substance without reacting chemically or otherwise resulting in deterioration.

"must" - indicates that the particular action is required to meet compliance with Part 31 or the Part 5 Rules.

"should" - indicates that the particular action is a recommendation. 


\section{SOLID SALT AND SAND-SALT STORAGE}

Alternative deicing products and clean sand should be utilized whenever possible to eliminate salt contaminated runofr. However, if Solid Salt and Sand Salt are used, the following provides requirements and guidelines for proper storage.

One or a combination of the following options must be utilized in the storage of solid salt and sand-salt at road agency garages and at all salt docking and unloading sites.

A. All solid salt (except stored for 15 days or less) must be stored in an enclosed structure on an impervious pad. This practice will prevent the generation of salt contaminated runoff and will avoid the need for runoff collection and disposal. All solid salt must be stored at least 50 feet from the shore or bank of any lake or stream. Sand-salt should also be stored in this manner.

B. Solid salt awaiting transfer at regional distribution sites, and sand-salt not stored within an enclosed structure, must be stored on an impervious pad and covered with a waterproof tarp at all times prior to use. The pad must be sloped appropriately to direct salt contaminated runoff to an appropriate collection area, and in a manner that prevents the runoff from reaching the soil or surface waters. The curbing must also direct runoff to an appropriate collection area (as described under Salt Containment Runoff Collection and Disposal on page 4).

C. To eliminate the need for sand-salt mixture storage, sand and salt could be stored separately and batch-mixed on an as needed basis.

\section{TRUCK LOADING AREAS}

All truck loading areas must be maintained by one of the following options.

A. Loading areas must be constructed on an impervious pad and should be covered or enclosed within the storage structure to prevent the generation of salt contaminated nunoff.

B. Loading areas must be surrounded by curbing or graded appropriately to direct salt contaminated runoff to an appropriate collection area (as described under Salt Contaminated Runoff Collection and Disposal on page 4), and the drainage ways should be scraped clean of all salt and sand-salt mixture after trucks are loaded and dispatched. The collected salt or sand-salt should be used or returned to the proper storage area. 


\section{TRUCK WASH AREAS AND GARAGE FLOOR DRAYNS}

All truck wash areas must be located on an impervious pad. The pad must be sloped or curbed to contain the wastewater and direct it to a coliection area for recycling or proper disposal. The wastewater from all garage floor drains and truck wash areas, which is not collected and recycled, must be disposed of by one of the following options.

A. Discharged to a publicly owned sanitary sewer system with prior written approval from the wastewater treatment facility operator.

B. Discharged to a holding tank from which the waste is subsequently pumped and hauled by the wastewater generator or by a hauler licensed in accordance with Part 121, Liquid Industrial Wastes, of the Natural Resources and Environmental Protection Act, 1994 P.A. 451, as amended, (121 Waste Hauler) for disposal at a wastewater treatment facility (with prior written approval from the treatment facility operator). Recommendations for holding tank design and installation may be obtained from WMD. District staff.

C. Discharged to the groundwater or to surfacc water if so permitted, or exempted, or otherwise specifically authorized under Par 31. Generally, exemptions can be considered for washwater or snow meit only when it is without additives or other contaminants. Floor drains, in garages where repairs and maintenance occurs, are not eligible for an exemption.

\section{v. SALT CONTAMINATED RUNOFF COLLECTION AND DISPOSAL}

The best management option is to eliminate all salt contaminated runoff and thus eliminate the required collection and disposal of salt contaminated wastewater.

Salt contaminated wastewater (hereafter referred to as Light Brine) generated from salt and sandsalt storage area runoff can be managed in accordance with one of the following options:

A. Discharged directly to a municipal sanitary sewer (with prior written approval of the treatment facility operator).

B. Discharged to a holding tank from which the waste is pumped and hauled by the generator or by a licensed 121 Waste Hauler for disposal at a wastewater treatment facility (with prior written approval from the treatment facility operator), or hauled for disposal to an Environmental Protection Agency (EPA) and DEQ approved Class I Underground Injection Control (UIC) disposal well. Recommendations concerning holding tank design and installation may be obtained from WMD District staff. 
C. Collected in a lined lagoon from which it is pumped and hauled by the generator or by a licensed 121 Waste Hauler for disposal at a wastewater treatment facility (with prior written approval from the treatment facility operator), or hauled for disposal to an EPA and DEQ approved Class I UIC disposal well.

1. The lagoon must be lined with an impervious, compatible material which is capable of withstanding changing weather conditions without significant deterioration and/or loss of integrity. Please refer to Attachment A of this document for liner and lagoon design recommendations.

2. The lagoon must be accessible at all times of the year.

3. An appropriate test for lagoon leak detection should be performed annually.

4. The lagoon must have adequate storage capacity. Storage capacity should be determined by considering the frequency that the lagoon will be pumped and the maximum amount of rainfall or snow melt possible during that time. The lagoon must maintain at least one foot of freeboard above the lagoon water level at all times.

D. Collected in a holding tank or lagoon and utilized as a road dust control agent if done according to "normally accepted or regulated practices." See

$R$ 323.2209(1)(b) of Part 31 Rules. It is recommended that if light brine is used as a dust control agent, it is used only as make-up water on commercial products.

\section{BRINE STORAGE .}

Brine storage facilities must meet all of the following conditions.

A. All above-ground brine storage tanks must have spill containment dikes. The dike must be lined with or constructed of an impervious material. Soils are not impervious. If a concrete or asphalt liner is used, it must be free of cracks and covered with a compatible waterproof coating. Please refer to Attachment A of this document for liner and lagoon design recommendations.

B. The diked area must have an enclosed storage area so as to be able to contain a volumetric capacity of at least $100 \%$ of the largest tank's capacity within the diked area or at least $100 \%$ of the largest tank truck that will be transferring brine to or from the tanks, whichever is larger. The diked area must be constructed so that no volume of brine can escape through drains, sewer systems, or otherwise directly or indirectly into any sewer or to the surface waters or groundwaters of the state.

C. The bottom of the dike must be structurally capable of supporting the tanks. Tanks set on ring foundations should be tested each year to insure that there is no leaking inside the ring. 
D. All accessory pipes, hoses, valves, and pumps must also be located within the diked area. Top loading and unloading piping is recommended.

E. The truck loading/unloading area must be located on an impervious, curbed pad which directs drainage into the diked area or into a holding tank (for tank design and installation recommendations, contact WMD District staff). A responsible observer should be present at all times at the hoses and valves during brine transfer.

F. A plan should be developed to transfer brine from a leaking storage tank, tank truck, or from the diked area to a safe holding area. This plan should also include steps to promptly collect and transfer brine from any disabled or damaged tanker. on the road.

G. The diked area should be designed so it is accessible at all times and so there will be easy removal of storm water and spillage by a non-automatic sump, if so required.

H. Uncontaminated storm water collected in the diked area may be pumped and disposed of on the surface of the soil outside the diked area in accordance with Part 31. Spilled brine, however should be pumped and transferred to another tank or tank truck for use or disposal.

\section{REPORTING POTENTIAL INCIDENTS OF CONTAMINATION}

A. In accordance with Rule 323.1164 of Part 5, Administrative Rules of Part 31, potential contamination incidents such as brine spills, containment facility failures or overflows, or unauthorized discharges of salt in solid or liquid form must be immediately reported to the DEQ. This may be accomplished by immediately calling the Pollution Emergency Alert System operated by the DEQ (see below). Then, within ten (10) days of receiving knowledge of such a spill or contamination, the facility manager must file a written report with the DEQ of the incident; outlining the cause, its discovery, and the procedures taken to remove the contaminating materials from the waters of the state. Complete this in accordance with the Par 5 Administrative Rules of Part 31.

B. If DEQ staff deems that a spill or other discharge to the ground warrants an investigation, the road agency or other responsible party may be required to conduct a hydrogeological investigation to determine one or more of the following factors:

1. Groundwater flow direction.

2. Groundwater flow rate.

3. Horizontal and vertical extent of contamination 
4. Potential adverse effects on the human and natural environment from the discharge.

5. Alternative remedial actions to consider.

6. Other factors deemed necessary by DEQ staff.

POLLUTION EMERGENCY ALERTING SYSTEM

In Case of Environmental Emergency

During Daily Working Hours - Contact Local DEQ District Office

AFTER WORKING HOURS - Call 1-800-292-4706

24 Hours Per Day 


\section{APPENDIX A}

\section{LAGOON DESIGN AND INSTALLATION RECOMMENDATIONS}

Treatment and storage lagoons for wastewater regulated under Part 31 shall be designed to prevent, to the maximum extent possible, discharges to the groundwater. The following criteria are acceptable to the Waste Management Division (WMD), Department of Environmental Quality (DEQ), as guidance for treatment and storage lagoon design. Also attached, in Appendix $\mathrm{B}$, are acceptable components of a construction quality assurance program that can be used to document and/or verify there was adequate lagoon construction.

A composite liner is a system that consists of both of the following components:

1) An upper component that consists of a flexible membrane liner which is installed in direct and uniform contact with the lower compacted soil component. The flexible membrane liner shall have nominal thickness not less than 30 mils ( 0.030 inch). For high density polyethylene components, the flexible membrane liner shall have a nominal thickness not less than 60 mils (0.060 inch).

2) A lower component that consists of any of the following soil layers:

(a) Compacted soil which is not less than two feet thick and which is in compliance with the provisions of R 299.4913 of the Administrative Rules promulgated pursuant to Part 115 Solid Waste Management, of the Natural Resources and Environmental Protection Act, 1994 P.A. 451, as amended, (Part 115 Rules).

(b) A bentonite geocomposite liner that is in compliance with the provisions of R299.4914 of the Part 115 Rules.

(c) A natural soil barrier that is in compliance with the provisions of R299.4912 of the Part 115 Rules

(d) An alternative soil layer that is approved pursuant to the provisions of the Part 115 Rules.

An ideal wastewater treatment lagoon or storage lagoon liner consists of a composite liner as defined above consisting of a soil base meeting the criteria established in Appendix B, (I) for a natural soil barrier, (II) for a compacted soil barrier, or (III) for a bentonite geocomposite liner, directly overlain by a flexible membrane liner (FML) meeting the requirements of (IV).

Alternate composite designs will be considered by the WMD District Office and approved, if the altemative design provides the same or greater environnental protection.

Prior to initiating lagoon construction, the following must be approved in writing by the appropriate WMD District Office, DEQ (see Appendix C). 
A. Preliminary soil study verifying that an adequate volume of clay exists on site or can be brought which meets the soil criteria for the clay portion of the composite liner

B. Engineering plans for lagoon construction

C. Construction Quality Assurance Plan

Recertification of liner construction must be done after sludge removal, or any maintenance or other activity which can potentially jeopardize the liner integrity. 


\section{Appendix B}

\section{Acceptable Components of a Construction Quality Assurance (CQA) Plan}

I. Natural soils may be used as a portion of the composite liner system.

A. A natural soil barrier used as a portion of a composite liner shall meet the following criteria:

1. Not less than 10 feet thick.

2. Meets soil classification of $\mathrm{SC}, \mathrm{ML}, \mathrm{CL}$ or $\mathrm{CH}$ by $\mathrm{ASTM}$ test method D2487-93.

3. Has a saturated vertical hydraulic conductivity that does not exceed $1 \times 10^{\circ}$ ${ }^{7}$ centimeters per second.

B. If utilized, perimeter dike walls shall be keyed into a subjacent natural clay base, be at least 10 feet thick, and have saturated horizontal hydraulic conductivity of not more than $1 \times 10^{-7}$ centimeters per second.

C. Hydraulic conductivity shall be determined using the methods in ASTM D 508490, as modified by the Department in R299.4920 of the Part 115 Rules.

D. A work plan will be submitted, and approved by the appropriate WMD District Office or the DWRPD District Office, which details the number and location of soil borings, depth and frequency of testing to verify the natural clay meets the criteria of $I(A)(1-3)$.

E. Any alternative test and investigative methods must be submitted to the DEQ for review and approval.

F. An adequate base surface must be prepared for the placement of the FML, which has been prepared as follows:

1. The surface must have been adequately compacted.

2. The clay must be free of stones, roots, water or desiccation cracks.

3. Grade must be smooth, and verified by field measurements that elevations are within 0.2 feet of the approved plans. 
Il. A compacted soil base or barrier may be used as a segment of the composite liner system.

A. The compacted soil barrier shall meet the following criteria:

1. Have a minimum thickness of two feet.

2. Have a laboratory hydraulic conductivity that is equal to or less than $1.0 \mathrm{x}$ $10^{-7}$ centimeters per second within the density and moisture content range specified for construction as determined by a laboratory study of the relationship between moisture, density, and the hydraulic conductivity of the soil.. Hydraulic conductivity testing shall be as specified in I(C).

3. Have a unified soil classification of $\mathrm{SC}, \mathrm{CH}, \mathrm{CL}, \mathrm{CL} / \mathrm{ML}$ or $\mathrm{ML}$ as determined by ASTM D2487-93.

B. A registered professional engineer shall verify that the soil source meets the standards specified in II.A.2.-3., by obtaining random samples of the soil and testing for all the following:

1. The relationship between hydraulic conductivity, moisture, and density. The relationship shall be established using the modified proctor test, ASTM D1557-91. The relationship shall be redetermined if the nature of the source changes so that the required hydraulic conductivity will not be achieved. This data shall be graphed and analyzed to determine the acceptable moisture content/compaction combinations that meet the requirement of II.A.2.-3.

2. The moisture-density relationship of the soil determined by the modified proctor test, ASTM D1557-91, shall be tested at least once every 5,000 cubic yards of material placed and whenever the texture of the soil changes.

3. The unified soil classification of the soil determined ASTM D2487-93, shall be tested at least once every 5,000 cubic yards of material placed and whenever the texture of the soil changes.

C. The owner and operator of a facility shall provide for the construction of a compacted soil liner that will meet all of the following requirements:

1. The lift thickness is generally not more than 6 inches after compaction. 
2. Each lift is thoroughly and uniformly compacted at the density and moisture content determined necessary to achieve a hydraulic conductivity not more than $1.0 \times 10^{-7}$ centimeters per second. Soil shall not be compacted at moisture contents less than optimum, or to less than $90 \%$ of the maximum dry density, as determined by the modified proctor test, ASTM D1557-91.

3. Each lift is compacted using a penetrating foot compactor weighing not less than 50,000 pounds, and capable of penetrating the thickness of each compacted lift.

4. Each lift is integrated into the previous lift by techniques such as scarifying each lift and by using compaction equipment that is capable of penetrating the thickness of each compacted lift

5. Construction of the liner is such that the bottom liner and sidewall liner or dike will be continuous and completely keyed together at all construction joints.

D. A registered professional engineer shall verify that a compacted soil barrier is constructed in accordance with these guidelines by performing all of the following quality control tests:

1. The field density-moisture of the barrier immediately after compaction, as specified by ASTM D2922-96, at the frequency of 5 tests/acre/ift or 1 test $/ 100 \mathrm{ft}$. grid/lift, with a minimum of 3 tests per day of construction or lift of soil. The location of soil samples shall be rotated with each lift to maximize the coverage of the tests.

2. Undisturbed hydraulic conductivity by the test method specified in ASTM DS084-90 as modified by R299.4920 of the Part 115 Rules. A minimum of one Shelby tube shall be extracted from the liner for sampling for each 10,000 cubic yards of soil barrier material compacted. The sample must not be recompacted before testing. A minimum of three tests per lagoon must be conducted.

3. Measurement of composite soil liner thickness and slope by final elevation checks.

E. The owner and operator of a facility shall provide for the protection of the compacted soil barrier from detrimental climatic effects during construction by assuring all of the following are done:

1. Removing all ice and snow during winter construction prior to placing a lift, and not using frozen soil in any part of a compacted soil barrier. 
2. Recompacting any soil lift that has been subjected to a freeze and thaw cycle before the liner is in place.

3. Insuring that soil barriers are not subject to desiccation cracking before the liners are in place by doing one of the following:

a. Sprinkling the liner with water, as necessary.

b. Covering or tarping the soil.

c. Taking other preventative measures.

4. In the event desiccation has occurred, remove and recompact any soil which has experienced desiccation cracking before compacting the next lift or installing the next composite liner system component.

F. A registered professional engineer shall inspect and document quality control tests and submit the documentation as part of a quality assurance report to the Department for review and approval.

G. The owner and operator of a facility shall insure that the compacted clay barrier or natural clay liner surface is prepared for placement of the FML liner by doing the following:

1. Inspecting the clay liner surface to insure there are no cracks, holes, defects or other features that may increase the liner permeability or damage the FML.

2. Inspect the clay liner to insure there are no stones at the surface of the clay liner.

3. Assure that all defective areas have been repaired or removed and replaced.

4. Complete a final inspection to insure all slopes, elevations and liner thickness are according to specifications.

5. A registered professional engineer shall document the final inspection and submit the documentation as part of a quality assurance report to the Deparment for review and approval. 
III. A bentonite geocomposite liner may be used in place of a compacted clay liner.

A. The bentonite composite liner shall meet the following criteria:

1. The combination of its thickness and hydraulic conductivity results in liquid migration through the liner that does not exceed the rate of liquid migration through 2 feet of clay that has a saturated vertical hydraulic conductivity equal to $1.0 \times 10^{-7}$ centimeters per second.

2. A bentonite geocomposite liner shall consist of sodium bentonite that is contained on each side by a fabric, geotextile, or flexible membrane liner.

3. A bentonite geocomposite liner shall be seamed in accordance with the manufacturer's specifications so as to prevent leakage at the seams.

4. A bentonite geocomposite liner shall not be laid during precipitation events and shall be covered immediately by a flexible membrane liner or other protective cover.

5. A bentonite geocomposite liner shall be installed in accordance with the manufacturer's specifications and quality assurance quality control plans that are approved by the Director.

IV. The Flexible Membrane Liner (FML) which will be placed directly over a lower soil component to form a composite liner which will conform to certain specifications.

A. The FML shall meet the following specific criteria:

1. The liner shall have a nominal thickness not less than 30 mils thick. For high density polyethylene components, the flexible membrane shall have a nominal thickness of not less than 60 mils. Other material thickness must be approved prior to installation.

2. An FML shall be covered, immediately after placement, by at least two feet of soil or other approved material to prevent puncture by equipment and to protect the exposed portion of the FML from degradation by ultraviolet light.

3. Be of sufficient tensile strength to withstand anticipated stresses without failure.

4. Be chemically resistant to anticipated wastes based on EPA method 9090. EPA method 9090 is part of the publication entitled "Test Methods for the Evaluation of Solid Waste,".

5. Be sufficiently durable so that the properties of the liner are not significantly impaired by any of the following: 
a. Exposure to sunlight, precipitation, or anticipated temperature variations.

b. Abrasion, shocks, or other mechanical actions.

c. Irreversible shrinkage of the liner.

6. Be of sufficient elasticity to withstand anticipated deformations.

7. Have a friction angle that is capable of supporting overburden material without slippage on sideslopes, given the angle and length of such slopes.

8. Be capable of being seamed so that the seam meets liner specifications.

9. Installation over a sufficient area to cover the entire area of earth material that would be in contact with the treated or stored effluent.

B. The foundation for a flexible membrane liner shall be prepared by doing all of the following:

1. Compacting the soil to not less than $90 \%$ of the maximum dry density, as determined by the modified proctor test, ASTM D1557-91.

2. Grading the foundation to a smooth and true line and grade, not deviating more than 0.2 feet from those shown on approved plans.

3. Insuring that the foundation is free from stones, organic material, roots or other material that may puncture the liner.

C. The owner and operator of a lined lagoon shall assure that the liner's field seams of an FMI are made in a manner which insures all of the following:

1. That field seams are installed parallel to the line of maximum slope, when possible.

2. That the searn area is properly prepared for seaming and is free of moisture, dust, dirt, debris and foreign material of any kind before seaming.

3. That the field seaming is not done in adverse weather conditions that could impair the quality of the liner, unless protective structures or other methods are used to maintain seam integrity during construction.

4. That seaming is done in accordance with manufacturers specifications. 
D. The owner and operator of a facility shall provide assurance that an FML is otherwise installed to assure all of the following:

1. That any imperfections found in a liner or seam are repaired immediately.

2. That the anchor trench for the liner is excavated to the depth and width shown on approved plans, and that the liner is sufficiently anchored within this trench.

3. That the liner is covered with soil or other material specified in approved plans within 30 days after placement in a manner that protects the liner from degradation.

E. A registered professional engineer shall insure that the following quality control tests are conducted according to approved ASTM methods where applicable, and document the results of these tests in both field notes and the quality assurance report:

1. The following information on the raw materials used to manufacture the synthetic liner:

a. Origin and identification of the raw materials.

b. Copies of quality control certificates issued by the producer of the raw materials.

c. Reports of tests conducted to verify the quality of the raw materials, such as specific gravity, melt flow index, and percent testing.

d. Published or actual test data verifying compatibility of the FMI with the wastewater to be treated or stored.

2. The following quality control testing of any flexible membrane liner fabricated at the factory:

a. Continuous visual inspection for uniformity, damage, and imperfections, including holes, cracks, thin spots, tears, punctures, excessive wrinkling, blisters and foreign materials.

b. Non-destructive seam testing on all fabricated seams along their full length.

c. Destructive seam testing on a minimum of 1 sample per fabricated unit.

3. The following quality assurance testing performed in the field: 
a. Continuous visual inspection for uniformity, damage, and imperfections, including holes, cracks, thin spots, tears, punctures, excessive wrinkling, blisters and foreign materials.

b. Non-destructive testing on all field seams according to manufacturers specifications.

c. Hourly records of ambient air temperature and liner temperature during liner installation or field seaming. Ambient air temperatures shall be recorded within 24 inches of the liner surface.

d. Destructive tests shall be conducted for seam strength and peel adhesion. The frequency of testing shall be not less than 1 sample per day per seaming crew or machine, or every $S 00$ feet of seam, whichever is greater. Strain measurements from field tests of production searns will not be accepted. For double wedge seam samples, both welds shall be tested.

4. The following are passing criteria for machine welded seams:

a.

Seam strength in peel shall be tested according to ASTM D4437-84 (1988):

1) Failure is by film tear bond, as defined in National Sanitation Foundation standard 54, definition 2.15, 1993 edition.

2) Yield strength for the seam is not less than $62 \%$ of the minimum manufacturer's specified strength of the parent material for a seam fabricated using an extrusion fillet weld.

3) $75 \%$ of the manufacturer's specified minimum yield strength of the parent material for a seam fabricated using thermal fusion.

b. Seam strength in shear shall be tested according to ASTM D443784 (1988):

1) Failure is by film tear bond, as defined in National Sanitation Foundation Standard 54, definition 2.15, 1993 Edition.

2) Yield strength for the seam is not less than $95 \%$ of the manufacturer's specified minimum strength of the parent material.

V. The owner and operator of a facility shall provide for quality assurance reporting by insuring that a registered professional engineer certifies in a report that construction of the 
storage or treatment lagoon is in accordance with engineering plans approved by the DEQ, WMD or the DWRPD. The report shall include the following:

A. A narrative description of the results of the quality assurance program.

B. Construction records for each component of the composite liner, including all field notes and results of all quality assurance testing. Drawings should be prepared, which reference the location of each test to the respective result.

C. A summary of the testing methods used in the quality assurance program.

D. For quality assurance results that did not meet specifications contained in the approved engineering plans, the methods for bringing the components of the composite liner into compliance with approved specifications.

E. A set of as built engineering plans, signed and sealed by a professional engineer including. the following:

1. Dimensions, location, and elevation of the basc of the excavation.

2. Elevations of the surface and the base of the clay liner(s).

3. Elevations of the surface of the protective layer.

4. Cross sections of the lagoon, including dike locations, keying details, and flexible membrane anchor trench details.

5. All elevations are to be \pm 0.2 feet, United States Geological Survey Datum.

6. A membrane panel layout drawing showing panel and seam locations, repair locations, slope directions and slope toe locations. 


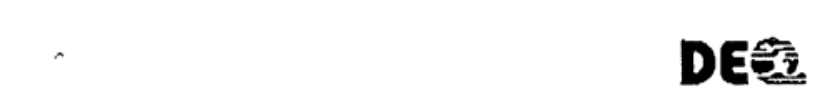

MICHIGAN DEPARTMENT OF ENVIRONMENTAL QUALITY

District Boundaries and Offices

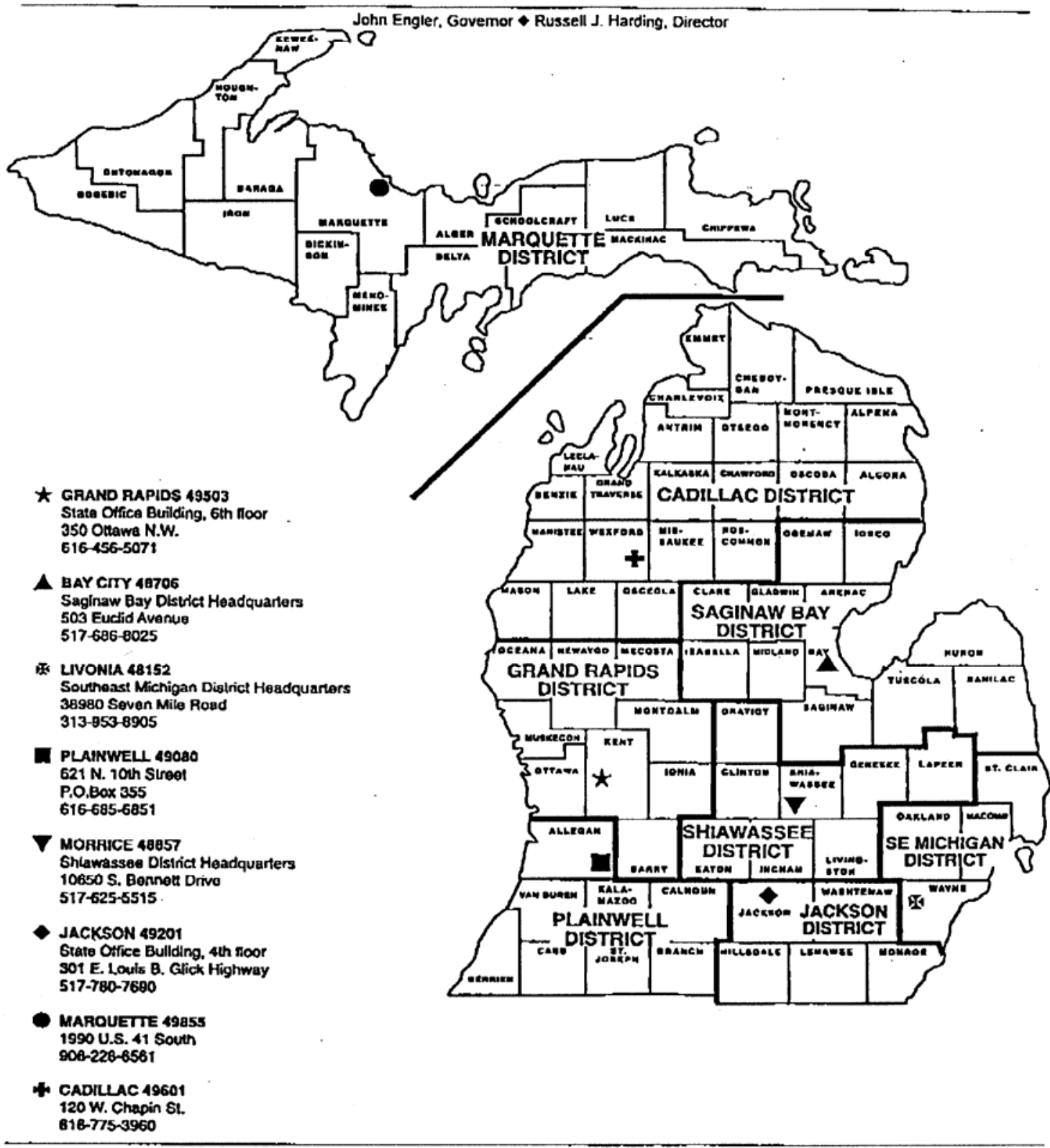

ENVIRONMENTAL ASSISTANCE CENTER (for general information):

Telephone:

Fax:

Email:
$1-800-662-9278$

1-517-241-0673

deq-ead-env-assist@state.mi.us
Pollution Emergencies:

$1-800-292-4706$

DEQ Internet Home Page: www.deq.state.mi.us 
Appendix I:

INDOT Yards Survey 


\begin{tabular}{|c|c|c|c|c|c|}
\hline District & Name of Facility & POTW Discharge? & \begin{tabular}{|l|} 
Site \\
Discharge?
\end{tabular} & O/W Separator? & NPDES Permit required? \\
\hline \multirow[t]{18}{*}{ Crawfordsville } & district shop & Yes & Yes & No & No if shop two hookup to POTW \\
\hline & Sub-District/unit & Yes & No & No (grease trap) & No \\
\hline & \begin{tabular}{|l} 
Terre Houte Sub- \\
District/unit \\
\end{tabular} & Yes & No & No & No \\
\hline & \begin{tabular}{|l|} 
Fort Harrison unit \\
\end{tabular} & Yes & Yes & No & No if outdoor washing stopped \\
\hline & Frankfort Sub-District/unit & Yes & No & Yes & No \\
\hline & Cloverdale Sub-District/unit & Yes & Yes & No & No if hookup to POTW (in process) \\
\hline & Plainfield unit & Yes & Yes & No & No if hookup to POTW (in process) \\
\hline & Ashboro unit & No - too far & Yes & No & Yes \\
\hline & Romney unit & No - too far & Yes & Yes & Yes \\
\hline & Carbondale unit & No - too far & Yes & No & Yes \\
\hline & Brainbridge unit & No - too far & Yes & Yes (not working) & Yes \\
\hline & $\begin{array}{l}\text { Veedersbudg Sub- } \\
\text { District/unit }\end{array}$ & No - too far & Yes & 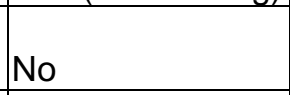 & Yes \\
\hline & Bloomingdale unit & No - too far & Yes & No & Yes \\
\hline & Newport unit & No - too far & Yes & No & Yes \\
\hline & Fowler Sub-District/unit & No - refused & Yes & No & Yes \\
\hline & Lafayette unit & No - refused & Yes & No & Yes \\
\hline & Lebanon unit & No - pending & Yes & No & No if hookup to POTW (in process) \\
\hline & Lizton unit & No & Yes & No & No if hookup to POTW $<1$ mile \\
\hline \multirow[t]{9}{*}{ Greenfield } & district/Sub-District/unit & Yes & No & Yes & No \\
\hline & Shellbyville unit & Yes & No & Yes & No \\
\hline & Anderson unit (new) & Yes & No & Yes & No \\
\hline & Alexandria unit & Yes & No & No & No \\
\hline & \begin{tabular}{|l|} 
Richmond unit \\
\end{tabular} & Yes & Yes & No & Yes \\
\hline & \begin{tabular}{|l|}
$\begin{array}{l}\text { Cambridge City unit (new-to } \\
\text { be built) }\end{array}$ \\
\end{tabular} & Yes & No & Yes & No \\
\hline & \begin{tabular}{|l|l} 
Tibbs Ave unit \\
\end{tabular} & Yes & No & Yes & No \\
\hline & \begin{tabular}{|l|}
$65 t h$ St. unit \\
\end{tabular} & Yes & No & Yes & No \\
\hline & Madison and Morris St. Unit & Yes & No & Yes & No \\
\hline
\end{tabular}




\begin{tabular}{|c|c|c|c|c|c|}
\hline District & Name of Facility & POTW Discharge? & \begin{tabular}{|l|} 
Site \\
Discharge?
\end{tabular} & O/W Separator? & NPDES Permit required? \\
\hline & Winchester unit & Yes & Yes & No & Yes \\
\hline & Tipton Sub-District & Yes & No & Yes & No \\
\hline & $\begin{array}{l}\text { Albany Lab/Future Albany } \\
\text { Sub-District }\end{array}$ & Yes & No & No & No \\
\hline & Liberty unit & No - not available & Yes & Yes & Yes \\
\hline & Rushville unit (new) & No - not available & Yes & No & Yes \\
\hline & \begin{tabular}{|l} 
Indianapolis Sub- \\
District/unit (Five Points)
\end{tabular} & No - not available & Yes & Yes & Yes \\
\hline & Kokomo unit & No - not available & Yes & No & Yes \\
\hline & $\begin{array}{l}\text { Anderson Sub-District/unit } \\
\text { (old) }\end{array}$ & No & Yes & No & No if unit moved out in Jan, 1999 \\
\hline & Fortville unit & No & Yes & No & Yes \\
\hline & $\begin{array}{l}\text { Certerville Sub-District/unit } \\
\text { (old) }\end{array}$ & No & Yes & No & No if moved out \\
\hline & New Castle unit & No & Yes & No & Yes \\
\hline & New Castle Testing lab & No & Yes & Yes & Yes \\
\hline & Cambridge City unit (old) & No & Yes & No & No - moving \\
\hline & 71st St. unit & No & Yes & No & Yes \\
\hline & $\begin{array}{l}\text { Ridgeville Sub-District/unit } \\
\text { (old) }\end{array}$ & No & Yes & No & No - moving \\
\hline & Muncie unit & No & Yes & No & Yes \\
\hline & Trenton unit & No & Yes & No & No - moving \\
\hline & Portland unit & No & Yes & No & Yes \\
\hline & Westfield & No & Yes & No & Yes \\
\hline & Old Rushville unit & (no processing) & & & No \\
\hline & $\begin{array}{l}\text { I-70 Westbound weight } \\
\text { station }\end{array}$ & (no processing) & & & No \\
\hline \multirow[t]{3}{*}{ LaPorte } & Sub-District office & Yes (shop floor drain only) & No & Yes & No \\
\hline & Monticello Sub-District/unit & Yes (shop floor drain only) & No & Yes & No \\
\hline & New Gary Sub-District & Yes (shop floor drain only) & N.A. & Yes & N.A. \\
\hline
\end{tabular}




\begin{tabular}{|c|c|c|c|c|c|}
\hline District & Name of Facility & POTW Discharge? & \begin{tabular}{|l|} 
Site \\
Discharge?
\end{tabular} & O/W Separator? & NPDES Permit required? \\
\hline & District office & Yes (sanitary only) & Yes & No & No - moving \\
\hline & Longansport unit & Yes (sanitary only) & Yes & No & Yes \\
\hline & Mishawaka unit & Yes (sanitary only) & Yes & No & No if all effuent hooked up to POTW \\
\hline & $\begin{array}{l}\text { Valparaiso Sub-District/unit } \\
\text { (old) }\end{array}$ & Yes (sanitary only) & No & No & No \\
\hline & Miller unit & Yes (sanitary only) & No & Yes & No \\
\hline & Hammond test lab & Yes (sanitary only) & & & No \\
\hline & South Bend lab & Yes (sanitary only) & & & No \\
\hline & Logansport lab & Yes (sanitary only) & & & No \\
\hline & Michigan City rest area & Yes & No & No & No \\
\hline & Rensselaer Sub-District & Yes & Yes & No & No if all effuent hooked up to POTW \\
\hline & Winamac Sub-District (new) & Yes & No & Yes & No \\
\hline & Winamac unit 1 (new) & Yes & No & Yes & No \\
\hline & Kentland unit 1 & No - not available & Yes & No & Yes \\
\hline & Roselawn unit & No - not available & Yes & No & Yes \\
\hline & Chesterton unit & No - not available & Yes & Yes & Yes \\
\hline & Medaryville unit & No - not available & Yes & No & Yes \\
\hline & Crown Point unit & No - not available & Yes & No & Yes \\
\hline & Wanatah & No - in process & N.A. & N.A. & N.A. \\
\hline & Hanna unit & No & Yes & No & Yes unless moved \\
\hline & Michigan City unit & No & Yes & No & $\begin{array}{l}\text { Yes unless taps into POTW line 100' away } \\
\text { under S.R. } 20\end{array}$ \\
\hline & Flora unit & No & Yes & No & Yes \\
\hline & Plymouth Sub-District/unit & No & Yes & No & Yes \\
\hline & Rochester unit & No & Yes & No & Yes \\
\hline & South Bend unit & (no washing done) & & & No \\
\hline & Remington Salt Pad & (no processing) & & & No \\
\hline & Pulaski Rest area & $\begin{array}{l}\text { (has NPDES permit for } \\
\text { sewer plant) }\end{array}$ & & & No \\
\hline & Gary Sub-District/unit (old) & & & & No - moving \\
\hline
\end{tabular}




\begin{tabular}{|c|c|c|c|c|c|}
\hline District & Name of Facility & POTW Discharge? & $\begin{array}{l}\text { Site } \\
\text { Discharge? }\end{array}$ & O/W Separator? & NPDES Permit required? \\
\hline & $\begin{array}{l}\text { I-65 Weight Station and } \\
\text { Truck Inspection Building - } \\
\text { no processing }\end{array}$ & & & & No \\
\hline \multirow[t]{23}{*}{ Vincenne } & Chrisney unit & Yes (sanitary only) & Yes & No & $\begin{array}{l}\text { Yes unless city allow washing bay effluent to } \\
\text { be hooked up }\end{array}$ \\
\hline & Jasper unit & Yes & Yes & No & No if hooked up to POTW \\
\hline & Paoli Sub-District/unit & Yes & No & Yes & No \\
\hline & District complex/unit & Yes & No & Yes & No \\
\hline & Linton Sub-District/unit & Yes & No & Yes & No \\
\hline & Bloomfield unit/lab & Yes & Yes & Yes & No if outside truck washing stopped \\
\hline & Dale Sub-District/unit (old) & Yes & Yes & Yes & No - moving \\
\hline & $\begin{array}{l}\text { Future Dale Sub-District } \\
\text { and testing lab }\end{array}$ & Yes & No & Yes & No \\
\hline & Nancy Hanks I-64 rest area & Yes & No & No & No \\
\hline & $\begin{array}{l}\text { Evansville Sub-District/unit } \\
2 \text { (new) }\end{array}$ & Yes & No & No & No \\
\hline & Evansville unit 1 (old)/lab & Yes & No & No & No \\
\hline & Poseyville unit & Yes & No & Yes & No \\
\hline & Chandler unit & Yes & No & No & No \\
\hline & Tell City Sub-District & Yes & No & Yes & No \\
\hline & Derby unit 2 & Yes & No & No & No \\
\hline & Petersburg Sub-District/unit & Yes & No & Yes & No \\
\hline & Washington unit & Yes & No & No & No \\
\hline & Princeton unit & Yes & No & Yes & $\begin{array}{l}\text { No (need construction permit for the } 6000 \\
\text { gallon brine storage tank) }\end{array}$ \\
\hline & Grantsburg unit 1 & No - not available & Yes & No & Yes \\
\hline & Birdseye unit 3 & No - not available & Yes & No & Yes \\
\hline & Bedford unit & No - in process & Yes & Yes & No if hooked up to POTW \\
\hline & Paxton unit & No & Yes & No & Yes \\
\hline & Shoals unit & No & Yes & No & Yes unless moved \\
\hline
\end{tabular}




\begin{tabular}{|c|c|c|c|c|c|}
\hline District & Name of Facility & POTW Discharge? & \begin{tabular}{|l|} 
Site \\
Discharge?
\end{tabular} & O/W Separator? & NPDES Permit required? \\
\hline & $\begin{array}{l}\text { Santa Claus Construction } \\
\text { field office }\end{array}$ & (no washing done) & & & No \\
\hline & Mt. Vernon Stockpile & (no washing done) & & & No \\
\hline & $\begin{array}{l}\text { Spry Road construction } \\
\text { field office }\end{array}$ & (no washing done) & & & No \\
\hline & $\begin{array}{l}\text { Mitchell construction field } \\
\text { office }\end{array}$ & (no processing) & & & No \\
\hline & Black River rest park & $\begin{array}{l}\text { (has NPDES permit for } \\
\text { sewer plant) }\end{array}$ & & & No \\
\hline \multirow[t]{19}{*}{ Seymour } & Brookville unit & Yes (sanitary only) & Yes & No & No if all effuent hooked up to POTW \\
\hline & North Vernon unit \#2 & Yes (sanitary only) & Yes & No & $\begin{array}{l}\text { No if outdoor washing stopped and floor } \\
\text { drains hookup to POTW }\end{array}$ \\
\hline & Versailles unit & Yes - cannot handle salt & Yes & No & Yes \\
\hline & District/unit & Yes & No & No & No \\
\hline & Aurora Sub-District/unit & Yes & No & No & No \\
\hline & Bloomington Sub-District & Yes & No & Yes & $\begin{array}{l}\text { No (need construction permit for the } 6000 \\
\text { gallon brine storage tank) }\end{array}$ \\
\hline & Columbus Sub-District/unit & Yes & No & Yes & No if eliminate all outdoor washing \\
\hline & $\begin{array}{l}\text { Falls City Sub- } \\
\text { District/sellersburg unit }\end{array}$ & Yes & Yes & Yes & No if hook up drains to o/w separator \\
\hline & New Albany unit & Yes & No & No & No \\
\hline & Corydon unit & Yes & No & Yes & No \\
\hline & Aberdeen unit & No - not available & Yes & No & Yes \\
\hline & Greensburg unit & No - in process & Yes & No & Yes \\
\hline & Penntown unit & No & Yes & No & Yes unless hookup to POTW within 1.7 miles \\
\hline & Spencer unit & No & Yes & No & Yes \\
\hline & Martinsville unit & No & Yes & No & Yes \\
\hline & Beanblossom unit & No & Yes & No & Yes \\
\hline & Amity unit & No & Yes & No & Yes \\
\hline & Salem unit & No & Yes & No & Yes \\
\hline & Brownstown unit & No & Yes & No & Yes \\
\hline
\end{tabular}




\begin{tabular}{|c|c|c|c|c|c|}
\hline District & Name of Facility & POTW Discharge? & \begin{tabular}{|l|} 
Site \\
Discharge?
\end{tabular} & O/W Separator? & NPDES Permit required? \\
\hline & Scottsburg unit & (to be closed) & & & No \\
\hline & Madison Sub-District & (moving) & & & No \\
\hline \multirow[t]{21}{*}{ Fort Wayne } & Angola Sub-District/unit & Yes & No & No & No \\
\hline & district/Sub-District/unit & Yes & Yes & No & No if wash bay hook up to POTW \\
\hline & New Haven unit & Yes & Yes & No & $\begin{array}{l}\text { No if outdoor washing stopped and wash bay } \\
\text { hookup to POTW }\end{array}$ \\
\hline & Wabash Sub-District/unit & Yes & No & & No \\
\hline & Gas City unit & Yes & Yes & Yes & No if outdoor washing stopped \\
\hline & Marion test lab & Yes & & & No \\
\hline & Shipshewana unit & No - not available & Yes & No & Yes \\
\hline & Bluffton Sub-District/unit & No & Yes & Yes & Yes \\
\hline & Waterloo unit & No & Yes & No & Yes unless hookup to POTW \\
\hline & Markle unit & No & Yes & No & No if all effuent hooked up to POTW \\
\hline & Monroe unit & No & Yes & No & Yes \\
\hline & $\begin{array}{l}\text { U.S. } 27 \text { S. Unit and testing } \\
\text { unit }\end{array}$ & No & Yes & No & Yes \\
\hline & Elkhart unit & No & No & Yes & No \\
\hline & Goshen Sub-District & No & Yes & No & No if moving \\
\hline & New Paris unit & No & Yes & No & Yes \\
\hline & Brimfield & No & Yes & No & Yes \\
\hline & Peru unit & No & Yes & No & Yes \\
\hline & Warsaw Sub-District/unit & No & Yes & Yes & Yes \\
\hline & (Laud) Columbia City unit & No & Yes & No & Yes \\
\hline & N. Manchester unit & No & Yes & No & Yes unless hook up to POTW $1 / 2$ mile \\
\hline & Orland testing - old unit site & (site abandoned) & & & No \\
\hline \multirow[t]{4}{*}{ Toll Roads } & Porter Maintenance & Yes (sanitary only) & Yes & No & Yes \\
\hline & $\begin{array}{l}\text { Indiana State Police District } \\
\text { II }\end{array}$ & Yes (sanitary only) & Yes & No & Yes \\
\hline & 7 S. Maintenance Shop & Yes & Yes & No & Yes \\
\hline & LaPorte Maintenance & No & Yes & Yes & Yes \\
\hline
\end{tabular}




\begin{tabular}{|l|l|l|l|l|l|}
\hline District & Name of Facility & POTW Discharge? & $\begin{array}{l}\text { Site } \\
\text { Discharge? }\end{array}$ & O/W Separator? & NPDES Permit required? \\
\hline \multirow{5}{*}{} & $\begin{array}{l}\text { Administration Building } \\
\text { INDOT }\end{array}$ & No & Yes & No & Yes \\
\cline { 2 - 6 } & Elkhart Maintenance & No & Yes & Yes & Yes \\
\cline { 2 - 6 } & LaGrange Maintenance & No & Yes & Yes & Yes \\
\cline { 2 - 6 } & Steuben Maintnenace & No & Yes & Yes & Yes \\
\cline { 2 - 5 } & $\begin{array}{l}\text { All Toll Plaza - no permit } \\
\text { needed }\end{array}$ & & & No \\
\hline
\end{tabular}




\section{Appendix J: \\ INDOT Yard Proximity to Local POTW (i.e., Sites within 2 miles of POT}




\begin{tabular}{llcc}
\multicolumn{1}{c}{$\begin{array}{c}\text { INDOT } \\
\text { District }\end{array}$} & \multicolumn{1}{c}{$\begin{array}{c}\text { District } \\
\text { Site }\end{array}$} & $\begin{array}{c}\text { POTW } \\
\text { Connection status }\end{array}$ & $\begin{array}{c}\text { POTW distance } \\
\text { (miles) }\end{array}$ \\
Crawfordsville & Lizton unit & No & 1.06 \\
Crawfordsville & Fowler Sub-District/unit & No - refused & 1.12 \\
Crawfordsville & Lafayette unit & No - refused & 1.12 \\
Fort Wayne & Markle unit & No & 0.26 \\
Fort Wayne & Waterloo unit & No & 1.57 \\
Greenfield & Rushville unit (new) & No - not available & 1.23 \\
LaPorte & LaPorte Maintenance & Uncertain & 0.11 \\
LaPorte & Monticello Sub-District/unit & Yes (shop floor drain only) & 1.21 \\
LaPorte & Flora unit & No & 1.24 \\
LaPorte & Wanatah & No - in process & 1.25 \\
LaPorte & Logansport lab & Yes (sanitary only) & 1.6 \\
Seymour & Brookville unit & Yes (sanitary only) & 0.76 \\
Seymour & Versailles unit & Yes - cannot handle salt & 1.11 \\
Seymour & Aberdeen unit & No - not available & 1.72 \\
Vincennes & Chrisney unit & Yes (sanitary only) & 0.5 \\
& & ANDOT Yards Within 2 miles of Local POTW & \\
& & &
\end{tabular}

